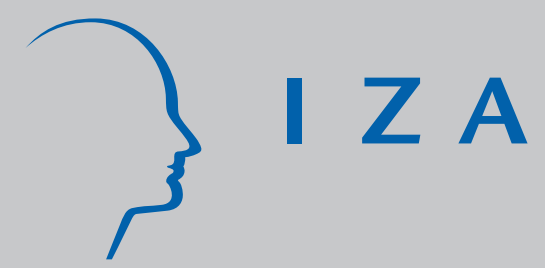

IZA DP No. 6890

Youth Unemployment and Vocational Training

Costanza Biavaschi

Janneke Pieters

Werner Eichhorst

Nuría Rodríguez-Planas

Corrado Giulietti

Ricarda Schmidl

Michael J. Kendzia

Klaus F. Zimmermann

Alexander Muravyev

October 2012 


\title{
Youth Unemployment and Vocational Training
}

Costanza Biavaschi

$I Z A$

\author{
Werner Eichhorst \\ $I Z A$
}

Corrado Giulietti

IZA

Michael J. Kendzia

$I Z A$
Janneke Pieters

$I Z A$

\author{
Nuría Rodríguez-Planas
}

IZA, IAE-CSIC and Universitat Pompeu Fabra
Ricarda Schmidl

IZA and University of Potsdam

Klaus F. Zimmermann

IZA and Bonn University

\section{Alexander Muravyev \\ IZA and St. Petersburg State University}

Discussion Paper No. 6890

October 2012

\author{
IZA \\ P.O. Box 7240 \\ 53072 Bonn \\ Germany \\ Phone: $+49-228-3894-0$ \\ Fax: +49-228-3894-180 \\ E-mail: iza@iza.org
}

\begin{abstract}
Any opinions expressed here are those of the author(s) and not those of IZA. Research published in this series may include views on policy, but the institute itself takes no institutional policy positions. The IZA research network is committed to the IZA Guiding Principles of Research Integrity.

The Institute for the Study of Labor (IZA) in Bonn is a local and virtual international research center and a place of communication between science, politics and business. IZA is an independent nonprofit organization supported by Deutsche Post Foundation. The center is associated with the University of Bonn and offers a stimulating research environment through its international network, workshops and conferences, data service, project support, research visits and doctoral program. IZA engages in (i) original and internationally competitive research in all fields of labor economics, (ii) development of policy concepts, and (iii) dissemination of research results and concepts to the interested public.
\end{abstract}

IZA Discussion Papers often represent preliminary work and are circulated to encourage discussion. Citation of such a paper should account for its provisional character. A revised version may be available directly from the author. 
IZA Discussion Paper No. 6890

October 2012

\section{ABSTRACT}

\section{Youth Unemployment and Vocational Training ${ }^{1}$}

This paper focuses on the determinants of the labor market situation of young people in developed countries and the developing world, with a special emphasis on the role of vocational training and education policies. We highlight the role of demographic factors, economic growth and labor market institutions in explaining young people's transition into work. We then assess differences in the setup and functioning of the vocational education and training policies in major world regions, as an important driver of differential labor market situation of youth. Based on our analysis we argue in favor of vocational education and training systems combining work experience and general education and give some policy recommendations regarding the implementation of education and training systems adapted to a country's economic and institutional context.

JEL Classification: J24, I25, O17

Keywords: vocational education and training, dual vocational training, youth employment, youth unemployment

Corresponding author:

Werner Eichhorst

IZA

P.O. Box 7240

53072 Bonn

Germany

E-mail: eichhorst@iza.org

\footnotetext{
${ }^{1}$ This IZA Discussion Paper is based on a Background Paper for the 2013 World Development Report. The Background Paper was commissioned to IZA by the World Bank in late 2012. It can be found online on the World Bank website: http://www.worldbank.org/wdr2013. The authors are grateful for comments received from the World Bank and two anonymous reviewers.
} 


\section{EXECUTIVE SUMMARY}

Explaining differences in youths' transition into employment needs to take into account, first, demographic developments and economic growth, and second, the interplay between these dynamics and long-standing institutional patterns, in particular regulatory provisions influencing the supply of flexible or permanent jobs as well as education and training policies. Both general education at schools as well as different forms of vocational education and training, either at schools or on the job or combining both elements in a 'dual apprenticeship' are necessary preconditions for the employability and productivity of young people. Vocational education and training is a crucial element as it can link young people's competences with employers' needs. Bringing vocational training closer to the needs of dynamically changing and evolving labor markets and economies can help young people move into more productive and sustainable jobs. Taking the perspective of young people, a 'good job' is a job that initiates a long-term investment in and attachment to the labor market. A job combined with formal training is by definition a good job. This paper is about the creation of good jobs for the young.

The study argues in favor of promoting vocational education and training tailored to labor market needs, but taking into account peculiar starting conditions found in a given national or local context. While good education and training can contribute to economic productivity and social cohesion, vocational education and on-the-job-training with young workers and companies also need to involve governments, social partners or other societal actors to be stable and effective. Given major differences in the institutional setup in different parts of the world the paper discusses feasible options for implementing vocational training under largely differing economic and institutional conditions. In the developmental context it is also crucial to find solutions how society can partner on vocational training with the informal sector.

Challenges, but also capacities to act vary across countries and world region, depending on economic, institutional and societal context. Yet, there are some general points to be made which are relevant for most medium- and low-income countries.

\section{Promoting general education}

In many low- and medium income countries, policies to ensure primary and secondary school attendance, avoid early school drop-outs and leaving school at low levels of qualification are needed. Policy makers should aim at providing basic skills to every young person by compulsory participation in support classes and intensified personal support. This implies stronger emphasis on individualized, tailored support to young people at risk, educational guidance and job search assistance (also considering incentives to parents such as conditional cash transfers). The increase of the statutory schooling age might be an avenue to increase the overall educational attainment of youth - e.g., up to upper the secondary schooling level. To minimize dropout rates, this should be done taking into account differences in motivation, ability and opportunity costs of schooling. Tracking systems, based on pupil performance and preferences might 
help reduce the number of drop-outs. However, the permeability and interconnectedness of tracks is crucial to prevent the emergence of low and high quality tracks.

Stimulate the creation of formal and sustainable jobs

In countries where high shares of informal employment form a major barrier to upward mobility and economic progress policies should be designed to create more enterprises in the formal sector which offer formal jobs. This can be addressed by economic policy reforms such as the abolition of bureaucratic business registration procedures, tax reforms, stimulating investment in the private sector and creation of formal companies start-up support. In countries with a large segment of fixed-term contracts with limited access to training and promotion to more stable jobs, overcoming the regulatory divide between permanent and temporary jobs is the major priority. This can best be achieved by creating a flexible system of employment protection easing the barriers between fixed-term and permanent jobs.

\section{Modernize vocational schooling}

Many countries should strengthen the vocational part of their educational schooling system and bring existing vocational education and training systems closer to the current needs of the labor market so that young people can experience a smoother transition to jobs. In particular, vocational education provided in the framework of secondary schooling (vocational schools or vocational tracks) should be modernized and complemented with phases of practical work experience, e.g. via internships or passing the final year with an employer. Employers should also be consulted regarding the design of vocational schooling curricula. This requires a systematic coordination with networks or associations of employers. Furthermore, in order to avoid a negative perception of vocational education as a dead-end option, transition to further education, including tertiary education, should be facilitated. Finally, in some countries reducing vocational education fees can help raise enrollment.

Bring academic education closer to the private sector

In countries with high shares of university graduates with major difficulties in finding adequate jobs a major option is to make academic training more labor market-oriented, incorporating internships with employers into academic curricula so that some experience with current work practices in the private sector can be acquired. Governments responsible for funding academic education can require public universities to modify academic curricula accordingly. 
As can be seen from many examples in the developing world even under adverse conditions, some elements of (dual) vocational training can be implemented - and with sufficient support and interest from governments and employers regional or sectoral training clusters can be established. Most countries could therefore implement feasible or 'lighter' forms of dual vocational training with limited institutional requirements. Starting points could be existing sectoral or regional clusters of firms with a shared interest in a specifically skilled labor force in particularly relevant occupations, larger (also foreign-owned) firms in modern sectors or sectoral training schemes run by employer associations. Where there is a basic agreement on training curricula and training provision this can lead to mutually recognized certificates; public support would be helpful such as support for schooling phases and some non-bureaucratic regulation of training elements and standards so that acquired skills can be recognized.

\section{Upgrading vocational training in the informal sector}

Providing better training for the informal sector is a core issue for many developing countries (ILO 2012). In countries where traditional or informal apprenticeships are dominant, but mainly confined to traditional crafts, these apprenticeships should be articulated better with the schooling system and the formal sector. They should also be opened up to new technologies and occupational change. This, of course, requires some recognition of informal employment as part of the economic and social reality in many countries.

A first option is to bring societal initiatives aimed at better training closer to the informal sector, family business and local networks. A concrete step could be to encourage informal workers and employers to participate in training activities, e.g. by providing informal apprentices with some vocational schooling focusing on more general skills and theoretical aspects. Participation in vocational courses for young people working in the informal sector could be increased by setting some incentives to participants and employers, in particular compensating for hours not worked because of training courses. To avoid deterrence, these courses should not be delivered by governments directly but rather by NGOs, churches or non-profit associations with sufficient acceptance and in-depth knowledge of the economic situation in local communities. Involving larger employers or (formal) training centers is another option. Funding may come from governments and international donors. NGOs, churches or other non-profit associations can also facilitate the creation of (informal) associations or networks of informal employers.

Given the fact that traditional or informal apprenticeships tend to be restricted to a number of traditional craft, raising productivity and potentials for innovation is crucial. Experiences from the African continent show that master craftsmen benefit from skill upgrading courses so that they can better develop their businesses and become more innovative and productive. They also benefit from better access to technical equipment and capital, which should be made more easily accessible to informal firms. 
Furthermore, some experiences from Sub-Saharan Africa show that ensuring skill recognition outside the local community by some sort of official skill testing open to informal apprenticeship graduates raises the attractiveness of these training courses and enhances mobility on the job market.

\section{Data and evaluation}

Finally, research into the effects of vocational training and related ALMPs would benefit enormously from the availability of better data and a suitable program design allowing for the proper evaluation of policy initiatives. Regarding data, the generation of representative survey data, in particular longitudinal data with a full set of individual characteristics, is essential. Training and ALMP programs should be accompanied by a systematic collection of evaluation data. 


\section{Table of Contents}

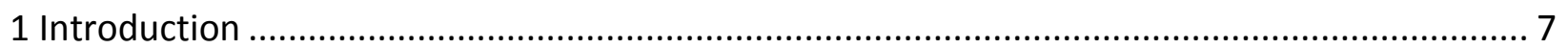

2 Youth Unemployment, Employment and Training: Global Facts ...................................... 9

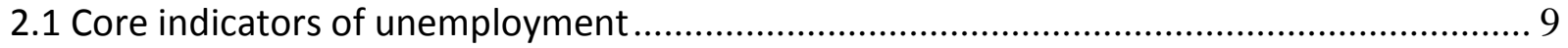

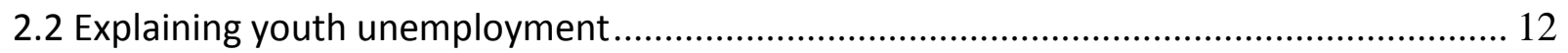

2.3 The contribution of general education and vocational training.................................... 15

2.4 The contribution of active labor market policy programs ............................................... 23

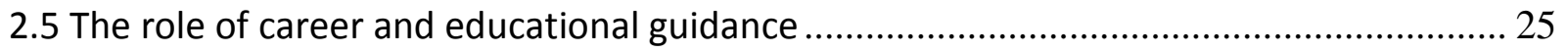

2.6 Youth unemployment and the role of training: a summary of the findings ..................... 26

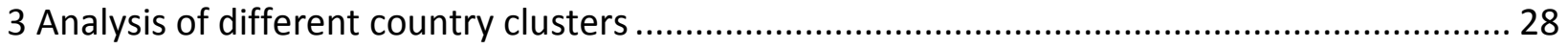

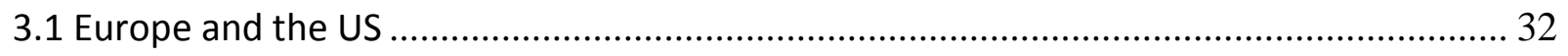

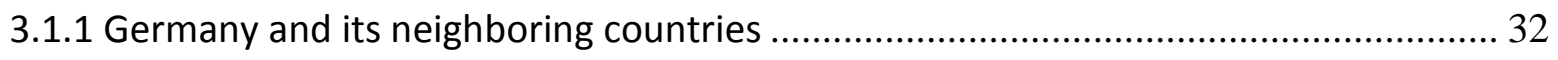

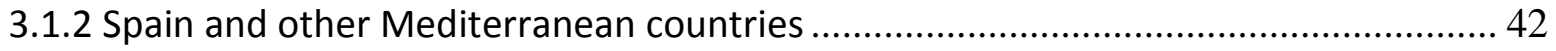

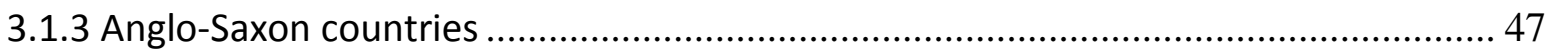

3.1.4 Transition Countries: Russia and Eastern Europe.............................................. 52

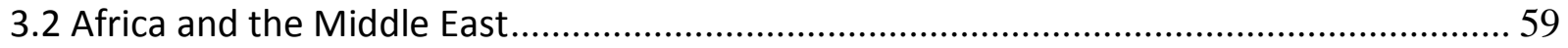

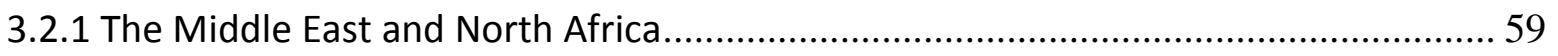

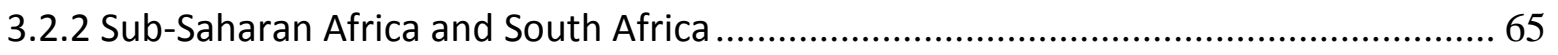

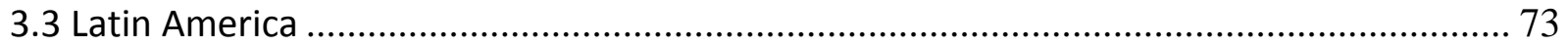

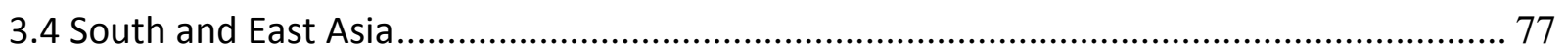

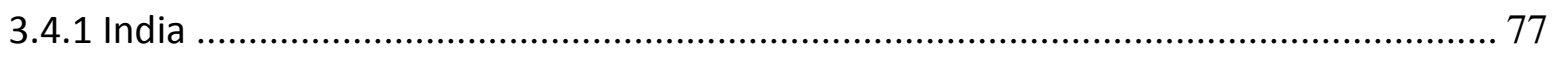

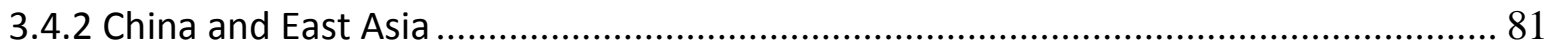

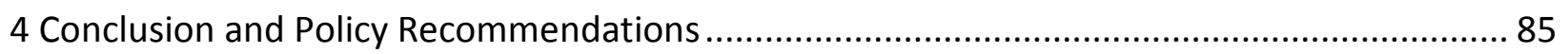

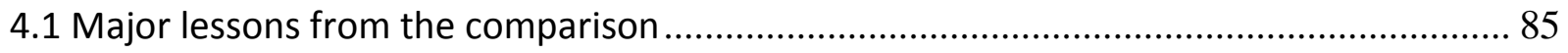

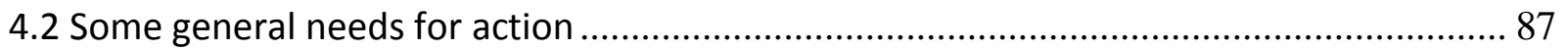

4.3 Policy recommendations for different types of countries........................................... 90

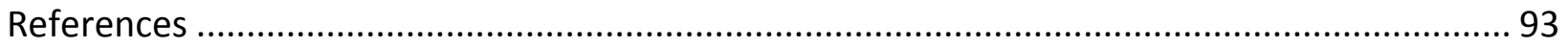




\section{List of Figures}

Figure 1: Youth Unemployment rates, 1999 and 2009, in \%................................................. 10

Figure 2: Relations between youth and adult unemployment rates, 2009............................. 11

Figure 3: NEET rate in OECD countries, 2000 and 2010, in \%............................................ 11

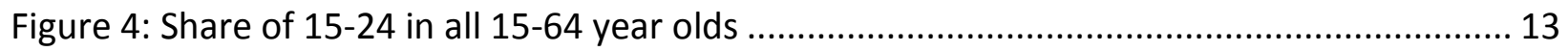

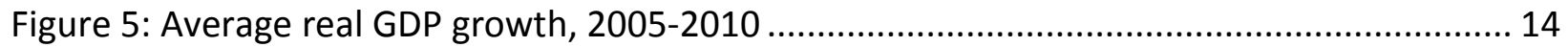

Figure 6: Unemployment rate by educational achievement, 2007 ....................................... 16

Figure 7: Technical/Vocational enrolment in ISCED 2 and 3 as \% of total enrolment in ISCED 2

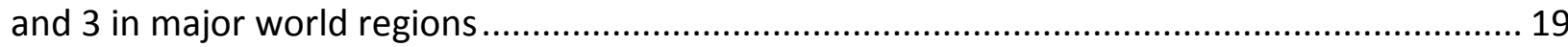

Figure 8: Shares of vocational and general secondary education enrollment in selected

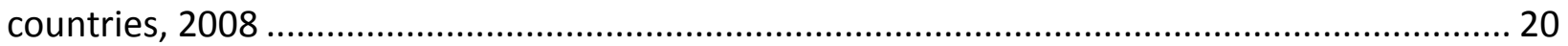

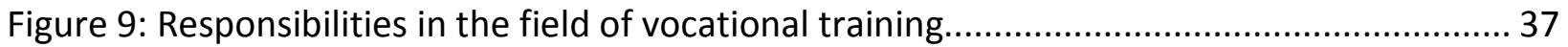

Figure 10: Temporary employees as a percentage of the total number of employees 15 to 24

years old, Mediterranean countries (\%) ......................................................................... 44

Figure 11: Technical/Vocational enrolment in ISCED 2 and 3 as \% of total enrolment in ISCED 2

and 3

Figure 12: Technical/Vocational enrolment in ISCED 2 and 3 as \% of total enrolment in ISCED 2

and 3 for representative countries, over time 83

\section{List of Tables}

Table 1: Youths' labor market situation and the role of vocational training ............................ 30

Table 2: Per 1,000 distribution of the labor force ............................................................. 78

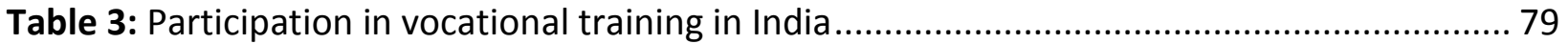

Table 4: Number of Job-seekers on the live register of employment exchanges in the country classified by age-group 2004-2008 (in thousands) ............................................................ 80 


\section{Introduction}

Entering the labor market poses major challenges for young people in many countries. While it is true that in general young people tend to be in a more vulnerable position than prime-age workers, the recent economic crisis has shown that youth integration into the labor market is problematic in some countries while it seems easier in other countries. In fact, some countries have been able to maintain stable employment over the last years and decades, also in times of recession, while elsewhere unemployment rates increased steeply. This clearly shows that institutional settings and public policies play a prominent role in influencing the transition from school to work. Promoting a successful transition from school to work not only prevents longterm negative consequences of early phases of youth unemployment and idleness, but it also enhances individual professional careers, earnings increases, economic productivity and social cohesion.

Explaining differences in youths' transition into employment needs to take into account, first, demographic developments and economic growth, and second, the interplay between these dynamics and long-standing institutional patterns, in particular regulatory provisions influencing the supply of flexible or permanent jobs as well as education and training policies. Both general education at schools as well as different forms of vocational training, either at schools or on the job or combining both elements in a 'dual apprenticeship' are necessary preconditions for the employability and productivity of young people. Vocational training is a crucial element as it can link young people's competences with employers' needs. Bringing vocational training closer to the needs of dynamically changing and evolving labor markets and economies can help young people move into more productive and sustainable jobs. Taking the perspective of young people, a 'good job' is a job that initiates a long-term investment in and attachment to the labor market. A job combined with formal training is by definition a good job. This paper is about the creation of good jobs for the young.

The first part of this study discusses main factors influencing youth unemployment and the transition into employment bringing together evidence on demographic issues, economic growth and their interaction with institutions, in particular general education and vocational training, active labor market policy programs as well as the regulation of labor markets. Stressing the difference between general education and vocational education and training, we differentiate between four types of education and outline differences in the skills they convey, their places of learning and their transferability across occupations and firms. By their stronger link to the labor market, vocational education and training paths that combine general skills with occupation- or firm-specific skills are seen as an important tool to promote a fast entry anda sustainable attachment in the labor market.

In the subsequent section the study provides an overview of the situation of young people in major world regions with a particular emphasis on the role of training systems and complementary active labor market policies. The study adopts a broad understanding of regional clusters reflecting similar challenges with respect to youth unemployment on the one hand and institutional factors influencing the situation of young people on the other. 
The final part discusses the most pressing policy challenges in different world regions and gives some recommendations in particular with respect to improving vocational training as we suggest that vocational training (including dual schemes) are a promising investment for public policy. The study argues in favor of promoting vocational education and training tailored to labor market needs, but taking into account peculiar starting conditions found in a given national or local context. While good education and training can contribute to economic productivity and social cohesion, vocational education and on-the-job-training with young workers and companies also need to involve governments, social partners or other societal actors to be stable and effective. Given major differences in the institutional setup in different parts of the world the paper discusses feasible options for implementing vocational training under largely differing economic and institutional conditions. In the developmental context it is also crucial to find solutions how society can partner on vocational training with the informal sector. 


\section{Youth Unemployment, Employment and Training: Global Facts}

Analyzing the labor market integration of young people requires a framework that allows for the understanding of major variations over time as well as for more long-term cross-country differences in the transition from the general education system into work. This section gives, first, a general assessment of comparative data on youth unemployment and exclusion before, second, reviewing major explanatory factors such as demographic developments influencing labor supply and economic activity determining labor demand on the one hand and institutional patterns such as the regulation of labor markets, general education and vocational training and active labor market policies on the other.

\subsection{Core indicators of unemployment}

Key issues:

1. Comparative indicators on the socio-economic situation of young people are not straightforward, in particular when it comes to a wider geographical coverage. A reliable picture can only be drawn by combining different indicators.

2. Young people tend to face particular difficulties in entering the labor market. In general, young people are in a more vulnerable position than prime-age members of the labor force, and they are more severely affected by economic fluctuations.

Comparing the labor market situation of young people is not straightforward in particular when countries at different stages of economic development are to be compared. The typical approach - and the one that we follow in this section - is to rely on standard indicators. Yet, caution is required when comparing these figures across countries, due to a series of issues. First, due to data limitations, phenomena such as youth unemployment or inactivity cannot be mapped comprehensively (OECD and ILO 2011; Scarpetta, Sonnet and Manfredi 2010.) Second, some indicators may have a different relevance in a specific context (e.g. depending on the incidence of the informal sector in a country). Third, in order to obtain a more reliable picture, one should consider a combination of different indicators as well as go beyond the aspect of their "size" (e.g. see the discussion about quality of jobs in low income countries in Cho et al., forthcoming.) Bearing in mind these caveats, standard indicators are the only ones for which some geographical coverage is available to date. Hence in the following, we will hinge on them to provide a country comparison.

Relying on comparative youth unemployment data from World Bank sources covering different world regions, one can see that most countries witnessed an increase in youth unemployment in recent years (Figure 1), and some countries both in Europe and in the Mediterranean region as well as South Africa now exhibit youth unemployment rates of more than $20 \%$ not including 
other forms of underemployment or idleness. Furthermore, youth unemployment is in general much higher than adult unemployment (Figure 2), but there are notable differences across regions and countries. For those OECD countries for which data is available, variation is also notable regarding the share of young people neither in education nor in training or employment (NEET) (Figure 3).

Figure 1: Youth Unemployment rates, 1999 and 2009, in \%

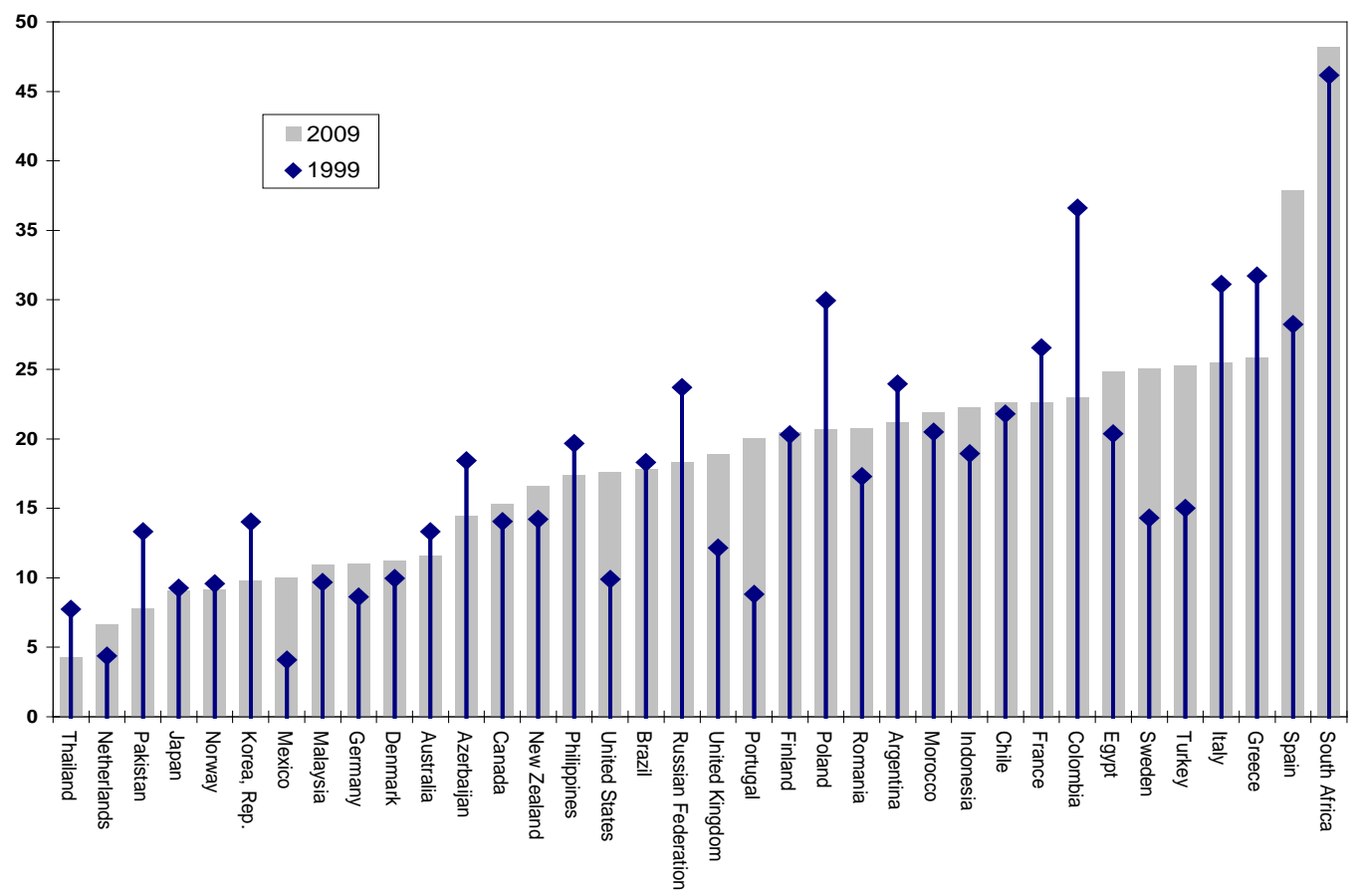

Source: World Bank. 
Figure 2: Relations between youth and adult unemployment rates, 2009

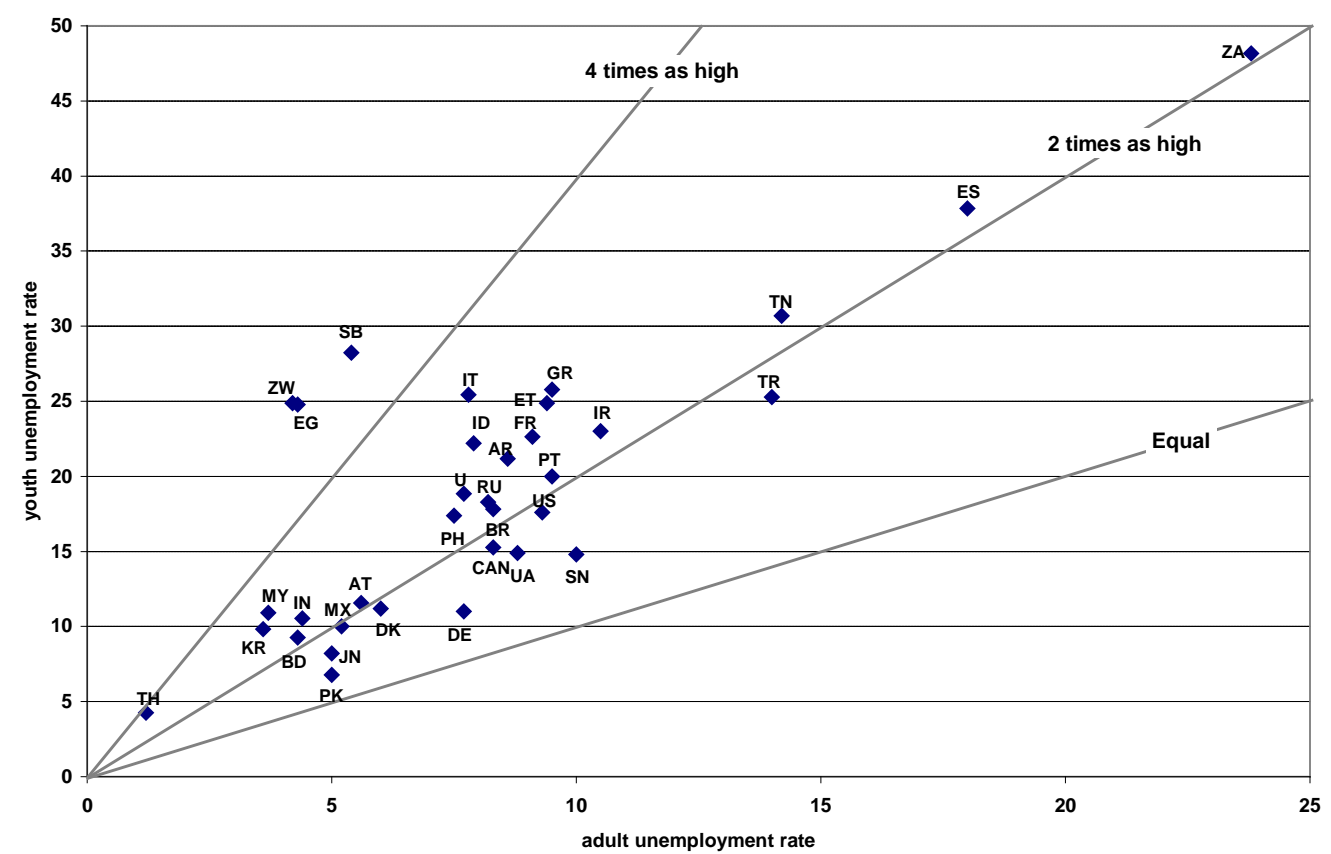

Source: World Bank.

Figure 3: NEET rate in OECD countries, 2000 and 2010, in \%

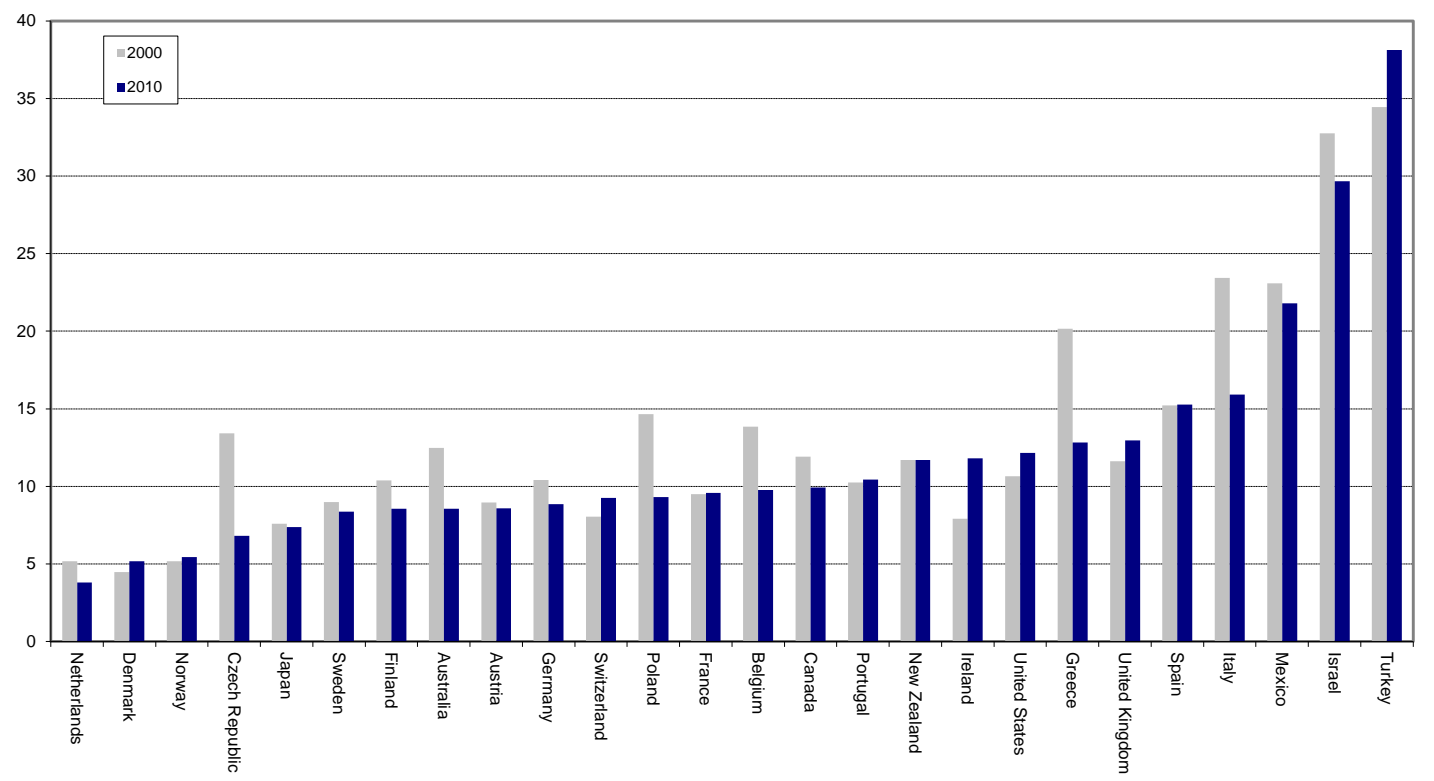

Source: OECD Education Database. 


\subsection{Explaining youth unemployment}

Key issues:

1. The labor market situation of young people is influenced by demographic factors, in particular cohort size and labor demand in the economy. However, patterns of youth integration into work are heavily influenced by institutional factors which can mitigate or aggravate obstacles of transition.

2. The transition from school to work is structured in different ways across countries and world regions. Training, but also active labor market policies as well as regulatory policies such as minimum wages and employment protection are highly relevant institutional factors.

3. Regulatory policies influence the availability of flexible entry jobs, but a strong divide between flexible parts of the labor market and permanent jobs or between informal and formal work creates additional barriers to mobility.

To explain differences in the integration of young people across time and space one has to take into account the interaction of economic and demographic factors on the one hand and labor market institutions on the other:

1. the demographic structure, in particular the size of younger cohorts, determining young people's labor supply,

2. labor demand patterns given by the structure of the economy and economic growth,

3. labor market flexibility as determined by minimum wages and employment protection for permanent and temporary jobs,

4. education and training preparing young people for the world of work, distinguishing between general education, vocational training and learning on-the-job,

5. active labor market policy programs designed to further the labor market attachment of disadvantaged youths, in particular those who failed to enter and complete general education and vocational training.

All these factors interact with each other and provide particular patterns of youth employment or unemployment in different countries or world regions.

Regarding the evidence on demographic factors first, empirical research has shown that demographic factors, in particular cohort size, and economic demand matter in determining youth employment (Korenman and Neumark 2000; Blanchflower and Freeman 2000; Garcia and Fares 2008c). Figure 4 shows that there is a large variation in the demographic composition of major world regions. Young cohorts at the age of entering the labor market are particularly large in 
Northern and Sub-Saharan Africa while demographic ageing is a major phenomenon in most high-income countries in Europe, North America and Eastern Asia.

Figure 4: Share of 15-24 in all 15-64 year olds

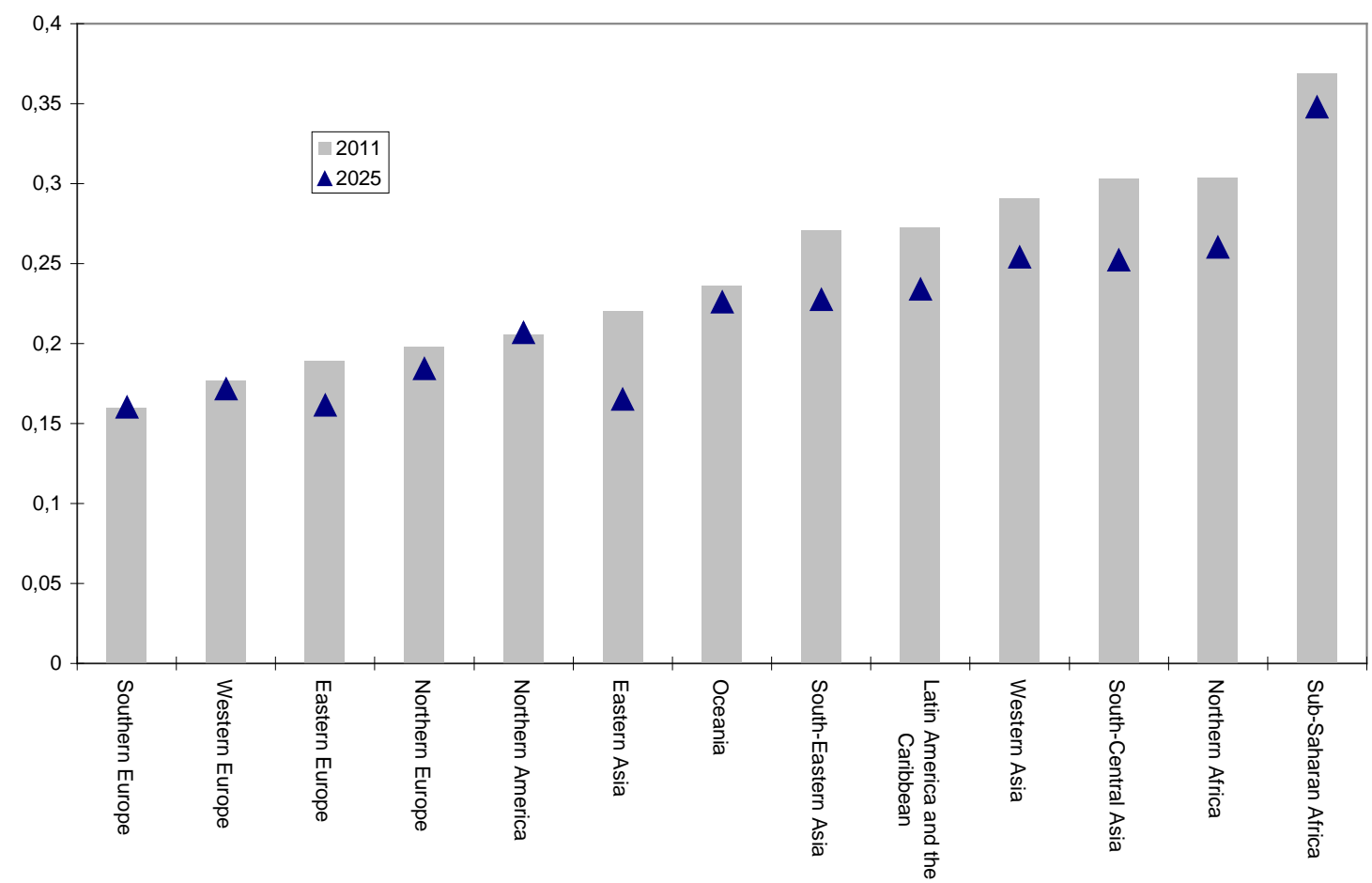

Source: UN World Population Prospects 2010 Revision.

While cohort size gives an indication of labor supply, labor demand is mainly influenced by the structure of the economy and economic dynamism. Population growth can be driving force for economic growth, but if large cohorts of young people try to enter the labor market under difficult economic conditions or sluggish demand so that job creation is limited longer queues will emerge. The capacity of the labor market to absorb these young people is insufficient then. And if permanent or formal jobs are lacking, there will be strong pressure to expand flexible or informal employment. Figure 5 presents data on real GDP growth in major world regions. From this, it becomes clear that real GDP growth was strongest in South and East Asia. The relatively large youth cohorts in Sub-Saharan and North Africa faced a more adverse situation as economic growth was less pronounced there. 
Figure 5: Average real GDP growth, 2005-2010

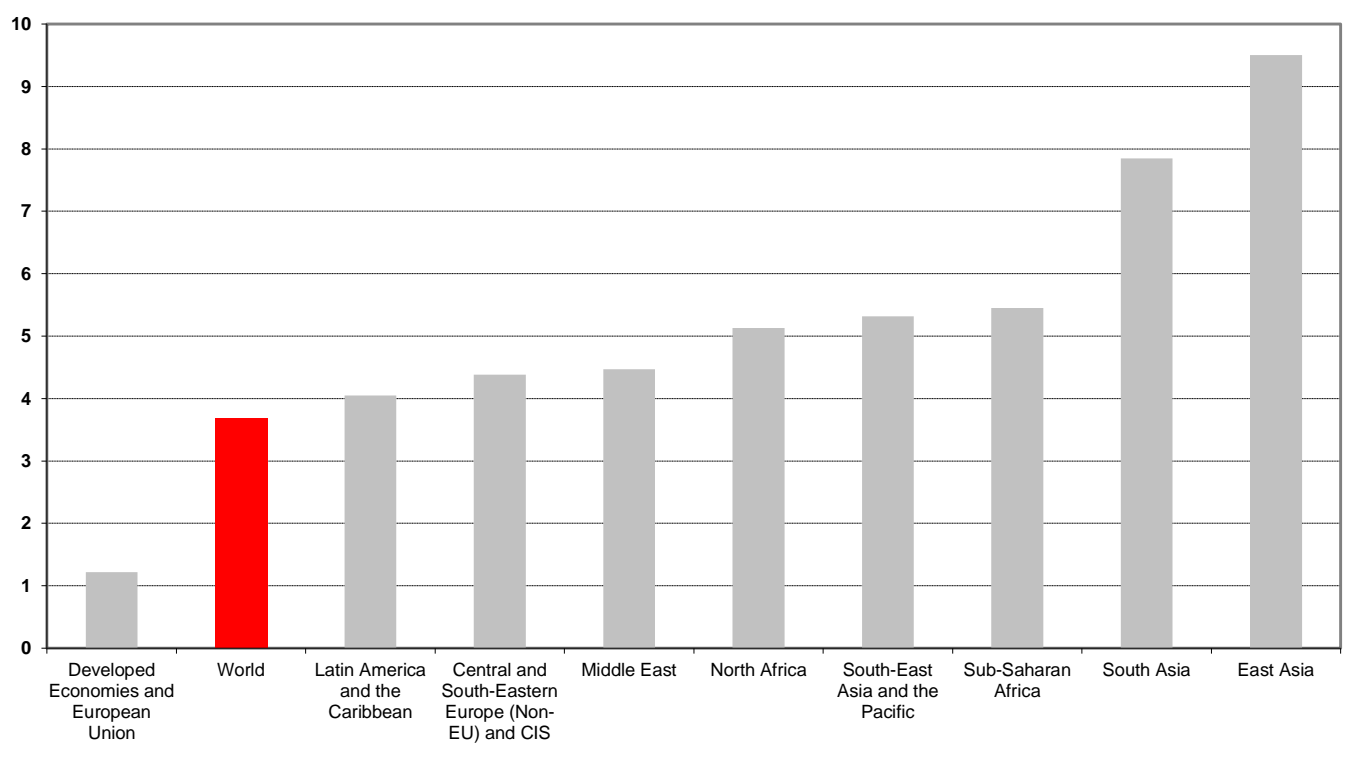

Source: ILO Global Employment Trends 2011.

Both growth and demographic features cannot explain cross-country and intertemporal variation of youths' integration into employment alone. They interact with labor market institutions in determining youth unemployment or employment and the easiness of a transition from school to work. Institutional framework conditions play a role in structuring the transition of young people into employment, in particular minimum wages and employment protection (Gomez-Salvador and Leiner-Killinger 2008), but also education and training as well as active labor market policy schemes.

Turning to the role of minimum wages first, there is quite consistent evidence that high minimum wages tend to have negative effects on young labor market entrants - this is why young workers are often covered by a specific, somewhat lower minimum wage (Neumark and Wascher 2007; Abowd et al. 2000; Gomez-Salvador and Leiner-Killinger 2008).

Second, many countries combine strict employment protection legislation for open-ended contracts with increasingly flexible regulation of fixed-term contracts and temporary agency work. While strict dismissal protection tends to raise youth unemployment (Bassanini and Duval 2006), the liberalization of temporary jobs has created a segment of flexible employment which provides points of entry into the labor market in particular for young people and stepping stones to permanent jobs. But a strict division of permanent and temporary contracts hampers the transition into jobs with longer tenure so that young people are trapped in temporary jobs with lower pay, frequent job changes and limited participation in training (see also Quintini and Manfredi 2009). 
Formal institutional arrangements have a different, somewhat limited relevance in many low income countries and emerging economies. In many of these countries informal employment constitutes a segment of a more easily accessible form flexible work largely comparable with some forms of non-standard contracts in developed countries (Jütting and de Laiglesia 2009). As with the cleavage between permanent and temporary jobs found in EU or OECD countries, there is a major divide between formal employment and informal jobs which is hard to overcome. Large shares of informality and self-employment in particular in developing countries can also be seen as a reaction to an overly regulated and taxed formal sector. The more formal employment is burdened with taxes, social contributions or bureaucratic red tape the more there is a tendency to circumvent such regulations by expanding informal activities. In a situation of strong labor supply from younger cohorts a stagnant formal labor market tends to go along with a growth of informal employment amongst young people.

\subsection{The contribution of general education and vocational training}

Key issues:

1. In general, better educated young workers have better access to gainful employment and better jobs. Vocational education and training add to general education and bring young people closer to the labor market.

2. Rigorous evaluation of training schemes is less widespread than the evaluation of active labor market policy programs.

3. Comparing vocational schooling and dual apprenticeship models, a dual system tends to be associated with a smoother transition from school to work and low youth unemployment so that the risk of scar effects during the subsequent labor market career is minimized.

4. There is some evidence that complementary active labor market policy schemes addressing the disadvantaged youth can improve their situation on the labor market if these measures are designed and implemented effectively. This also holds for training schemes combined with hiring subsidies.

\section{The general role of education}

The transition from school to work is structured in different ways across countries and world regions. Apart from country-specific dynamics in demographic and economic development, the patterns of youth employment are heavily influenced by the institutional frame given by regulatory policies on the one hand and the education system on the other hand. Hence, upon entering the labor market youths are found to experience a transition phase of different length and intensity and varying labor market risks (e.g. spells of unemployment, temporary employment, low pay). A feature commonly shared by many countries, however, is the fact that young peo- 
ple with low levels of qualification face particularly high risks of exclusion and lacking access to employment. Unemployment rates of higher skilled people tend to be lower than those of low skilled, and average employment rates are higher (Bell and Blanchflower 2011b; OECD and ILO 2011; Quintini, Martin and Martin 2007; Gomez-Salvador and Leiner-Killinger 2008). Young people without proper training also tend to experience persistent long-term scar effects of early phases of unemployment and a more vulnerable labor market position (Scarpetta, Sonnet and Manfredi 2010).

Education and training are hence considered a core factor in determining the chance of a successful transition into work. While the expansion of general education observed in many countries in recent years has seen a substantial increase in overall levels of educational attainment, the integration of youth into the labor market is still considered a major hurdle in many countries, highlighting the importance of the quality of the education system and its linkage to the labor market. For instance, in some countries with high shares of university graduates, unemployment or underemployment can be a consequence of educational mismatch as a high formal qualification cannot be translated into matching jobs.

Figure 6: Unemployment rate by educational achievement, 2007

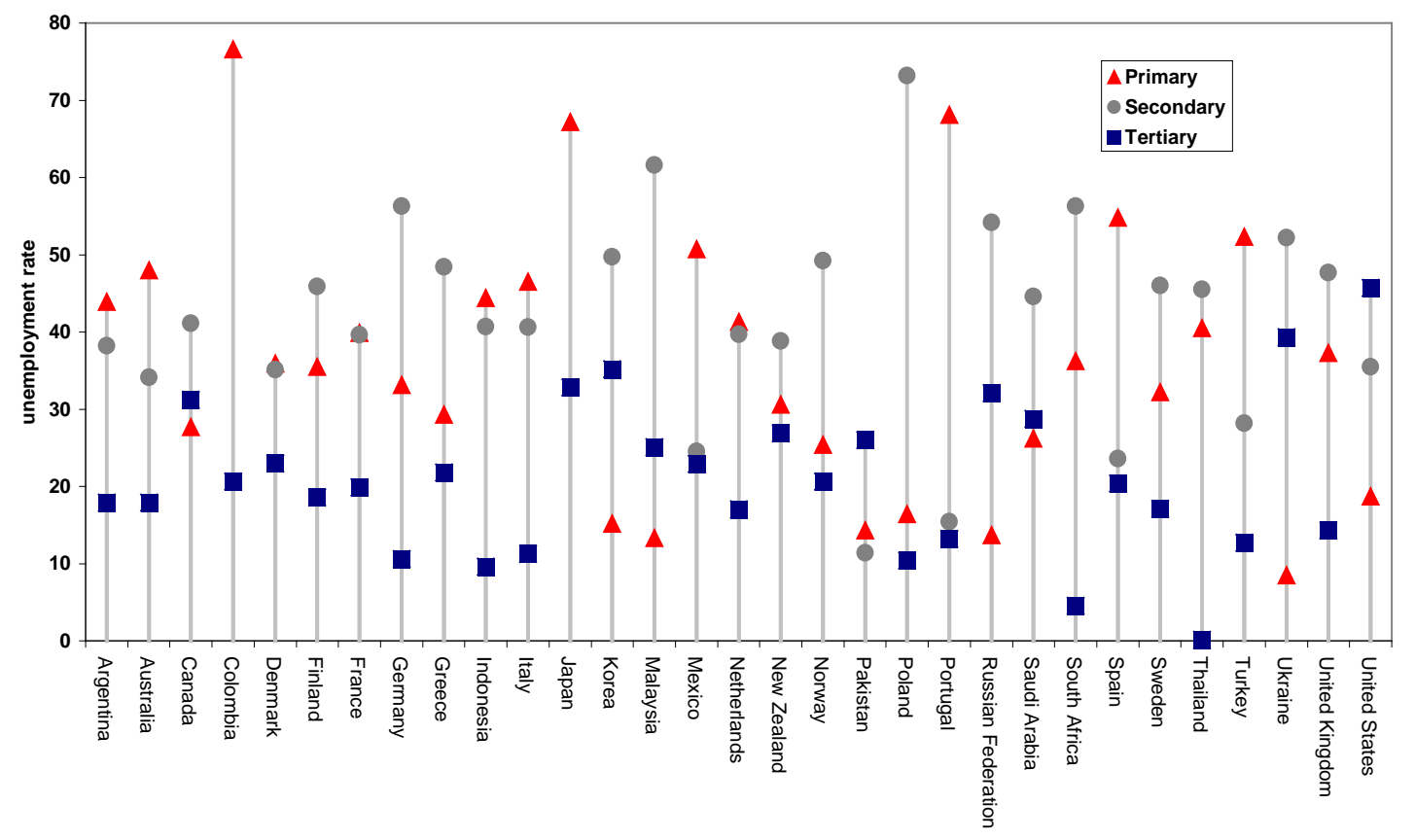

Source: World Bank. 


\section{General vs. vocational education, vocational schooling vs. dual apprenticeships}

In all developed countries and some countries of the developing world, the education system implies a two-step integration of school leavers into the labor market comprising participation in labor market-relevant training and education at the first stage and subsequent integration in the labor market at the second stage. While there exists substantial variation in the type of labor market training provided across countries, different forms of training may also co-exist within a country oriented towards different employment types and career paths. Following the economic literature that differentiates between training options along the dimensions of specificity, the place of training (school or work) and the degree of formalization, one can distinguish between general education on the one hand and vocational training on the other, with vocational training being further divided in school-based training, the 'dual' apprenticeship systems and learning on the job(for a discussion see Quintini and Martin 2009, DFID 2007), respectively:

1. General knowledge and skills are usually provided in the form of purely school-based or academic education at the upper secondary or tertiary level. The skills provided are characterized by a high degree of generality in the sense that they are aimed to improve the cognitive skills of youth with a low occupational or sectoral concentration, thereby providing the basis for further - more practically oriented - learning at the work place. While often considered the best way to access higher paid jobs, this type of education bears the risk of being only weakly linked to labor market demand. The societal costs of skill mismatch are often more severe as in the other education options due to the long duration and high individual costs of studies and graduates being unwilling to accept jobs below their formal level of education. Furthermore, as academic education does not impart practical work experience, the initial integration into the labor market might become difficult. Hence, in many countries there is a strong tendency to bring university education closer to applied studies.

2. Dual vocational education and training combines work place experience and training with school-based (vocational) education, usually within a particular occupation or sector of work. The provision of dual education is often divided between the public and companies: while firms offers and finances the work-place training, the state provides for the education in vocational schools. During vocational training, apprentices have a fixed-term employment contract with an employer at a reduced wage level. The aim of the duality is to complement the rather firm-specific technical skills acquired by learning on the job within a training company, with general skills that are transferrable across employers within the occupation. While practical workexperience within the firm is expected to provide higher motivation and higher return for practically-oriented youth, standardized curricula and central examinations are used to counteract overspecialization and low levels of transferability. Training standards in firms, as well as the alignment of skills taught in the schools and at the workplace, has to be ensured by collaboration with the employers, unions and the educational institutions likewise. 
3. Purely school-based vocational education or training is often delivered at training centers atthe post-compulsory (upper) secondary level, or as a specialization track during compulsory schooling. In general, it is state-funded, and follows a formal curriculum that combines general skills with occupation-specific education. Being more practice-oriented than academic studies, this training option is often aimed at medium-level, clerical positions or restricted to specific occupations not necessitating practical within-firm work experience. It is less demanding in time and costs than general school-based training, and hence aimed to increase the participation of youths with higher budgetary constraints. By the provision of technical skills, participation in school-based vocational education is aimed at a direct entry into the labor market, requiring only little on-the-job training by employers, and might hence be thought to create incentives for employer hiring. The success of the school-based training depends crucially on the alignment of skills taught in the schools to the labor market, and hence requires the close collaboration of employers, unions and the educational institutions.

4. Pure on-the job training allows for the direct transition from school to work - generally leading to better pay in the short run compared to participation in qualifying training programs in a first stage. However, as the acquisition of skills is restricted to learning on the job and done without certification, this type of learning is likely to be of less value when moving jobs. Due to the lack of general occupation skills, employability is more limited entailing a higher risk of ending up in a vulnerable labor market position.

The role of different types of young people's vocational training varies significantly across clusters of countries as Figure 7 shows. Only in a number of mostly continental European and Scandinavian countries vocational education is a prominent part of secondary education. 
Figure 7: Technical/vocational enrolment in ISCED 2 and 3 as \% of total enrolment in ISCED 2 and 3 in major world regions

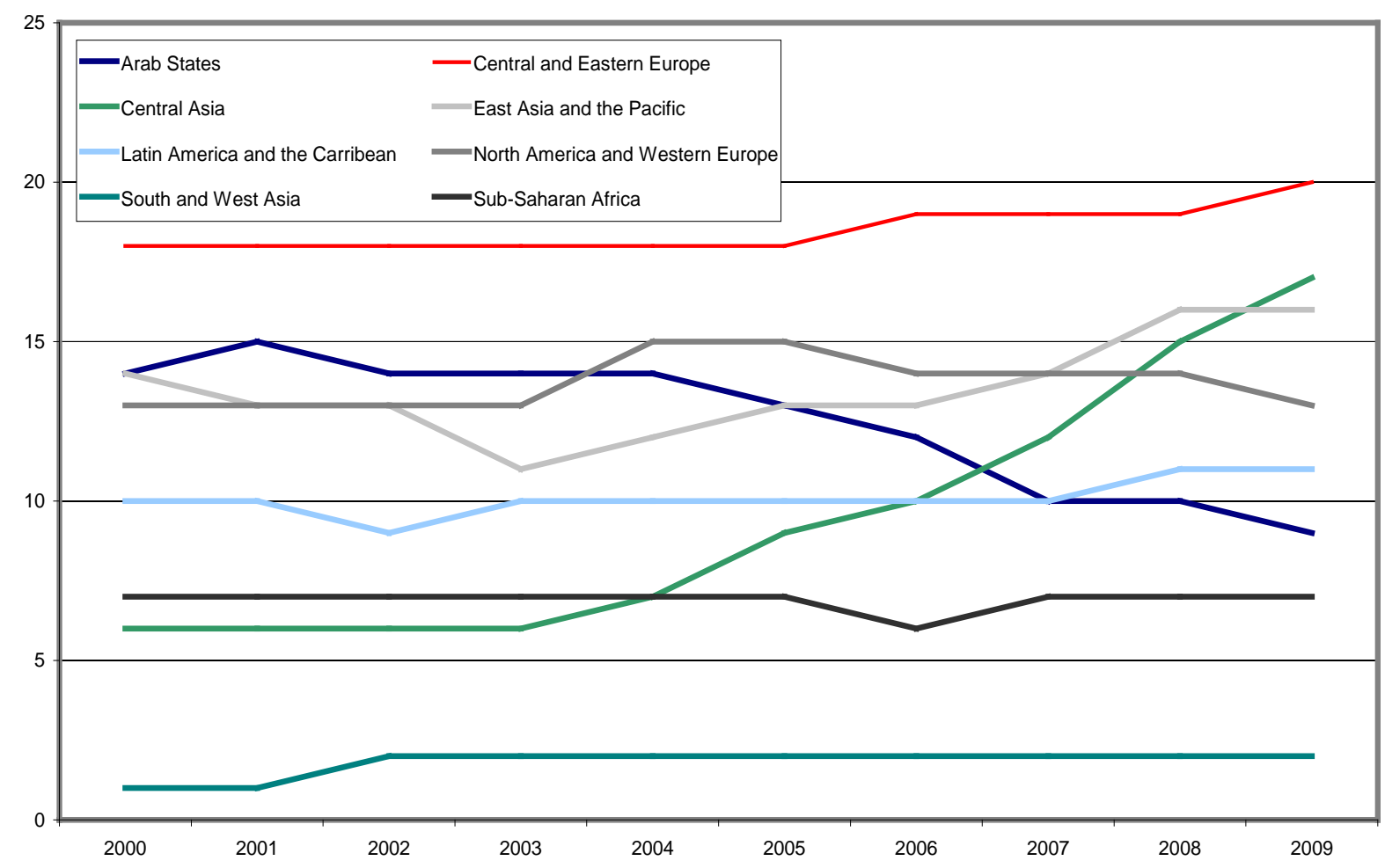

Source: Unesco Institute for Statistics. 
Figure 8: Shares of vocational and general secondary education enrollment in selected countries, 2008

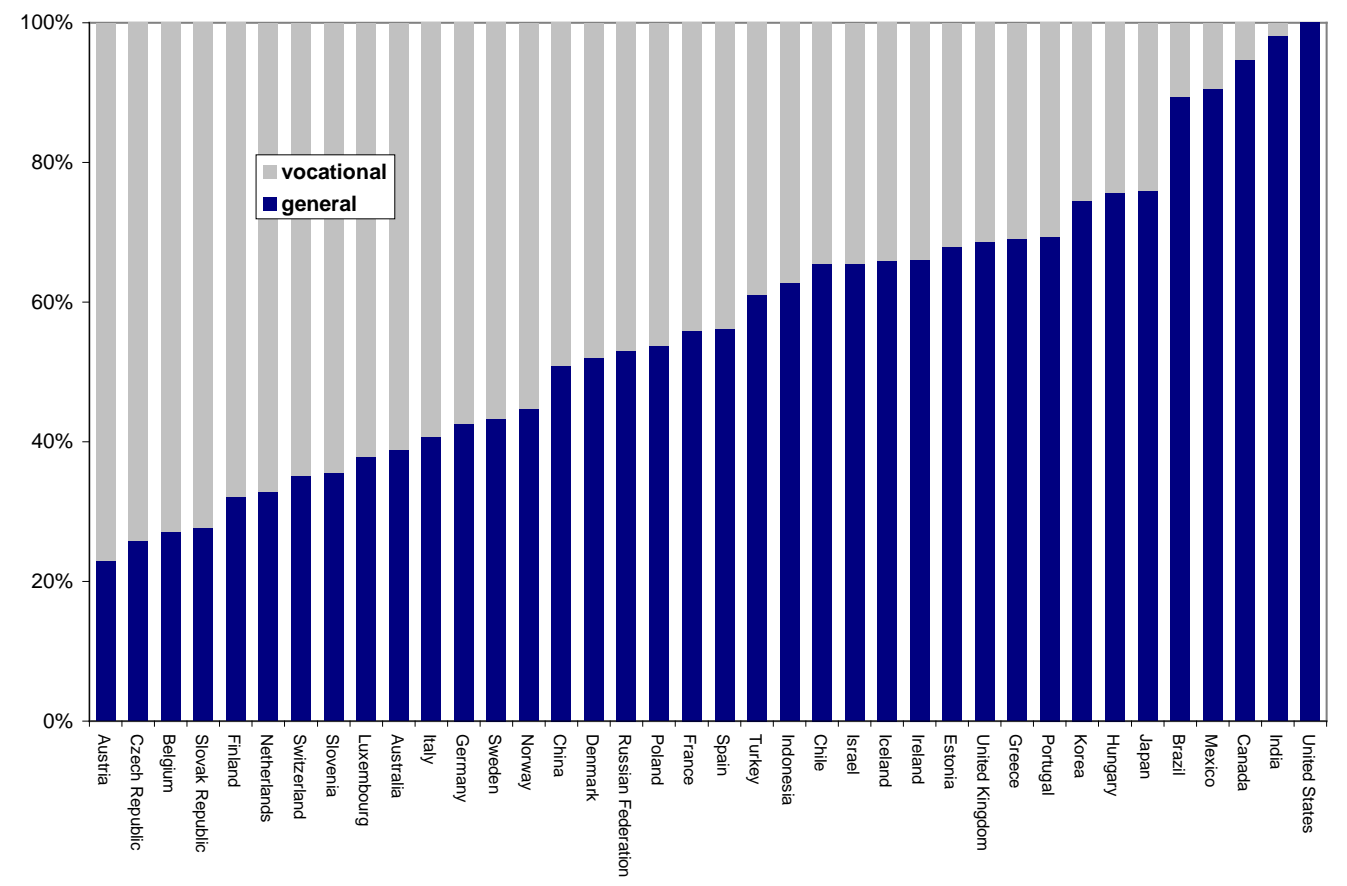

Source: OECD, Education at a Glance 2010.

\section{Assessing the effectiveness of vocational and general education}

The relative performance of the respective training options in enabling participants a smooth initial labor market integration and positive long-term labor market returns is a highly relevant question. The causal empirical evidence is rather sparse, however, and refers almost exclusively to developed countries where several of the training options co-exist. Besides limited data availability impeding the analysis of net benefits of the respective training options, assessing the individual benefit of participation within a country is complicated by several identification issues (Wolter and Ryan 2011): 1) identification of the relevant counterfactual situation in the presence of occupation-specific labor markets 2) non-random selection into the training options based on unobservable characteristics; 3 ) heterogeneous outcomes by field of training; 4) general equilibrium effects.

In cross-country comparisons it is generally found that countries maintaining a substantial dual apprenticeship system, i.e. Austria, Denmark, Germany and Switzerland, exhibit a much smoother transition from school to work, low NEET rates, low youth unemployment and below average repeated unemployment spells than other countries (Quintini and Manfredi 2009; Quintini, Martin and Martin 2007). One has to note, however, that labor market transitions of youths only provide partial evidence on the relative performance of the training systems in the 
respective countries. A causal analysis is impeded by the co-variation of other relevant institutional factors. Further problems arise from the absence of a unified framework for defining the respective training options and collecting data on the costs and benefits experienced by the state, the firms and trainees (Hoeckel 2008).

Earlier evidence on the relative performance of vocational versus general upper secondary and tertiary education is summarized by Ryan (2001) for country studies of France, the UK and the US. These studies point to an increased employment probability of participants in occupationspecific training - evidence on wage differential is mixed, finding wage penalties, similar wages as well as wage bonuses. More recently, Malamoud and Pop-Eleches (2010) investigated the differences in employment patterns in the transition economy of Romania, comparing men who were trained under policy regimes emphasizing either occupational or general education schemes. Based on expectations from earlier work that generally finds a penalty associated with occupation-specific training, they do not find any significant differences in the employment patterns or wages paid. They conclude that the general perception of a bad performance of occupation-specific training is driven by a differential selection of workers into the two training tracks.

Most recently, Hanushek, Woessmann and Zhang (2011) adopted a life-cycle approach to analyzing employment differences of general and vocational schooling over the course of individuals' working life. In line with previous findings, their descriptive evidence points at a faster initial integration into the labor market of vocational education participants, but a faster decreasing labor market participation towards the end of their working life.This seems suggestive of occupation-specific knowledge that outdates faster and hence leads to lower employment opportunities later in life. More reliable evidence on the perceived trade-off remains to be produced, however, as the causal interpretation of these findings is impeded by occupationspecific segregation of the labor market and the limited availability of long-term panel data.

An additional important aspect addressed when comparing vocational training and more general training concerns the "permeability" of the respective training options, i.e., the ability of participants to access further education options. Regarding this, it was found that youths participating in the vocational track are less likely to return to higher general education, thus raising the question whether a reduced permeability leads to vocational tracks as educational dead ends (Ryan 2001).

A more extensive area of research exploits the co-existence of apprenticeships and other types of vocational schooling within countries to infer about their relative effectiveness in general and, more specifically, the relevance of firm-specific skills. For the case of Germany, studies by Winkelmann (1996) and, more recently, Parey (2009), show that, compared with other options of the vocational schooling system, participation in the dual apprenticeship has the particular advantage of improving the early career labor market attachment and a faster and more structured integration into the labor market. This advantage fades out over time however as other education participants find a foothold in the labor market. The studies further show that the fast initial transition does not hinge on finding employment in the training firm, suggesting that firm-specific skills do not play a big role in the German apprenticeship system. Investigating wage differentials, Parey does not find any significant differences in return to the training op- 
tions in the early working life. A recent study by Adda et al. (2011) looks at the relative employment and wage profiles of participants in the dual apprenticeship system and unskilled workers in Germany over 15 years following initial labor market entry. As expected, they find that having participated in formal, work-related training (the apprenticeship) leads to overall higher wages compared to pure on-the-job training (unskilled) and a stronger labor market attachment, which compensates workers for initially low wages during the apprenticeship training.

Similar results on the performance of apprenticeship training versus school-based training are found in studies by Bonnal et al. (2002) for France and by Plug and Groot (1998) for the Netherlands. Correcting for the negative selection of youths into the dual apprenticeship, both studies find that apprenticeships performs significantly better in integrating youths into their first employment relationship by the higher labor market relation of their training. Again, this advantage is found to fade over time and not associated with higher wages.

The observed negative selection of youth into the dual apprenticeship system in some countries suggests that vocational training might be more apt to promote educational motivation for youths with low previous school experience. Besides the faster initial work experience, the dual apprenticeship could hence be important as an entry pathway for youths at risk of discouragement. A recent study by Alet and Bonnal (2011) shows for the case of France that young people integrated into the dual apprenticeship system rather than vocational schooling are more likely to successfully complete their final exam and of undertaking further education.

In countries where the dual apprenticeship is not seen as a 'trainer of last resort' for lower skilled individuals, the apprenticeship system is also found to partially act as mechanism to level the playing field for youths with low school performance. Exploiting information on PISA test scores to capture differences in ability across students Bertschy et al. (2009) show for Switzerland that lower performing youth tend to select into less demanding apprenticeship occupations and are thereby penalized in the labor market - however, their initial test-score (as signal of their ability) is not important anymore in determining labor market outcomes.

By stimulating the development of vocational training policies policy makers in developed and developing countries have aimed to achieve better labor market integration of young people (see in particular World Bank 2007; DFID 2007). To promote vocational training, support by employers, young people and their parents as well as government agencies is crucial butnot always present in specific national context. Yet, some elementary forms of apprenticeship training are also widespread in the informal sector in many countries.

\section{Assessing the effectiveness of informal training}

Due to the sizeable and persistent share of the informal sector employment in many developing countries an important question concerns the role of informal vocational learning. In India and many African countries the predominant source of vocational education or training is conveyed in a so-called traditional or informal apprenticeship system, outside formalized vocational or 
general schooling. While in "traditional apprenticeships" knowledge is transmitted between generations within a family or clan, "informal apprenticeships" are open to apprentices not belonging to a family or clan (ILO 2011b, 2012). ${ }^{2}$ Despite taking place in the informal sector, these traditional or informal apprenticeships have some locally standardized structure and duration, and are based on some contractual agreement between the patrons of small local businesses/the craftsman and the trainee. During the training period apprentice receive no or only little remuneration, and may even have to pay a fee to the trainer - the training is generally entirely work-based, but it may follow an informal training plan (ILO 2012).

Compared to informal jobs without training, the informal types of vocational training is considered to improve the chance of being promoted inside informal businesses from unskilled to skilled worker and earn a higher wage. Training is essential to become a master craftsman and set up or take over a business in these fields after some years of activity (Aggarwal, Hofmann and Phiri 2010; Nübler, Hofmann and Greiner 2009). Furthermore, compared to vocational schooling, which often relies on outdated curricula and lacks involvement of employers in many developing countries, informal and traditional apprenticeships are coupled with current skill demands and work practices in the informal sector so that informal apprenticeship graduates can more easily be employed than graduates coming from vocational schools. Given that they do not require any formalized entry criteria informal training is often the only opportunity for school-leavers to obtain vocational education (Walther 2011).

Traditional and informal apprenticeships tend to be confined to crafts where technological innovation and company growth are limited. The transferability of skills acquired in traditional and informal apprenticeships is limited due to the lack of certification of training and work experience on the one hand and missing vocational schooling parts emphasizing general skills on the other. If some certificate is issued by the informal training employer, the acceptance of such a certificate is often restricted to a local community. Due to the lack of a legal framework to enforce certain training standards the informality of training may also bear certain risks to the trainee. Particular concerns are potential exploitation of children as cheap laborers, gender discrimination based on traditional gender roles, and unenforceable contractual agreements, as, e.g., low levels of training quality, the extension of the apprenticeship duration, etc (ILO 2012).

\subsection{The contribution of active labor market policy programs}

In addition to general education and vocational training, active labor market programs can act as complementary or compensatory programs for those young people at risk of being unemployed or excluded in particular due to a lack of basic skills or failed access to either work or vocational training. Making general statements about the effectiveness of particular programs is difficult given the variation of program design, national framework conditions and target

\footnotetext{
${ }^{2}$ However, the distinction between traditional and informal apprenticeships is not consistent in the literature.
} 
groups, in particular with respect to the effects on unemployed in general compared to the impact on youth. Given available evidence of evaluation studies (as summarized by Card, Kluve and Weber 2010; Martin and Grubb 2001; Quintini, Martin and Martin 2007 for developed countries) it seems to fair to conclude in general:

1. Job search assistance and sanctioning have positive short-run effects on the termination of unemployment.

2. Publicly sponsored training has positive medium run effects, particularly if delivered in high quality tailored to labor market needs and firms' skill demands which can be achieved by mobilizing employers and local communities.

3. Targeted and temporary hiring subsidies to employers are effective, but costly, and they tend to have significant side effects so that net employment gains are less clear cut.

4. Direct public job creation is most problematic in promoting transition to employment.

5. Start-up support has proven to be a quite effective instrument.

It has to be noted, however, that - according to the meta-analysis by Card, Kluve and Weber (2010) -most ALMP schemes targeted on young people seem less effective than general schemes targeting unemployed in general. At the same time, evidence points at the important role of early intervention in favor of those young people most at risk, both with respect activation at an early stage of unemployment (Martin and Grubb 2001; Quintini, Martin and Martin 2007) and, most importantly early in life (Heckman 2000; Rodriguez-Planas 2011), i.e. before leaving school. In many countries participation in activation policies has been made compulsory during benefit receipt along the principle of 'mutual obligations' either stressing swift integration into work('work first') or demanding participation in training ('train first'), often as a 'youth guarantee' scheme. Integration into work via 'work first' tends to bring about short-run gains but is less effective than participation in training in the medium and long run. Training measures and comprehensive programs with a strong training element are most prominent in youth ALMPs.

A review of almost 300 measures from around the world (developed and developing countries) included in the World Bank's Youth Employment Inventory (Puerto 2007b) shows that middleincome countries focus on training whereas low-income countries invest more in entrepreneurship schemes. About half of the measures focus on low income youth, half of the training measures on low-skilled young people. A meta-analysis shows that program success of youth employment policy measures depends more on targeting and economic as well institutional context than on the type of measure. Youth measures seem to be more successful in developing countries, even when controlling for the quality of program evaluation which is often less rigorous in developing or transition countries.

Recent work by the World Bank and others focuses more in depth in developing countries and conduct a short overview on the effectiveness of different programs based on micro data. For instance, in the early 1990s in Latin America, several programs emerged that provided with practical experience to help their entry into the formal labor market and targeted disadvantaged youth (see Section 3.3. for a thorough discussion on these programs and their effective- 
ness) These new programs seemed to have guaranteed increased employability of the participants and higher earnings upon graduation (Betcherman et al. 2007).

\subsection{The role of career and educational guidance}

As many countries strive to diversify their professional education portfolio with the implementation of vocational training structures, the question arises whether and how these efforts should be accompanied by career guidance schemes (CGS) to increase acceptance and awareness among school-leavers and their parents of the increased number of opportunities. Besides providing general labor market information it seems crucial to give up-to-date and convincing information that can remove traditional misperceptions on the payoffs of the non-tertiary vocational training track. As TVET is often considered inferior (blue-collar) education and as a deadend track, specifically trained counselors and wide-spread information dissemination can help to improve the reputation of TVET. For example, a recent project of the American Millennium Change Corporation in Mongolia (MCA-MC) that aims at extending the TVET system in Mongolia was accompanied by training of 120 career counselors to improve information dissemination and public outreach (http://www.mca.mn/en/).

A general assessment of the scope and from of CGS in different countries was done by a comprehensive and standardized questionnaire administered by the OECD (OECD 2004), the World Bank (Watts and Fretwell, 2004), the European Commission (Sultana, 2004) and the ETF (Sultana and Watts, 2007; Sweet, 2007) during the last ten years. In total these analyses cover 55 countries, among them member and neighbor states of the European Union, the Middle East North Africa countries (MEDA), middle-income countries (Chile, Poland, Romania, Philippines, Russia, South Africa and Turkey), Australia, Canada and Korea. Based on these studies, the OECD (OECD, 2004) and the ILO (ILO, 2006) Handbooks for policy makers were synthesized. The definition of career guidance adopted in these analyses refers to "services intended to individuals (...) to make educational, training and occupational choices and to manage their careers" (Sultana and Watts, 2004, p. 107). While the availability and role of these services in developing or transition countries is rather limited, it was found that almost all developed countries (in particular Western countries) maintain a rather extensive system of career counseling and guidance for school-leavers. They may be delivered by various institutions (schools, universities or other training institutions, public or private employment services or companies) and in various intensities -e.g., integrated in the school curriculum or as separate one-time seminars - at the individual or the group level, web-based or personalized.

The objectives and setup of CGS are further found to vary substantially depending on the economic development of a country. Early career guidance in high-income countries is seen in light of a lifelong learning strategy and hence emphasizes the need to identify personal skills, abilities and tastes. As the majority of youths are able to make career and education decisions independent of their socio-economic background CGS are often tailored to accommodate the needs 
of disadvantaged youths experiencing difficulties of entering into the labor market. In contrast to that, in low or middle income countries, the ability of youth to pursue their personal notion of a career has to be considered in a different cultural and economic context that put limits on individual choice and self-fulfillment, as well as employment opportunities. In particular, career choices of youth

- are strongly shaped by parental expectations, familial ties and traditional gender roles,

- follow traditional perceptions on the returns to certain types of education, rather than current and projected labor market developments,

- is often be centered around careers in the informal sector, and focused on migration to other countries,

- receive little attention when operating at the minimal subsistence level,

- are generally done with little involvement of public employment services.

Within these boundaries, CGS implemented in these countries are found to be focused on rising the information level regarding current labor market needs by the implementation of webbased labor market information systems (LIMS) or disseminating information in communal information centers. Further efforts are targeted towards fostering self-employment by providing training or assistance opportunities for aspiring entrepreneurs and raising awareness of business opportunities in the formal or informal sector. To divert the strong focus on finding employment in shrinking public sector, recent efforts are directed to promoting the reputation in the private sector, by pointing out business opportunities and training of business skills (e.g. the Business SHABAB initiative in Syria, see Kabbani and Al-Habash, 2008). To train the abilities of students in realizing and pursuing their own choices, labor market and career guidance are integrated in school curricula (e.g. Life Orientation in South Africa).

By the often non-uniform implementation of career guidance services in low income countries, empirical evidence on their effectiveness is not available on a broad basis. Evidence on the success of CGS in high or middle income countries is also comparably scarce, pointing to changes in behavior of the "treated" youth, but the medium- to long term effectiveness of the respective measures needs further investigation (OECD, 2004). A crucial element of success for these initiatives however lies the provision of guidelines and sufficient resources to ensure the maintenance of up-to-date information on labor market opportunities and training of competent and qualified body of career guides. To date CGS are often provided by individuals with insufficient training and/or secondary to some other job, many countries do also not provide binding guidelines for the provision of career guidance.

\subsection{Youth unemployment and the role of training: a summary of the findings}

Youth tends to be affected disproportionally from difficult demographic and economic conditions hampering access to the labor market and, in particular, to stable and well-paid jobs. However, comparative studies can show that institutions and therefore public policies make a 
difference. Well-designed pathways from school to work can help young people to make a successful transition and prevent societal and individual, potentially persistent damages from spells of unemployment or exclusion at a young age.

First, flexible or informal entry jobs constitute a first step into the world of work. But they can only be considered good jobs if they create options for mobility to better paid and more stable jobs. In institutional terms, this implies that institutional reforms need to overcome deeply segmented labor markets with high obstacles for transition from temporary to permanent jobs or from informality to formality.

Second, education and training systems are a major factor structuring the pathway from school to work. General education at the primary and secondary level provides the necessary foundation, but available evidence shows that vocational training, in particular in a dual fashion, is able to establish an early link with employers, acquire skills relevant in the labor market and to move to skilled permanent positions later on. Comparing vocational schooling on the one hand and dual apprenticeship systems on the other, the evidence suggests that a smooth and timely transition from school to work without encountering major breaks can best be achieved via dual vocational training. Compared to fixed-term contracts without training, apprenticeships are better temporary contracts as they include systematic training and favourable prospects for subsequent job promotion, wages and employment stability. To be operational, vocational training needs to provide the right balance between general skills, occupation-specific skills and learning on the job so that the human capital acquired in these schemes is neither too general nor too specific and narrow. Furthermore, certification of occupation-specific skills makes qualifications more transferable and can therefore enhance mobility between employers in a given field. 


\section{Analysis of different country clusters}

The subsequent analysis of youth labor markets and the role of vocational training distinguishes different clusters of countries which, more or less, share a certain profile of economic development, performance regarding youth integration into work and core labor market institutions, in particular the dominant type of training received by young people.

Key findings from the regions are the following:

1. In Germany and many of its neighboring countries dual vocational training is the dominant pathway from school to work and provides young people with a relatively smooth transition in the labor market. This model relies on strong social partnership and government support as well as active participation of employers. However, major efforts have to be undertaken to help integrate young people unable to enter the vocational training system via active labor market policy schemes, involving preparatory training schemes.

2. In Anglo-Saxon countries such as the United Kingdom or the United States there is a clear divide between general and vocational schooling on the one hand and learning onthe-job on the other hand. Dual vocational training exists in some sectors, but is to implement at a larger scale given the lack of social partner structures. In general, this model makes young people quite vulnerable in an otherwise flexible labor market setting. To compensate for some of these deficits and contain youth non-employment ALMPs become more important over time.

3. In the transition countries in Central and Eastern Europe, dual vocational training dating from the times of the planned economy collapsed. Nowadays mostly school-based vocational education dominates. Vocational training is still more relevant than in many other regions, however, but it lacks modernization and adaptation to cover growing sectors. This could only be done by involving employers. In general, youths are in a difficult situation in these countries as youth unemployment is considerable and labor markets are segmented, with informal employment on the increase.

4. In Mediterranean countries there is clear divide between different segments of the labor market, in particular between fixed-term and permanent employees, most notably in Spain. Mostly school-based vocational training only plays a marginal role. The educational structure is polarized between school dropouts on the one hand and a large share of university graduates on the other; both low-skilled and academically trained young people find it hard to enter into sustainable jobs under these circumstances.

5. In the Middle East and North Africa (MENA) region strong demographic pressure (i.e. the 'youth bulge') and low economic growth lead to particularly difficult situation of youth. While participation in general secondary and tertiary education increased and the formal educational level is considerable, access to the labor market is highly problematic as the public sector, the traditional employer of university graduates, is overcrowded and the private sector is largely underdeveloped to create sufficient formal jobs. Many young people therefore end up in informal work or inactivity. Pilot projects 
on dual vocational training show some positive results, but lack sustainability, whereas vocational schooling seems obsolete and underrated.

6. Somewhat similar to the MENA region, in Sub-Saharan and South Africa there is a large informal sector still providing most of the employment opportunities for young people in the absence of a dynamic formal private sector and private companies as potential employers. The agrarian sector remains the main employer. Traditional apprenticeships in the informal sector are still important, but confined to the crafts sector. Existing vocational schooling is outdated, detached from the economy and perceived as inefficient and unattractive, but attempts at implementing modernized vocational training show potential some. Hence, there is a strong preference and expansion of general secondary and subsequent tertiary education.

7. Latin American countries have dated and declining industrial vocational training programs which are not up to date. In recent years, temporary training programs targeting more at the disadvantaged youths have been most prominent, but Latin American countries still miss a stable and modern vocational education system. Hence, there is growing mismatch between demands for skilled labor and current training and education activities, with employment and training in informal activities still being important.

8. Despite youth unemployment in Asia is low when compared to other regions, labor market entrants face major challenges in achieving decent job conditions. General education is predominant in most countries, often leading to informal employment and casual work on the one side and to the polarization of labor markets and educational structures on the other. The incidence of vocational training varies substantially across countries, while pilot training programs are usually characterized by their limited coverage.

Vocational education and training systems can enhance employability and increase the chance of entering into a stable job in the private sector as well-designed vocational education and training reduce skills mismatch by tying skill acquisition to current and expected demand. This can only work if employers are involved systematically.

While dual vocational training facilitates a relatively smooth transition from school to work, international experiences show that attempts at implementing such schemes often fails. Dual vocational training - and vocational training in general - only works sustainably if there is significant institutional support and acceptance by major actors. Dual vocational training can only be effective if employers engage with this type of structure and systematic training and if training curricula are up to date. This requires the participation of employers in the design of training schemes as only they know their current and expected needs. Furthermore, vocational training only works if it is generally accepted as an attractive option for starting a career in a given national labor market.

School-based vocational training clearly shares some of the potentials of the dual model as it can also contribute to the acquisition of occupation-specific skills, but school-based vocational training tends to lack a clear link with current needs of employers. Problems arise in such a system if it relies on outdated training standards or on declining sectors. These systems must be 
adapted to changing economic structures and new types of occupations and jobs. Hence, vocational schooling needs to be kept up-to-date by bringing employers in. Otherwise it runs the risk of becoming obsolete and unattractive to both employers and youths.

Particular problems arise in countries with a strong expansion of tertiary education where young people expect to enter the public sector. If this fails, their formal qualification is of questionable use as their skills are quite detached from private sector needs.

Finally, informality and related traditional apprenticeships within informal firms are still a major form of employment and training in many low- and medium-income countries. While they provide access to work and income, these types of training are restricted to traditional crafts and sectors.

Table 1: Youths' labor market situation and the role of vocational training

\begin{tabular}{|c|c|c|c|c|}
\hline & $\begin{array}{l}\text { Role of vocational } \\
\text { training vs. gen- } \\
\text { eral education }\end{array}$ & $\begin{array}{c}\text { Major features } \\
\text { of the labor } \\
\text { market }\end{array}$ & $\begin{array}{l}\text { Major outcomes } \\
\text { regarding youth }\end{array}$ & Main challenges \\
\hline $\begin{array}{l}\text { Continental } \\
\text { Europe, mainly } \\
\text { German- } \\
\text { speaking coun- } \\
\text { tries }\end{array}$ & $\begin{array}{l}\text { Dominance of } \\
\text { 'dual' vocational } \\
\text { training }\end{array}$ & $\begin{array}{l}\text { Relative resili- } \\
\text { ence of employ- } \\
\text { ment }\end{array}$ & $\begin{array}{l}\text { Relatively smooth } \\
\text { transition from } \\
\text { school to work, low } \\
\text { youth unemploy- } \\
\text { ment }\end{array}$ & $\begin{array}{l}\text { Labor market inte- } \\
\text { gration of youths } \\
\text { failing to enter voca- } \\
\text { tional training }\end{array}$ \\
\hline $\begin{array}{l}\text { Mediterranean } \\
\text { countries, in } \\
\text { particular } \\
\text { Spain }\end{array}$ & $\begin{array}{l}\text { Some school- } \\
\text { based vocational } \\
\text { training, but gen- } \\
\text { eral education } \\
\text { tends to dominate, } \\
\text { problem with early } \\
\text { school leaving }\end{array}$ & $\begin{array}{l}\text { Severe dualiza- } \\
\text { tion with fixed- } \\
\text { term contracts, } \\
\text { subsidized forms } \\
\text { of employment }\end{array}$ & $\begin{array}{l}\text { High youth unem- } \\
\text { ployment, mainly } \\
\text { unstable jobs for } \\
\text { young people }\end{array}$ & $\begin{array}{l}\text { Brining academic } \\
\text { education closer to } \\
\text { the labor market, } \\
\text { strengthening ap- } \\
\text { prenticeships, pre- } \\
\text { vent youth exclusion }\end{array}$ \\
\hline $\begin{array}{l}\text { Anglo-Saxon } \\
\text { countries }\end{array}$ & $\begin{array}{l}\text { Clear division be- } \\
\text { tween school- } \\
\text { based education } \\
\text { and learning on- } \\
\text { the-job }\end{array}$ & $\begin{array}{l}\text { In general, rela- } \\
\text { tively flexible and } \\
\text { volatile labor } \\
\text { markets }\end{array}$ & $\begin{array}{l}\text { strong youth un- } \\
\text { employment in- } \\
\text { crease during the } \\
\text { economic crisis, } \\
\text { good chances by a } \\
\text { secondary degree }\end{array}$ & $\begin{array}{l}\text { Ensure better general } \\
\text { schooling comple- } \\
\text { tion, establish links } \\
\text { between colleg- } \\
\text { es/schools and world } \\
\text { of work }\end{array}$ \\
\hline $\begin{array}{l}\text { Transition } \\
\text { countries }\end{array}$ & $\begin{array}{l}\text { Dual vocational } \\
\text { training declined, } \\
\text { now mostly } \\
\text { school-based, ex- } \\
\text { pansion of tertiary } \\
\text { education }\end{array}$ & $\begin{array}{l}\text { Ageing issue, } \\
\text { moderate eco- } \\
\text { nomic growth, } \\
\text { low employment } \\
\text { protection, poor } \\
\text { enforcement of } \\
\text { labor laws }\end{array}$ & $\begin{array}{l}\text { Youth often in vol- } \\
\text { atile positions }\end{array}$ & $\begin{array}{l}\text { Expand existing voca- } \\
\text { tional training to } \\
\text { include employers }\end{array}$ \\
\hline Middle East & Dominance of & Strong demo- & Dominance of in- & Stimulating formal \\
\hline
\end{tabular}




\begin{tabular}{|c|c|c|c|c|}
\hline & $\begin{array}{l}\text { Role of vocational } \\
\text { training vs. gen- } \\
\text { eral education }\end{array}$ & $\begin{array}{c}\text { Major features } \\
\text { of the labor } \\
\text { market }\end{array}$ & $\begin{array}{l}\text { Major outcomes } \\
\text { regarding youth }\end{array}$ & Main challenges \\
\hline $\begin{array}{l}\text { and North } \\
\text { Africa }\end{array}$ & $\begin{array}{l}\text { general education, } \\
\text { some school- } \\
\text { based vocational } \\
\text { training and tradi- } \\
\text { tional apprentice- } \\
\text { ships }\end{array}$ & $\begin{array}{l}\text { graphic expan- } \\
\text { sion (youth } \\
\text { bulge), economic } \\
\text { growth too weak, } \\
\text { skills mismatch, } \\
\text { expanding infor- } \\
\text { mal employment }\end{array}$ & $\begin{array}{l}\text { formal jobs or inac- } \\
\text { tivity }\end{array}$ & $\begin{array}{l}\text { private sector, pre- } \\
\text { pare young people } \\
\text { for jobs outside pub- } \\
\text { lic sector, improve } \\
\text { quality of education }\end{array}$ \\
\hline $\begin{array}{l}\text { Sub-Saharan } \\
\text { and South } \\
\text { Africa }\end{array}$ & $\begin{array}{l}\text { Dominance of } \\
\text { general education, } \\
\text { some school- } \\
\text { based vocational } \\
\text { training and tradi- } \\
\text { tional apprentice- } \\
\text { ships, }\end{array}$ & $\begin{array}{l}\text { Strong demo- } \\
\text { graphic expan- } \\
\text { sion (youth } \\
\text { bulge), economic } \\
\text { growth too weak, } \\
\text { dominant infor- } \\
\text { mal sector, high } \\
\text { dependence on } \\
\text { agriculture }\end{array}$ & $\begin{array}{l}\text { Mainly employ- } \\
\text { ment in informal } \\
\text { sector }\end{array}$ & $\begin{array}{l}\text { Stimulating formal } \\
\text { private sector, bring } \\
\text { some formal training } \\
\text { to informal jobs, } \\
\text { improve quality of } \\
\text { education }\end{array}$ \\
\hline $\begin{array}{l}\text { South and East } \\
\text { Asia incl. India } \\
\text { and China }\end{array}$ & $\begin{array}{l}\text { Expansion of gen- } \\
\text { eral education, } \\
\text { vocational training } \\
\text { mostly school- } \\
\text { based and margin- } \\
\text { al, traditional ap- } \\
\text { prenticeships, } \\
\text { preparatory pro- } \\
\text { grams at small } \\
\text { scale }\end{array}$ & $\begin{array}{l}\text { Dynamic econo- } \\
\text { mies, diverse } \\
\text { demographic } \\
\text { picture, informal } \\
\text { sector very im- } \\
\text { portant, over- } \\
\text { supply of low- } \\
\text { skilled workers }\end{array}$ & $\begin{array}{l}\text { Underemployment, } \\
\text { informal employ- } \\
\text { ment }\end{array}$ & $\begin{array}{l}\text { Decent working con- } \\
\text { ditions for youths, } \\
\text { increasing vocational } \\
\text { training in a system- } \\
\text { atic way }\end{array}$ \\
\hline Latin America & $\begin{array}{l}\text { More dated and } \\
\text { limited vocational } \\
\text { training, wave of } \\
\text { temporary training } \\
\text { programs }\end{array}$ & $\begin{array}{l}\text { Lack of skilled } \\
\text { individuals but } \\
\text { also underem- } \\
\text { ployed people }\end{array}$ & $\begin{array}{l}\text { Severe labor mar- } \\
\text { ket dualization and } \\
\text { informality }\end{array}$ & $\begin{array}{l}\text { Modernization of } \\
\text { vocational training } \\
\text { meeting dynamic } \\
\text { labor market de- } \\
\text { mands, overcoming } \\
\text { segmentation }\end{array}$ \\
\hline
\end{tabular}




\subsection{Europe and the US}

\subsubsection{Germany and its neighboring countries}

Key issues:

1. Germany and many neighboring countries are characterized by 'dual' vocational training combining work experience, learning on-the-job and classroom education as the dominant pathway from school to work. Apprenticeship graduates generally have a smooth transition into employment.

2. This system depends on support in particular from employers, trade unions and the government regarding regulation and funding. It also depends on the acceptance of apprenticeship contracts paid below regular contracts by trade unions in exchange with the willingness of many employers to provide training according to occupational curricula, to send apprentices to vocational school leading to certified occupational qualification and to give them a credible prospect of sustainable employment. Furthermore, support from the government providing not only vocational schools and teachers, but also preparatory training for young people failing to enter apprenticeships, is crucial. Finally, vocational training is accepted as a solid alternative to academic education by young people and their parents. The complex German institutional and cultural environment has grown over time and cannot easily be transplanted.

3. A major challenge is the labor market integration of young people failing to enter regular vocational training. To tackle this, a large set of publicly supported preparatory training programs has been established.

\section{Vocational training in Germany}

Taking a closer look at Germany, the distribution of the German working-age population between 25 and 64 years by the highest level of educational attainment shows that $85 \%$ of individuals have acquired an educational degree beyond the lower general schooling levels (ISCED $0-2$ ). Among these individuals the vast majority (70\%) has an upper secondary degree (ISCED 3 and 4 ), and $30 \%$ a higher tertiary degree (ISCED 5 and 6). The high rates of upper secondary education reflects the fact that for the majority of Germans general schooling is followed by participation in upper secondary vocational education as a standard pathway into the labor market. The returns to obtaining a secondary or tertiary vocational degree are substantial; individuals with an upper secondary qualification are only half as likely to be unemployed as individuals with no vocational qualification, individuals with tertiary education three times less likely.

Vocational qualifications can be acquired by participating in one of the options of the highly institutionalized vocational training system. The different pathways available can be catego- 
rized into three different tracks which vary with respect to the weight of general and more specific skills provided:

(i) The dual vocational training system, with alternating school- and firm-based training.

(ii) Full-time vocational schooling with a predominantly application-oriented curriculum.

(iii) Tertiary education at colleges, vocational academies or universities.

Among the options of non-tertiary education, the dual apprenticeship constitutes by far the most important one. Compared to the total number of youths completing general schooling each year, two thirds enter the dual apprenticeship system, and about one fifth participate in full-time vocational schooling. The central role of the dual apprenticeship system is generally seen as the major reason for the low levels of youth unemployment in Germany and the relatively smooth transition from school to work for the majority of them. In particular during the recent economic crisis, Germany was one of the few countries that could keep low youth unemployment rates.

The German system is determined by some quite unique characteristics. First, the firm-based training is subject to nationally defined standards regarding the content and quality of skills. Second, a wide range of firms participate in skill formation and, lastly, the state offers support but relies on private sector incentives sponsoring vocational training (Thelen 2007). The dual apprenticeship system is based on occupation-specific regulations issued by the federal government. It currently covers 350 officially recognized occupational degrees defined with the advice of employers and trade unions. Based on these uniform regulations regarding the duration, content and syllabus of training, the training firm and the trainee sign a temporary contract for the duration of the apprenticeship. A committee of the local Chamber of Crafts or Commerce monitors whether working and training standards in the firms are met and also carries out the final examinations required for certification. The regulatory exclusivity of the training and certification process aims to ensure transparency and transferability of the skills acquired. Continual efforts are made to adapt the training standards to changing labor market needs. The Federal Institute for Vocational Education and Training (BIBB) aggregates continuous research for this purpose and provides a platform for the dialogue between the federal government, employer representatives and trade unions, such as reforming or introducing training occupations. In general, the setup of the dual apprenticeship is standardized to two to four years' duration, during which the trainee participates in training within the firm and, in an alternating manner, within a vocational school. While the school-based training provides general as well as occupation-specific knowledge, training within the firm contains some firmspecific elements.

From the firms' perspective training of apprentices provides a valuable investment into a welleducated workforce with firm-specific knowledge, and provides the additional advantage that the period of the apprenticeship serves as screening device for the quality of potential future employees. Not all firms decide to train however, as they have to provide part of the costs and meet certain formal criteria in order to be able to provide training. In particular, companies have to invest in training facilities and personnel and provide some basic level of remuneration 
to the trainees during the apprenticeship. The costs of training incurred by education at vocational schools are borne by the government. Of all firms registered with the Chambers of Crafts or Commerce, around $50 \%$ of companies are authorized to provide training within dual apprenticeships, however only half of them actively provide apprenticeship places (BMBF 2011). Firms seem to adapt their training activities to economic conditions and the projected demand for skills, which makes the number of apprenticeship offers sensitive to economic fluctuations. Similarly, the decision to employ youths in the firm after the end of the apprenticeship depends on the current economic environment. Between 2000 and 2009, the rate of conversion of apprenticeship contracts into regular employment varied between $50 \%$ and $60 \%$ (BMBF 2011). Apart from firm-based training, the apprentices are schooled in vocational education and training schools and typically spend 12 hours a week at the schools. The teachers hold academic qualifications if they teach theoretical subjects, however, teachers conveying practical training are not required to hold university degrees but they need substantial experience in the relevant occupation as foreman or master craftsmen. For both types of teachers continuous in-servicetraining is compulsory (Hoeckel and Schwartz 2010).

According to Fedorets and Spitz-Oener (2011), apprenticeship graduates dispose of sufficient general skills which enable them to move between even different professions. In this way the dual vocational training system has proven to be able to adapt to changing labor market needs but nevertheless the need for ongoing evaluation and modernization persists. A discussion regarding upward job mobility amongst policy makers has, for instance, recently led to some changes facilitating the transition to tertiary education for apprenticeship graduates. Each "Land" has introduced its own policies which may broadly be summarized as follows: In general, it is now possible for apprenticeship graduates to pursue tertiary education. Master craftsmen face the least obstacles in pursuing degree courses and may study any subject at universities without taking pre-examinations. Apprenticeship graduates with at least two years of vocational training and additional professional experience may take up a degree course related to the initial dual vocational training (often after passing entrance tests). Finally, apprenticeship graduates with at least two years of dual vocational training and professional experience may also study non-consecutive degree programs if they pass certain entrance examinations and a trial period upon matriculation (KMK 2011).

\section{Complementary active labor market policies for disadvantaged youths}

Although there are no legal prerequisites to entering the dual apprenticeships, some disadvantaged youths face substantial obstacles. As firms are free to choose whether and whom to train, youths must compete for the training places. Particular problems arise for youths who fail to formally complete schooling or leave with week school performance, lacking basic qualifications.

In response to these difficulties, a large number of permanent labor market schemes are in place to lower the first barrier to labor market entry between school and vocational training. The regular policy initiatives at the federal level are complemented by policies at the state-level as well as by temporary labor market programs at the federal, state and municipal level (see 
BMAS, 2010 for an overview of the state-level programs). At the federal level, the standard regulations of ALMPs are captured in the Social Act (SGB II und SGB III) and comprise an extensive set of instruments to promote the fast integration of individuals looking for an apprenticeship or employment.

For youths who fail to enter the vocational training system because of their adverse characteristics, an extensive preparatory training system aims to provide them with a sufficient set of skills to increase their chances of integrating into regular vocational training. These medium- to long-term measures range from school-based education to practical experience and internships. Although the long-term effectiveness of preparatory measures has not yet been fully assessed, their relative importance has gradually increased over the last 20 years: over the past decade the number of youths entering the preparatory training system was comparable to the number of all entries into the dual apprenticeship system (BMBF 2009). If supply-sided restrictions impede the integration of youth, fully subsidized substitutes to the dual apprenticeship are offered. These external apprenticeships are similar in terms of educational content and qualification degree and aim to provide an equivalently high level of practical in-firm training. In regions with structurally low supply of apprenticeships such as most regions in Eastern Germany, up to one third of the dual apprenticeships are financed completely by the government. There are also measures to promote the completion of an apprenticeship: particularly disadvantaged youths, in terms of their pre-training skills, may receive government-financed counseling to improve their chances of finishing the apprenticeship. The training system was also stabilized by the National Pact for Training ('Ausbildungspakt') between government and employers in 2004, and recently extended to 2014. With this pact employers committed themselves to providing more apprenticeship places in exchange with continuing public support by way of preparatory ALMP measures and an updating of vocational training curricula.

In 2009 the states and the federal government spent around 7.3 billion euros on the regular vocational training system; and an additional 5.5 billion euros on measures aimed to promote or improve the functioning of the (preparatory) training system (BMBF 2011). Despite the high levels of financial support for these compensatory measures, the effectiveness of the different options of the (preparatory) vocational training system is not well known.

In 2010 about 1.7 million participants below the age of 25 were registered in ALMP in the SGB II and the SGB III that aim at a direct integration in the first labor market. The majority of these measures are not youth-specific as they are available to all individuals fulfilling the eligibility criteria, independent of age. Hence the type of measures offered cover the standard repertoire of ALMP schemes, i.e., counseling, job search assistance, short- and long-term training measures, wage subsidies as well as job creation schemes in the public sector. The only exception are specific employment subsidies that were granted to firms between 2007 and 2010 when hiring youths under 25 who had been unemployed six months prior to entering employment. The subsidy paid up to 50\% - capped at 1,000 euros - over a maximum period of 12 months. For youths without a qualification and for whom an apprenticeship was not possible, the wage subsidy was offered under the condition that training would be offered during the employment. In 2010 the most important measures aimed at labor market integration were cash transfers to cover costs related to the take up of a job (47\%), general measures for activation employed by the caseworker (28\%), public-sector job creation (11\%), further training 
measures (4\%) and wage subsidies (3\%). A recent evaluation of the effectiveness of the regular activation schemes for unemployed youths showed that except for public-sector job creation, all measures significantly and persistently improve the employment outcomes of youths. However, the study also shows that the least educated are not appropriately addressed by the programs as they are either not placed in these measures, or they are less successful for them (Caliendo, Künn and Schmidl 2011).

\section{Challenges of the German dual vocational training system}

In order to prevent a mismatch between general skills determined by formal curricula and actual practical skills needed at the work place, research work needs to constantly evaluate if the two pillars of dual vocational training are in accordance with each other.

Apart from that there has been a decline in dual vocational training places offered over the last 10-15 years. It is mainly due to three reasons. On the one hand, firms face a higher training cost because of changed and higher skill demands. New occupations often require broader and more theoretical training; hence, firms have to invest more before the trainee may contribute to the company's revenue.

The decline of manufacturing (a main provider of apprenticeships) and the transition to services have contributed to fewer dual vocational training places because the service sector is not able to fully implement the dual system on such a high level as was the case in manufacturing. At the same time, youths in ALMPs such as in preparatory years or in internships have increased substantially so that currently the number of people in dual training only slightly exceeds the number of people in alternative training. The continuing crisis in Eastern Germany also contributes to fewer positions in dual vocational training.

By implementing the new vocational training act, the German government has tried to motivate more firms to offer training positions and to enhance the flexibility of the dual vocational training system (Thelen 2007).

\section{Institutional requirements}

In general, it is important to see that the German type of dual vocational training depends on some essential preconditions. In order for the system to work, there must be legally binding laws and social partners cooperating with the government particularly regarding the development of the institutional framework for vocational training, the development and adjustment of curricula, the certification of competences and co-funding of plant-based and school-based elements. The Vocational Education and Training Act (BBiG) is the main legal framework regulating the dual vocational training system. Figure 9 depicts the responsibilities different stakeholders have within the vocational training framework. In particular, the Standing Conference of Ministers for Education and Cultural Affairs (KMK) issues framework curricula for vocational 
education at vocational schools whereas due to Germany's federal state organization, the Länder are obliged to implement apprentices' school-based education. "Curricula for general education at vocational schools are essentially developed by the individual Länder. The Federal Agency for Employment (BA) is responsible for consultancy on and provision and promotion of vocational education and training for young people and companies, on the basis of the Sozialgesetzbuch III (SGB III)" (Hippach-Schneider, Krause and Woll 2007, p. 19-20). Employer and employee representatives contribute to facilitating examinations and ensuring that training venues fulfill all required criteria for vocational training.

\section{Figure 9: Responsibilities in the field of vocational training}

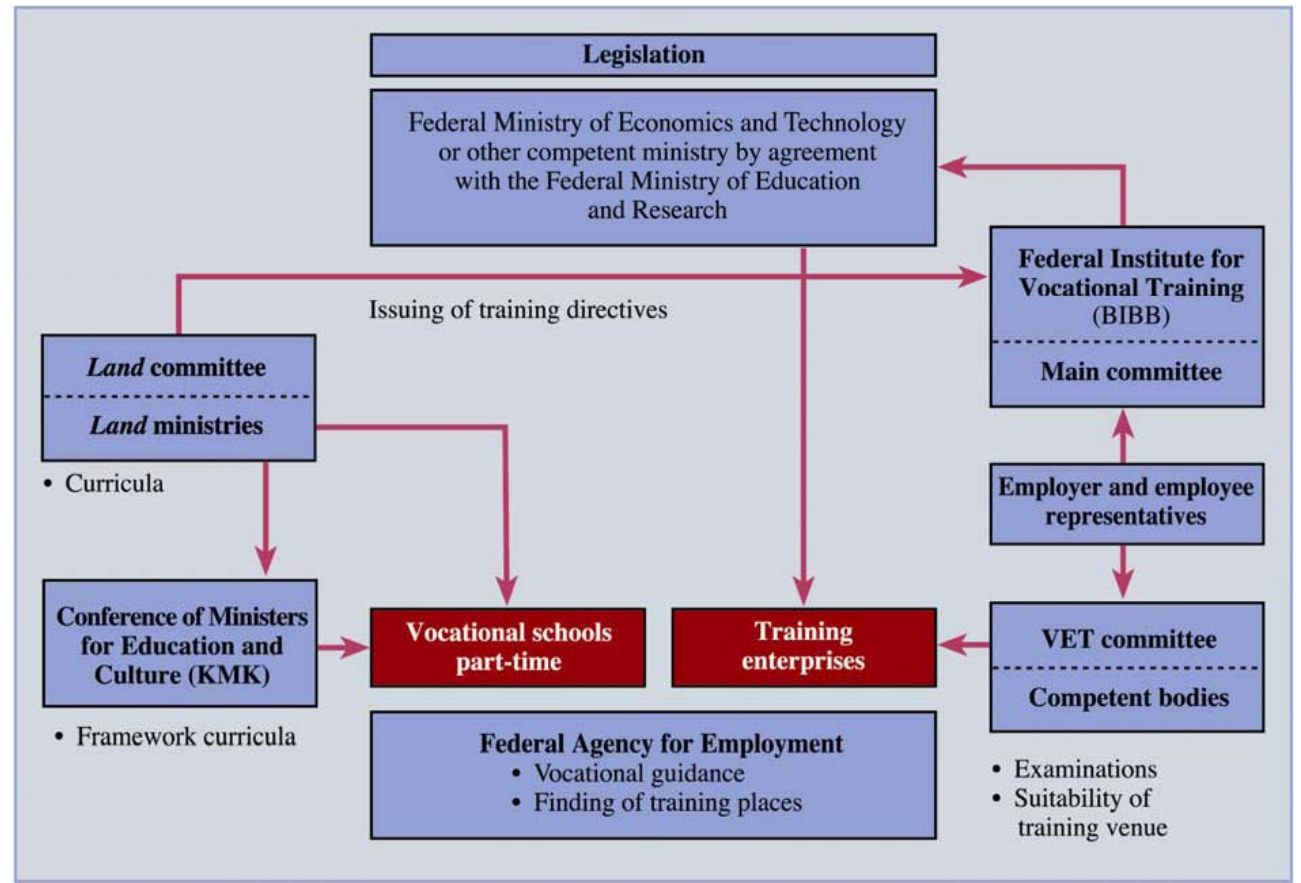

Source: Federal Institute for Vocational Education and Training, 2006 in: HippachSchneider, Krause and Woll 2007, p.18.

Apart from these regulatory and budgetary issues the German model depends on active support from the following actors:

- the acceptance of apprenticeship contracts paid below regular contracts by trade unions;

- the willingness of many employers to provide training not primarily in an informal manner but according to occupational curricula, to send apprentices to vocational school leading to certified occupational qualification and to give them a credible prospect of sustainable employment;

- support from the government providing not only vocational schools and teachers but also preparatory training for young people failing to enter apprenticeships; 
- last, but not least, the acceptance of vocational training as a solid alternative to academic education by young people and their parents.

These elements tend to reinforce each other. As they have developed over a long time, these conditions cannot easily be transplanted to a different institutional and historical context, yet expertise from the German background has been used to develop dual vocational training programs in countries such as Egypt, Turkey, Mexico, India, Thailand or Vietnam. Core elements are the establishment of occupational training curricula and related regulatory provisions, the mobilization of support from major government and business actors, the development of vocational education schools and training centers as well as the training of trainers.

\section{Promoting the 'German' dual vocational training system in transition and developing coun- tries}

Within the sphere of international cooperation concerning vocational education, the German Society for International Cooperation (GIZ, Gesellschaft für Internationale Zusammenarbeit) mainly implements projects as a part of development assistance whereas BIBB rather shares its competences and experiences and focuses on the creation of market opportunities for partner companies as well as on promoting the 'German dual vocational training system'. Thereby, BIBB offers its expertise to research institutes committed to vocational education on the one hand and cooperates with actors from the state and employers on the other.

Five features lying at the core of Germany's quite successful dual vocational training system have been identified. They are partly being implemented by the above mentioned organizations and their partners abroad. However, one should note that it is impossible to merely copy the system as a whole due to differing institutional and economic structures.

First, a close cooperation between government and economy (mainly the private sector) is indispensable if functioning vocational education structures are to be established. Unfortunately, in many countries skill mismatch prevails because the firms are not involved in the educational planning. However there is some (locally restricted) evidence that development assistance may help to overcome the gap between government and the private sector. In Uganda, where only $5-10 \%$ of the 800,000 graduates per year receive vocational training, the "Deutscher Entwicklungsdienst" (DED, recently merged with GIZ) supports the "Uganda Association of Private Vocational Institutions" (UGAPRIVI) founded in 1998 (UGAPRIVI, 2012). The German Development Service (DED, by that time it had not yet merged with InWEnt and GTZ to GIZ) started to participate in the program in 2002 by helping to improve the quality and image of private vocational institutions and to develop the vocational education and training sector in general. This intervention achieved that UGAPRIVI is now running nationwide. 520 schools are registered as members in the association and UGAPRIVI became a main stakeholder in the vocational sector. The association's network and database provide important information on the sector which would be very difficult to receive otherwise. Today, UGAPRIVI even has a seat in the Industrial Training Council. This shows that some success is possible if the government and local firms are willing to cooperate. Furthermore, BIBB supported the government of Thailand to develop a better administration of the vocational education. Together they created policies for 
a better cooperation between schools and economy. Today, about $20 \%$ of the Thai graduates receive vocational training.

Second, 'learning while working' in workplace training conveys practical skills to the trainees and enhances their future employability. It also secures that the skills learnt match current labor market needs efficiently. At the same time, young people as well as trade unions should be willing to accept lower temporary earnings in exchange for quality skill acquisition. Similar to the 'Mubarak Kohl Initiative' in Egypt, GIZ, jointly with other donors such as the Federal Ministry for Economic Cooperation and Development (BMZ), implemented the project "Cotton made in Africa" (CmiA) in various Sub-Saharan African countries and at the same time installed education training schemes for farmers. The initiative gives the label $\mathrm{CmiA}$ to African cotton products to improve their competitiveness in the global market. Since about 20 million people in SubSaharan Africa depend on the cotton industry, the need for further training and implementation of the label is evident. Up to now, BMZ supported cotton farmers in Benin, Burkina Faso, Cote d'Ivoire, Malawi, Mozambique and Zambia by teaching important skills from 2005 to 2010. More than 120.000 people took part in the project (Peltzer, 2011).

Third, society should accept common standards that both employees and employers have to meet in order to provide for comparable outcomes at the end of the vocational training phase so that job movements between companies become feasible. BIBB currently emphasizes the establishment of national standards. After the implementation of some standards in Korea, it is now widely accepted that in order to run a company one needs a master craftsmen certificate. In Turkey, BIBB supported the creation of national standards regarding the content of vocational training in textile production. These steps were mainly made due to a resulting better competitiveness with other textile producing countries. Equally important is the acceptance of vocational training as a proper means of qualifying for 'good jobs' and as a means of securing regular income and providing possibilities to move upward. In this way, vocational education must gain in reputation because employers as well as the state have to provide for sufficient funding. A main task of BIBB is to convince firms in developing countries to invest in dual vocational training, but it is a difficult one since employers often assign this task to the government. Based on the experiences of $\mathrm{BIBB}$, there is a general lack of firms in other countries willing to invest three years of vocational training. A further problem in transferring a dual system is that there are many developmental agencies from different countries trying to establish alternative systems such as a school-based vocational training model. That means that they tend to neutralize each other, for example when Germany tries to establish a dual vocational training and, at the same time, the European Union or the World Bank build vocational schools as they prefer school-based models (Stockmann, Menzel and Nuscheler 2010). Hence, better communication between the countries and organizations is necessary.

Fourth, qualified teachers contribute to a successful procurement of general skills in the school-based training. Under the mandate of BMZ, GIZ supported the government in Mozambique in reforming their education and vocational training strategy with the "Programme for Basic and Technical Education and Vocational Training" (Pro-Educação). GIZ supported the government by way of education policy advice, improving the educational planning and (financial) management skills of employees, promoting teacher training both on-the-job and in teacher training institutions, improving the quality of non-formal basic education for young people and 
supporting them to enter the labor market. The program started in 2003 and is still running. Over this period, a teacher training strategy has been designed and is already running across the country. The program has also contributed to establishing a reform commission which is now implementing the vocational training reform.

Most interventions of GIZ are placed at the micro-level such as the promotion of vocational training and employment in the province of Jiangxi, China. In this area, vocational schools can neither meet the high demand for skilled labor nor are they able to conform to the requirements of the employers. In six model schools, GIZ provided training support by adapting education to the labor market and developing exemplary curricula. Furthermore, GIZ supported the management of four partner schools in order to improve economic efficiency, quality management and the advisory service. When the project ended in 2009, over 1,000 teachers had been trained. This program demonstrates the so called "micro/macro paradox" (Stockmann, Menzel and Nuscheler 2010), i.e. most models do not spread out to the whole country because the project is either too small or the firms are not interested enough.

As a last and fifth core feature of the German dual vocational training system research and consulting work constantly checks if both practical and general skills match employers' needs. If necessary, these actors propose changes to e.g. training curricula and encourage their implementation. Cooperating with experts of BIBB, the Vietnamese government has recently founded an institute aiming to do research in the field of vocational education and training.

\section{Austria, Denmark and Switzerland}

In the Continental European cluster of countries, Austria, Denmark and Switzerland are most similar to Germany as these countries also rely on a strong dual apprenticeship system as part of their upper secondary vocational education. In all those countries a significant share of youths (Austria: 40\%; Switzerland: 80\%; Denmark: 50\%) participates in the dual apprenticeship system each year characterized by alternating school-based education and practical withinfirm-training and leading to a vocational degree after two to four years duration. Sharing a similar historic development, the institutional setup of the respective systems resembles the one in the German dual apprenticeship system:

1. A high degree of formalization that provides training only in centrally accredited occupational qualifications (currently about 240 in Austria, 230 in Switzerland and 123 in Denmark). The training content is continuously adapted to meet the changing requirements of the labor market.

2. Strong involvement of social partners in developing and maintaining curricula at the governmental and federal level through representative advisory boards; implementation and monitoring by regional trade and/or occupational committees.

3. The school-based part of the dual apprenticeships is provided by vocational colleges, covering general as well as occupation-specific education. The costs of training in the schools are borne by the government. 
4. Firms have to meet certain technical standards to be accredited as a training firm. Offering apprenticeships is optional for companies; the match between firms and trainees follows standard application procedures. The costs of training within the firm are covered by the training companies.

Besides sharing these institutional characteristics, recent labor market statistics are indicative of a similarly smooth integration into the labor market. In particular it can be found that all of these countries exhibit an above average employment rate of youths between 20 and 29 and relatively low youth-adult unemployment ratios compared to the overall EU-15 average.

Due to institutional, political and economic differences, there are some differences across the respective countries. Because of the simultaneously varying country characteristics, the substantial body of literature devoted to comparing and identifying the relevance of systematic changes in the program setup is oftentimes unable to provide clear-cut evidence.

Summarizing an extensive description of the Danish system by the Danish Ministry of Education (2008), differences between the Danish system and the German system arise in terms of a more decentralized planning of the educational content in the vocational schools. While the German system issues training plans in the school-based part on the Länder-level, the local entity in Denmark is much smaller and represented by 115 vocational colleges. Furthermore, these colleges enjoy a higher level of autonomy in terms of designing curricula as the Ministry only issues directives instead of concrete plans. The Austrian and Swiss systems are completely centralized with school and firm curricula being developed at the state level. This leads to a higher degree of standardization of the occupational degrees, potentially enhancing the mobility of workers across firms and regions (Ebner 2009).

The recent literature on the economics of education (Wolter and Ryan 2011) has devoted considerable attention to the questions of why firms decide to train individuals and investigated the benefit and costs for training firms. A particular puzzle arises by the finding that the net costs of apprenticeships are significant and positive in Germany but negative in Switzerland. Dionisos et al. (2009) indicate three reasons for this: 1) the lower level of wages paid to Swiss trainees, 2) more intensive utilization of trainees in the productive process of the firm in Switzerland, and 3) higher attendance of Swiss apprentices in the firm. Other hypotheses, however, point at the higher retention rate in German firms which are then more likely than Swiss firms to benefit from their initial investment into the firm-specific human capital.

Due to the voluntary participation of the firms in dual apprenticeship systems, all countries face the problem of cyclical variations in the supply of apprenticeship places which might leave youths entering unemployment before integrating in vocational training. Besides installing programs that youths could temporarily resort to, all countries implemented several incentives mechanisms for firms to stimulate the supply. In the 1990s Austria offered a bundle of incentives to training firms, comprising financial subsidies, tax exemptions, and the facilitation of the accreditation process to become a training company. In Denmark an "employers' reimbursement fund" was established already in 1977 to which all companies have to contribute as a function of their company size, but independent on whether they participate in the system or not. When they participate, $90 \%$ of the wages paid to trainees during the school-based training 
periods are financed by this fund. Denmark also offers the option of entering a "reduced" apprenticeship contract when firms are unable to support their trainees for the whole duration.

Furthermore, all countries share the same problem of disadvantaged youths unable to obtain a training contract with a firm or unable to persevere until the successful completion of the apprenticeship. For these "practically oriented youths" a support system was put into place. It is most developed in Denmark. Here, several modified versions of the apprenticeship and specialized vocational education programs aim to increase the chances of youths with learning disabilities or with other disadvantages to successfully complete upper secondary education: Basic vocational education and training constitutes an individualized vocational training program specifically designed for the particular requirements of individual youths below 30 unable to participate in ordinary vocational training. Production schools absorb youths below 25 who have had difficulties entering or staying in the other training options and provide a practical work experience in manufacturing-type jobs along with vocational guidance. Furthermore, partial qualification programs exists in the majority of training options offering a certified degree in a labor market relevant of the occupation obtained after shorter training duration. In Switzerland, youths with insufficient performance in compulsory education and who have difficulties entering the regular dual apprenticeship system, specific occupational training programs were initiated. Within these programs, youths are trained in standardized partial occupations for an average duration of two years. Upon completion they receive an occupational certificate which can be used to enter the labor market or start full occupational training.

\subsubsection{Spain and other Mediterranean countries}

Key issues:

1. Young people in Spain and other Mediterranean countries face particular difficulties when trying to enter the labor market successfully. Long-standing problems have been aggravated by the recent economic crisis.

2. One major factor is the deep segmentation of the labor market between permanent and flexible, in particular fixed-term contracts which can be attributed to strict dismissal protection and largely liberalized temporary employment. Transition to a permanent position is difficult.

3. The educational structure of younger cohorts is highly polarized in particular in Spain with both low-skilled youth and university graduates facing significant problems when trying to move into jobs. One particular issue is wage compression in low-skilled occupations. Vocational training only plays a marginal role and is mainly school-based. Better integration of employer-provided training could provide a viable bridge but this is largely underdeveloped. ALMPs which focus on hiring subsidies for apprentices have only limited impact in this context. 


\section{General facts}

The Mediterranean countries saw high youth unemployment even before the crisis and experienced a significant deterioration since 2008. In Spain the youth unemployment rate is now above $45 \%$ - more than double that of prime-age unemployment. While there is a cyclical component to this, the current situation in Spain clearly reflects structural issues with respect to training youth and institutional aspects of the labor market.

Spain exhibits a deeply polarized educational structure with a very high early school leaving rate on the one hand (around 30\%) and one of the largest shares of university graduates in Europe at about 39\% of the population between 25 and 34 (García 2011). Both groups have difficulties in accessing the labor market. Due to lack of skills and exclusion from training, early school leavers tend to have severe problems in succeeding in the labor market. They can only begin at a basic skill level which means their employment prospects are limited and highly contingent upon business cycle volatility. During the recent boom, some school leavers found well-paid jobs in the construction sector before the real estate bubble burst. At the other end of spectrum, university graduates find it very hard to enter the labor market in Spain and work in jobs corresponding to their formal skill level as labor demand does not match the supply. University graduates often lack more specific occupational skills and practical experience with employers. As a consequence, they have a high risk of unemployment and, if employed, tend to work in occupations which do not match their formal level of qualification. More than $40 \%$ of young Spanish university graduates work in occupations requiring only low or medium skills (García 2011).

The Spanish labor market is characterized by a strong dualization between permanent contracts, with strong dismissal protection on the one hand and flexible, fixed-term employment on the other (Dolado, Felgueroso and Jimeno 2000). Compared with other European countries and the Mediterranean cluster this is particularly severe (see Figure 10). Young people mostly enter the labor market with a fixed-term job and find it difficult to move to a permanent position even after some years in employment as conversion rates are persistently low and have been decreasing over time (Bover and Gómez 2004; Güell and Petrongolo 2007). They are also much lower than after a fixed-term apprenticeship contract in Germany. During good times allowing for flexible types of employment has clearly contributed to dynamic employment growth and declining unemployment in an otherwise strongly regulated labor market. Fixedterm employment, however, has been highly responsive to the crisis. Most employment adjustment took place via the termination of fixed-term contracts and therefore concentrated on the young (Bentolila et al. 2010, García 2011). In 2010 23\% of the Spanish youth were neither in employment nor in education or training (NEETs) compared to a little over $10 \%$ in Germany (Cedefop 2011a). 
Figure 10: Temporary employees as a percentage of the total number of employees 15 to 24 years old, Mediterranean countries (\%)

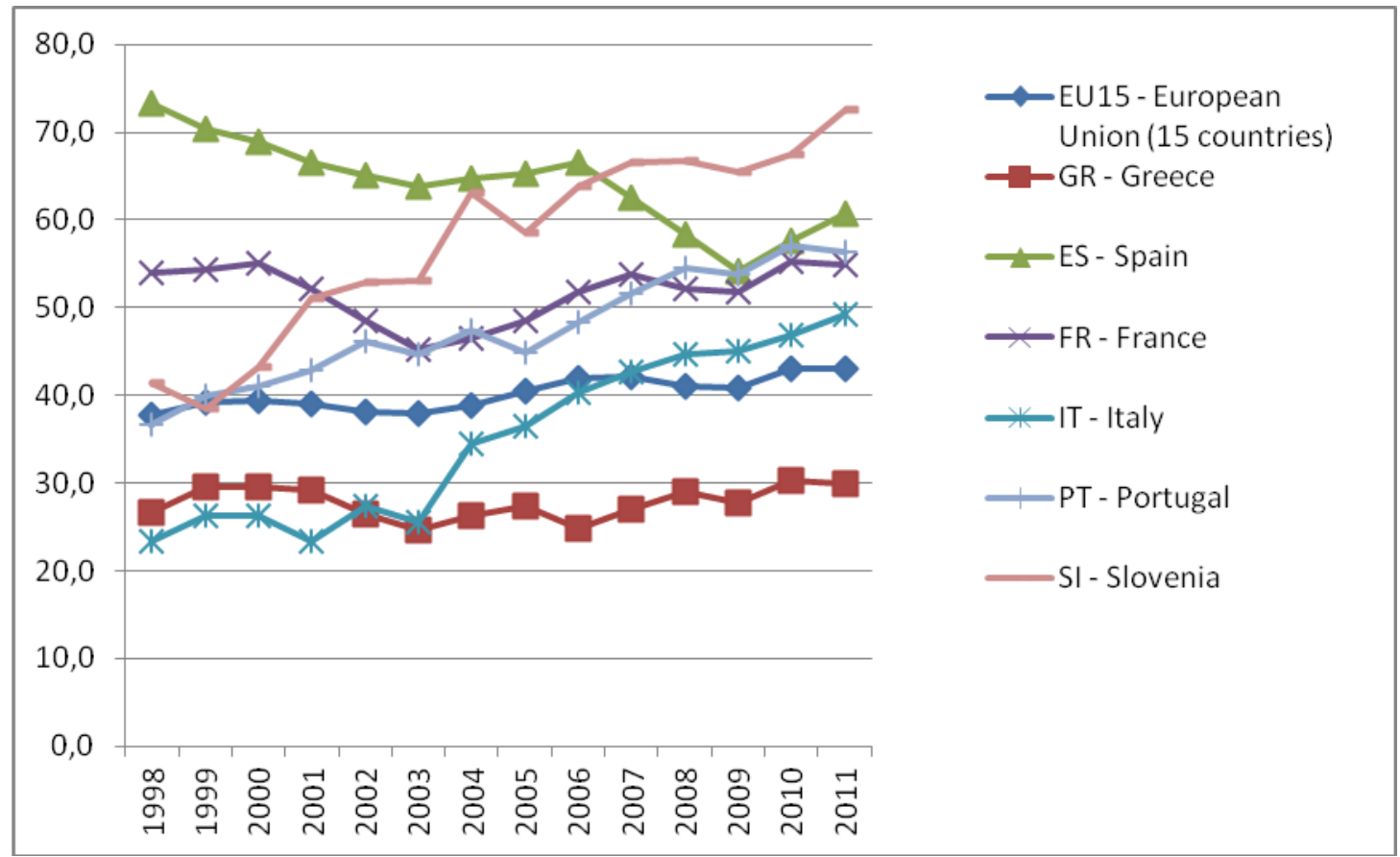

Source: Eurostat.

A further concern with the Spanish labor market is that the lower part of the wage distribution is compressed by collective bargaining. Centralized at the province/industry level, collective bargaining in Spain sets "entry minimum wage" above the legal minimum wage inflating the lower part of the wage distribution and resulting in relatively high earnings for young workers and the least qualified ones. This leads to high unemployment rates for these two groups of workers and lowers the relative returns to education. Indeed, in contrast with most developed countries, the relative returns to secondary and tertiary education in Spain have dropped since the mid-90s (Izquierdo and Lacuesta 2010; Pijoan-Mas and Sanchez-Marcos 2010). In addition to wage compression, the relative decrease in the returns of college education in Spain is due to a large increase of underemployed workers with tertiary education. According to Felgueroso, Garicano and Jiménez (2010), there are at least three explanations for this trend. First, the quality of Spanish tertiary education has decreased over time. Second, the Spanish production model has relied on low-skilled workers, increasing their demand and relative wages. Third, Spain has generated an excess supply of college-educated workers. This has severe consequences on the Spanish youths' beliefs regarding the usefulness of acquiring human capital. 


\section{Vocational training in Spain}

At the same time access to vocational training is limited in Spain. After compulsory education (at age 16), youths in Spain have two options. Either they enroll in vocational training-Ciclo Formativos de Grado Medio (CFGM), or they follow a (general) academic curriculum for two more years-Bachillerato. At the tertiary education level, there is again a dual track in Spain. Youths can enroll in college or vocational training of higher education-Ciclo Formativo de Grado Superior (CFGS). In contrast to the German situation with a share of $53 \%$ of youths in upper-secondary education enrolled in vocational training in 2009 , only $43 \%$ in Spain participated in vocational training (OECD 2011b). The relatively marginal role of vocational training can be explained by a limited interest of employers in more formal vocational training (given the dual employment structure), but also by strong expectations of upward social mobility on behalf of young people and their families which creates strong preference in favor of academic training (Planas 2005). A higher share of formalized vocational training at an intermediate skill level could provide a viable bridge from school to more sustainable jobs.

Perhaps a greater concern is that most of the vocational training in Spain takes place in school instead of within the firm. Only $4 \%$ of those in vocational upper-secondary education in Spain combine school- and work-based training, in sharp contrast with the $74 \%$ share in Germany (Cedefop 2010). Introducing work-based training in Spain could facilitate firms' screening of potentially good job matches and would provide youths with occupation-specific work experience.

Although ALMPs, which used to be very modest, have grown in importance in Spain over time, the share of public expenditure spent on training the unemployed remains relatively small. Most ALMPs in Spain consist of wage subsidies and reductions of non-wage labor costs in order to encourage hiring of unemployed or maintaining staff. Furthermore, subsidies set incentives to convert temporary into permanent contracts (Rodríguez-Planas 2006). Publicly sponsored training plays only a small role and is concentrated on training of those employed. In 2009 only $30 \%$ of total public expenditure on ALMPs was invested in training individuals with difficulties on the labor market (unemployed, employed at risk of job loss and inactive who would like to enter the labor market but are disadvantaged in some way) in Spain. This figure is in sharp contrast with the share in Germany of 55\% (Cedefop 2011a). Because youths form a large share of the unemployed, around $30 \%$ of all young people have participated in ALMPs in recent years(García 2011).

Over the 30 years Spanish youth employment policy has focused on offering training contracts (contratos de aprendizaje, formación y en prácticas), which mainly reduce the employers' costs of hiring young workers via subsidies. Because vocational training in Spain is not work-based, instead of increasing firms' investment on youth's specific-human capital, these contracts have backfired in several dimensions. First, they have increased youth employment turnover. Second, they have shifted the occupational distribution towards less qualified jobs. And third, because these contracts did not lower entering wages, they have provided (once again) the wrong incentives of dropping out of school at a young age (Felgueroso 2010). 


\section{Dual vocational training in other Mediterranean countries}

Other Mediterranean countries such as Portugal, Italy, Greece as well as France share many features with Spain although youth unemployment is not as high. However, these countries generally have persistent difficulties in integrating young people into the labor market. While they have above-average NEET rates, labor market entry is difficult not only for the low-skilled but also for high-skilled young people. One reason is the strong dualization of labor markets in these countries, which leads to a large share of fixed-term contracts with limited transition probabilities. The role of 'dual' vocational training is rather limited. In France, for example, vocational training takes place in schools (combined with internships) or as company-based 'apprentissage'. Only about one in four young people in vocational training has an apprenticeship. Both alternatives lead to vocational certificates (certificate d'aptitude professionelle, CAP, or brevet d'études sprofessionelles, BEP). Employers receive some support for training provision, funded by a training levy paid by all employers and additional resources from regional governments (Cedefop 2011b). To combat youth unemployment and address young people who failed to enter the training system, there is a long tradition in France to subsidize temporary employment and training contracts as part of ALMP. During the crisis, additional apprenticeships were supported as well as the conversion of temporary into permanent contracts. Yet the effectiveness of these measures is questionable (Roger and Zamora 2011). In Italy 'dual' vocational training does not exist. Vocational training is provided in vocational schools as part of secondary education either at istituti technici with programs of five years, combining general and occupation-specific qualification as well as university entry certificate (diploma di maturità) or by courses at istituti professionali lasting for three years and focusing more on specific occupations (diploma di qualifica). In crafts, retail and larger manufacturing companies there is a limited role of firm-level vocational training based on fixed-term employment contracts but the school part is more marginal than in the German model. Subsidized fixed-term training contracts had only limited effects (Tattara and Valentini 2009). 


\subsubsection{Anglo-Saxon countries}

Key issues:

1. During the recent crisis the Anglo-Saxon countries experienced a significant deterioration of youth employment.

2. In the Anglo-Saxon context, mixed vocational training systems are not institutionalized widely across Anglo-Saxon countries. Formal occupational competences are in general underdeveloped as young adults mostly receive on-the-job training within firms building upon some earlier school-based education.

3. A successful implementation of a dual vocational training system would depend on influential organizations bringing together business and the education community.

4. Empirical evidence suggests that some active labor market policies constitute useful educational measures facilitating several participants a higher education and thus boost their chances on the labor market.

\section{General facts}

In comparison with other developed economies, the Anglo-Saxon countries are characterized by particularly low levels of labor market regulation and a training and education system that is predominantly focused on imparting general labor market skills. The high labor market flexibility is generally found to translate into a higher volatility of the employment situation of youths. While youths are found to be hit particularly hard during economic downturns, they also tend to benefit more directly from the increase in labor demand in times of an economic boom (Verrick 2010; Bell and Blanchflower 2011b). Hence, earlier figures on the youth employment situation in these countries show a rather positive situation, with above EU-average employment rates and a rather dynamic school-to-work transition process (Quintini and Manfredi 2009). The more recent developments are rather gloomy, however. Besides the recent upsurge of youth unemployment rates, e.g., to $28.7 \%$ in Ireland, $19.1 \%$ in the UK and $18.4 \%$ in the United states, there is increasing evidence that the high labor volatility is particularly detrimental for disadvantaged groups in the labor market, i.e., the low-educated, with poor socio-demographic background. In particular in the UK and in the US, the recent economic crisis has brought to light several problems of the school-to-work transition process of youths, and called for policy makers to re-assess the current training and education system (OECD 2009) to prevent that the costs of the economic recession are not unequally distributed amongst youth-groups.

Recent descriptives of the US Census Bureau on the level of educational attainment in the population above 25 provide some inside in the structure of the current education system (Crissey 2009). Whereas about $16 \%$ of the population did not obtain any schooling degree, about $30 \%$ completed education with only a high school degree. Among the individuals who pursued upper secondary or higher schooling, about half finished with some college or a college degree, and the other half obtained a bachelor or higher tertiary schooling degree. Although the education 
expansion lead to a significant upward shift of the education levels of the recent cohort levels, this distribution of education levels closely applies to the one of current cohort of schoolleavers. Furthermore it can be found that the current distribution is shifted to left for blacks and individuals of Hispanic origin. While about $55 \%$ of blacks have obtained at most a highschool-degree, it is $68 \%$ of the Hispanic population.

\section{Structure of higher secondary education in the US}

The high share of youth entering the labor market without any upper secondary schooling degree points to the fact that for those leaving the education system after the high school, on-the job training is the predominant way of obtaining occupation-specific skills. In particular, a dual apprenticeship system comprising formalized school-based learning and work-based training has not spread in the US. During high school, occupation-specific knowledge can be obtained through practical work experience or so-called career and technical courses (CTC), however, this is generally conducted with only minor involvement of employers. Since vocational training systems are not institutionalized widely, occupation-specific competences are in general underdeveloped for youths leaving the formal education system before or with the high school degree (Lerman and Rauner 2012). This is particularly worrisome, as it an increasing divide can be observed between youth with or without an upper-secondary education, both in terms of employment opportunities and wages (Crissey 2009).

As we had seen by the education figures above, the school-based education offered by community colleges and technical colleges exhibits the conventional pathway from high school to jobs in the US. Community colleges, technical colleges (mostly public institutions) or Junior Colleges (private institutions) provide higher education for two years. Due to the 'open admission' policy even students without a high school diploma can enroll in community colleges. Some community colleges offer continuing or adult education. After graduating from such a college successful students obtain an Associate's degree. Students who decide to attend other colleges or universities afterwards can attain after two or three years a Bachelor's degree (so-called 2+2 programs). A major challenge of the college-track is currently seen in the high level of drop-out rates among college attendees and the limited linkage to labor market relevant skills.

Despite the limited role of a formalized apprenticeship system, structures similar to the European system exist, but are largely confined to adult education in so-called "Registered Apprenticeships" in the construction industry (e.g., such as electricians, carpenters and plumbers etc.). By the combination of time spend in theoretic instruction and work-based training the apprenticeship system is aimed to impart both general and occupation-specific knowledge - the place of training is however concentrated in the firm, as the apprenticeship system operates without any closer links to the formal education. Currently, there exist about 500,000 adult workers registered as apprentices - contrary to the European model, US apprentices are in their mid- to late 20s and have most likely already gained work experience. The Office of Apprenticeship (OA) in the US Department of Labor is in charge of the registration and evaluation of the VET. Thereby, the OA is supported by the "Advisory Committee on Apprenticeship" (ACA). Across 26 
states, State Apprenticeship Agencies (SAAs) are responsible for the apprenticeship programs which include the provision of technical assistance.

Efforts to establish a dual apprenticeship system for the vocational education of youth are made a number of times, e.g. by the National Youth Apprenticeship Act under the administration of George Bush and the School-to-Work Opportunity Act under President Clinton, but have failed in the majority of cases. By the inability of employer organizations to coordinate longterm training plans, and the federalist division of tasks of responsibilities that impeded a binding national framework for the training systems, a wide-spread participation in the youth apprenticeship could not be reached (Lerman and Rauner 2011). Despite the futile efforts at the federal-level some states were able to establish and maintain a functioning dual apprenticeship system for youths (e.g. the Youth Apprenticeship in Wisonsin).

Currently, several hurdles impede the more wide-spread use of vocational education and a closer link between school-based education and within-firm training. On the one hand, there seems to persists a general mistrust in the idea of imparting specific human capital, as it is likely perceived to lose its' value more quickly in a continuously changing labor market (Krueger and Kumar 2004). Furthermore, there seems to be the concern that the tracking of youth in highschool into occupation-specific and general education leads to a stigmatization and limited opportunities for the occupation bound youth. Finally, there appears to be a lack of interest on the part of employers in participating in this exchange. Part of the reason being, that they are not willing to endure the perceived high costs of training, not knowing whether they will be able to recover these costs at a later stage (Shapiro 1999).

\section{Structure of higher secondary education in the UK}

Similar to the US, the work-to-school transition of youths in the UK follows a rather unstructured way, with youth switching between spells of employment, unemployment and education; for some youths the transition between leaving school and entering employment takes up to 30 months. Shares of youths in NEET that range among the highest in the European comparison and a particularly high employment gap between low and high-skilled youths, point to the risk of a segregated labor market with disadvantaged youth being particularly likely to drop out of the labor force (OECD 2010b).

In contrast to the US that is largely focused on the provision of general skills, the training and education system of some countries in the UK seems to invest considerable efforts to provide general as well as occupation-specific skills at all stages of the education system. Since 2004, vocational, work-related English schools offer vocational training opportunities already at the lower secondary level, by the arrangement of work-based training, the provision of workrelated key-competencies, and the establishment of occupations-specific GCSE's (general certificate of secondary education). Wales started a 6-year trial period for an occupational Baccalaureate in 2003 (Cuddey and Leney 2005). 
Upon finishing lower secondary compulsory schooling youths have the possibility to either continue full-time schooling or to enter government supported training options (apprenticeships) that are structured within apprenticeship frameworks developed by the Sector Skills Councils (SSC). The SSC's are employer-led organizations aimed at identifying the current and future skills required in the economy and develop the training and education plan for the vocational training system. Their work is monitored by the government in the UK commission for Employment and Skills. Together they specify national occupational standards (NOS) that define the performance requirements of individuals within certain occupations. The NOS are then used as the basis for the National or Scottish Vocational Qualifications (NVQ or SVQ) that measure and certify the qualifications of individuals participating in the apprenticeship system. By the formalized structure of development of the respective occupational qualifications, the setup of the apprenticeship system is related to the one in the German-speaking countries (OECD 2009).

Note that a rigorous and central assessment of the apprenticeship qualification obtained did not exist in England, traditionally; albeit continuous government initiatives that aimed at reducing the number of different qualifications. Recent number show a significant upsurge of 'awarding bodies' - in 2009 there existed 2000. Clearly, this might reduce the transferability of the obtained degree as employers are unable to assess the value of the respective qualification. So far however, there does not seem to be problematic, with employers being well able to distinguish the quality of the degree within their field of sector. In contrast, it might also be that the awarding institutions are more able to mirror the recent labor market development than the government (Wolf 2011).

A further distinction to the German training system and the UK apprenticeship is that the duality between the school-and work-placed training location is not as clear-cut to refer to the system as a 'dual' one. Although there is some general or technical training content within the respective qualifications, the general training can be provided at the work-place or some external provider - furthermore, the importance of the firm- or occupation-specific skills is generally larger than in the German system. However, similar to the German speaking countries, the funding of the apprenticeship is divided between the government and employers. While the government pays for formal training, employers pay and hourly wage to the apprenticeship. Since 2010, apprentices are covered by the national minimum wage. In general it is found that the wage of apprentices in the UK is the well above other countries' pay such as Austria, Germany or France (Steedman 2010).

The high level of costs endured with apprenticeships might be one of the reasons why the supply of apprenticeship places is particularly low in the UK - with only $8 \%$ of all firms offering training places. Another trend potentially linked to the high level of training investment is that firms are increasingly shifting towards offering places to older youths who have previously worked at the company already (Wolf 2011). While youth aged 16-18 who just finished compulsory schooling still constituted the highest share of youth entering an apprenticeship in 2005, they were largely outnumbered by youth above 19 years and even above 25 years in 2009. Currently only 55 per cent of apprentices are on average new to their employer (OECD 2008). Whereas the preferences of recruiters for apprentices who already have gained some practical experience seems natural, given their high level of investment, this goes largely at the cost of the inexperienced school-leavers who are not willing to find apprenticeships. 


\section{ALMPs in the US and in the UK}

Regarding ALMPs, in the US the so-called 'YouthBuild' program created for disadvantaged youths concentrates on training measures within the construction sector. The program assists 16 to 24 year olds from low-income families with problems entering the labor market to receive either a high school diploma or a test-based upper secondary qualification, the General Educational Development test (GED) and provides occupational training in the construction sector (OECD 2010a). The GED consists of a series of tests including writing, science, reading and mathematics. It offers a degree for those having not achieved a high school diploma. If the test is passed, a certificate is issued (Lamb 2011). The program lasts from six months up to two years. Youth involved need to spend half of their time in education and related services and nearly the rest of their time in workforce activities such as work experience, occupational skills training, job search, internships, etc. Main funding comes from the Federal Government but also alternative contributors (e.g., private foundations and donors) play an important role. For 2010 and 2011 the budget was expanded from 50 million US\$ in 2009 up to 120 million US\$. Thus, the costs for the program remain high - each of the 10,000 participants receives between 15,000 and 18,000 US\$. Empirical evidence suggests that the program is a useful educational measure bringing one-third of its participants to a post-secondary education which helps boost their chances on the labor market. This model has meanwhile been introduced in other G20 countries (OECD 2010a).

In the UK, the "New Deal for Young People" (NDYP) has been introduced in 1998 targeting at people aged between 18 and 24. Young people belonging to that group and being on Job Seeker's Allowance (JSA) for more than six months receive mandatory and extensive advice regarding job search. In case of failure to comply with the program requirements benefits are cut. Thus, the program contains some 'carrots' in terms of job search assistance and 'sticks' regarding tougher monitoring practices. Recent evaluations found increased job finding rates of around 20\% (De Giorgi 2005; Petrongolo and van Reenen 2011). During the first phase of the NDYP program, the so-called 'gateway', all participants are supported intensively and personally. This can last up to four months and aims at finding an unsubsidized job opportunity for the participant. Unsuccessful recipients will then take part in one of four New Deal options encompassing subsidized work, education and training as well as work either in the voluntary sector or with the Environment Task Force. Thereafter, participants receive the same support as under the gateway part of the program (Wilkinson 2003).

Furthermore, the UK has taken major reform to promote apprenticeships. By 2017, the government strives for one in five young adults to have successfully completed an apprenticeship. To implement and enforce this goal, the government has passed the Apprenticeship, Skills, Children and Learning Act in 2009. The Act shall help achieve certificates of qualifications which are recognized and valued by employers. 


\subsubsection{Transition Countries: Russia and Eastern Europe}

Key issues:

1. In the aftermath of the transition, young people in Eastern Europe were among the losers of the transition to a market economy. Despite some improvement the situation remains difficult. Among those young people who work, many do so in second-best jobs (with lower wages and high turnover) or in the informal labor market. Since the early 1990s, the returns to education have risen rapidly. Similarly, the employment prospects have improved with education, leading to an increase in secondary and tertiary education enrollment (especially in the EU new member states).

2. With the industrial restructuring, the communist vocational training system came to an end, and the dual apprenticeship system of the socialist era was replaced by schoolbased training. The lack of on-the-job training or coordination of employers and training providers led to an increase in skill obsolescence and mismatch as well as increasing skills shortages.

3. The poor labor market prospects combined with the increased returns to education and the inadequacies of the vocational training system set in place during the transition are factors explaining the increase in the relative demand of general secondary education granting access to tertiary education. Creaming the most socially advantaged students towards the academic track is exacerbating social inequalities.

\section{General facts}

Youth unemployment and unemployment in general is a relatively recent phenomenon in the countries of Central and Eastern Europe, with a notable exception of the former Yugoslavia, where high unemployment existed already in the 1970s. Under central planning, the economies were characterized by huge job vacancies, no open unemployment, and high labor force participation. The high employment rates and close to zero open unemployment came, however, at a price as low labor productivity and labor hoarding were pervasive features of the centrally planned economy. The early 1990s saw a massive shedding of labor, in response not only to inefficient use of labor resources during the central planning period, but also to the collapse of output that these economies faced at the start of the transition. Since the early 1990s, unemployment became one of the key economic and social issues in the region.

Indeed, unemployment rates in many Central European economies quickly exceeded $10 \%$ and even approached $20 \%$ in the 1990s. Most countries of the former Soviet Union experienced somewhat lower unemployment rates as a bulk of labor market adjustment in that region came in the form of collapsing real wages, wage arrears, and reduced hours of work (Boeri and Terrell 2002). The resumption of economic growth in the transition region in the late 1990s resulted in falling unemployment rates, which nevertheless have remained considerable and often double- 
digit. The 2008 financial crisis led to yet another hike in unemployment rates, although they remain considerably lower than during the early transition period.

Not surprisingly, the virtual stop of hiring by existing firms with only slowly growing demand from the new private sector, which the transition economies experienced in the early 1990s, hit new entrants in the labor market particularly hard. Youth unemployment rates in the region skyrocketed to $30 \%$ and above. In general, youth unemployment rates in the countries studied have been twice as high as the overall unemployment rate. And similarly to the dynamics of the overall unemployment rate, there was a downward trend in youth unemployment during the first decade of the century, interrupted by the 2008 financial crisis. The crisis drove a considerable rise in youth unemployment in Central and Eastern Europe, from 21\% in 2007 to 27\% in 2009 (unweighted data) (Koettl, Oral and Santos 2011).

While the virtual collapse in the demand for labor explains the surge of youth unemployment in the transition region in the 1990s, its dynamics in the later periods was more and more closely determined by the institutional aspects of the labor market as well as of the education system. Recent analyses suggest that institutions, such as employment protection and ALMP indeed play a role in defining youth unemployment in the region. In particular, stricter employment protection is associated with higher youth unemployment, and larger spending on ALMP is associated with lower youth unemployment (Lehmann and Muravyev 2012). Overall, however, the countries of the region have a rather modest level of the rigidity of labor market institutions. For example, employment protection in most transition countries is less stringent than in the old EU member states and much less stringent than in the countries of Southern Europe. This is often coupled with poor enforcement of labor laws in Central and Eastern Europe (Eamets and Masso 2005). Similarly, the role of trade unions is rather modest and declining. One notable exception with respect to labor market institutions is minimum wages, which, measured in proportion to the average wage, are relatively high in Central Europe and may therefore be an obstacle for the entry of youth in the labor market. In the former Soviet Union, in contrast, statutory minimum wages are low (except for Ukraine) and poorly enforced, so that they are unlikely to play any significant role.

The changes in the education and training system in the transition countries over the last 20 years have been substantial. From the central planning period these economies inherited a relatively well developed education system. School enrollment was nearly universal, and the enrolment rates in secondary and tertiary education were well above those in countries with a similar level of economic development (Micklewright 1999).

The education system, highly centralized and state controlled, consisted of a combination of general and vocational tracks. Typically, there was a general track involving more academically oriented education, lower level vocational schools, as well as technical schools. At the tertiary level, universities provided more academically oriented education and various institutes provided more specialized education. Although most vocational education and training were provided by specialized schools, there was a close link between them and enterprises. In fact, many countries had an extensive dual system. This facilitated the transition from school to work, although it should be noted that the excess demand for labor under central planning de 
facto guaranteed the first workplace for all young people regardless of their educational attainment.

Since the start of the transition, the general trends have been the move of vocational education to schools, the weakening of the links between the schools and enterprises, the decline in enrollment in vocational and technical schooling, often counterbalanced by the expansion of general secondary schools and tertiary education (Saar, Unt and Kogan 2008). As noted by Micklewright (1999), this was due to a mix of demand and supply factors, such as the closure of enterprise-based schools and the shift of students towards general secondary schools with the purpose of obtaining broader education, more appropriate in a market economy, especially at the time of structural changes. The expansion of tertiary education in the region is often interpreted as indication of the desire of youth to postpone the entry in the labor market at the time of economic decline and uncertainty. The vocational school system, which used to produce more than $50 \%$ of all secondary graduates in most countries collapsed very quickly. Students left vocational schools in favor of general secondary education and the prospect of pursuing a tertiary degree, however, now employers assert that it is becoming harder to find graduates with technical skills (Sondergaard and Murthi 2012).

Although the overall trend in the transition countries is the shift from the vocational training system typical of Germany and neighboring mature economies towards a more Anglo-Saxon system, characterized by a clear distinction between education and work, important elements of the dual system remain in the region, especially in Central Europe. By now, they are visible in the Czech Republic, Hungary, Romania and Slovenia, but also Serbia. Some elements are also present in Poland and Slovakia, as well as in Croatia (Matkovic 2008). In the rest of CEE, as well as in Former Soviet Union countries, the system can be rather unambiguously classified as school-based.

\section{New EU Member States}

Youth unemployment rates in Eastern European countries are extremely high for EU standards. At $30 \%$, the average youth unemployment rate for the ten new EU member states almost doubled that of the EU-15 average of 17\% in 2005 (European Commission, 2006). The situation is even more alarming in some South East European (SEE) countries with youth unemployment rates in Macedonia and Serbia and Montenegro surpassing 60\%. Only in some of the European Commonwealth of Independent States (CIS), such as Ukraine and Moldova, youth unemployment rates have been close to the EU average. ${ }^{3}$ However, these relatively low rates do not reflect the difficulties young people in these countries experience in the labor market. The reason behind these low youth unemployment rates is the slow pace of reform adopted in the early

\footnotetext{
${ }^{3}$ The ten EU new members states comprise Bulgaria, Czech Republic, Estonia, Hungary, Latvia, Lithuania, Poland, Romania, Slovakia and Slovenia; SEE comprises Albania, Bosnia and Herzegovina, Croatia, Macedonia, Serbia and Montenegro and Turkey; the European CIS countries comprise Belarus, Moldova, Russia and the Ukraine; and, the non-European CIS countries comprises Armenia, Azerbaijan, Georgia, Kazakhstan, Kyrgyzstan, Tajikistan, Turkmenistan and Uzbekistan.
} 
1990s in most European (and some non-European) CIS countries. They opted for a policy approach that limited job destruction by adjusting through real wages instead of employment (Boeri and Terrell 2002; Rutkowski 2006).This policy was not limited to CIS countries. For instance, Romania combined this policy with the promotion of early retirement programs in an attempt to mitigate problems with massive industrial restructuring (Rodríguez-Planas 2010). Most frequently, the slow pace of reform only managed to contain job destruction, but eventually job destruction occurred and at higher rates (Rutkowski et al. 2005). Moreover, these policies pushed workers throughout this region out of the labor force and into low productivity jobs, primarily in subsistence agriculture, the urban underground economy, and the unregulated self-employed sector (Kotzeva and Pauna 2006).

Because of their more vulnerable situation, youths were the big losers of the transition period to a market economy. During the transition, the labor force participation rates of young people fell throughout the region. While in some countries (such as Hungary) youths moved into secondary and tertiary education, in others they exited the labor force without pursuing education or training. Between one-in-two and one-in-three young people in Albania, Bosnia and Herzegovina, Ukraine, Armenia and Tajikistan are not employed or studying (O'Higgins 2010). Both problems-high unemployment rates and high joblessness rates-are worsened for certain socio-demographic groups, including young women, young ethnic minority people, such as Roma, youths living in rural areas, the low educated young, and disabled young people. For instance, in Bulgaria, Hungary and Russia, the rural youth jobless rate is nearly twice the urban rate (Kolev and Saget 2005). Finally, many young people in Eastern Europe emigrated. In Moldova for example, official statistics estimate that 234,000 citizens are working abroad, but these are likely to underestimate the true effect. Indeed, unofficial data estimate that between 600,000 and $1,000,000$ people (between $15 \%$ and $30 \%$ of the population) have emigrated (La Cava et al. 2006).

Similar to what is observed in Spain and Mediterranean countries, in many Eastern European countries flexibility in the labor market has been achieved through the creation of less restrictive contracts for new entrants generating a strongly segmented labor market in which young and female workers are concentrated in unstable and poorly paid jobs (O'Higgins 2010).Another adverse effect of the transition to a market economy is that the informal employment sector throughout the region has become larger than the OECD average. Perhaps more concerning is that it continues to grow overtime. Again the young are disproportionally concentrated in this sector. At 52\% the incidence of informal sector employment amongst young workers in Serbia doubles that of adults (World Bank 2006). Similarly, in Georgia, 76\% of young workers are employed in the informal sector compared to $57 \%$ of the employed as a whole (Bernabè 2002).

Since the early 1990s, the returns to education have risen rapidly and are now largely in line with those found in OECD countries (Kolos et al. 1999; Newell and Reilly 1999; Commander and Kollo 2004; O’Higgins 2010, Sondergaard and Murthi 2012; Coupé and Vakhitova 2011).Differences in the employment prospects between those with more or less education have increased. Thus, low levels of education are associated with higher jobless rate, greater participation in the informal sector, and longer transitions school-to-work than high levels of education. Recent evidence finds that about $50 \%$ of those people 25 to 34 years old who did 
not complete secondary education in Serbia and the Ukraine do not find any sort of employment within two years of leaving school compared to only $10 \%$ of those who obtained a University degree (ETF, forthcoming). Similarly, in Bulgaria, the likelihood of joblessness among young people who had no more than primary education quadrupled that of those with some postsecondary education (Kolev and Saget 2005). The increase returns to education have, at least in part, led to an increase in secondary and tertiary education enrollment (especially in the EU new member states). As a consequence, the region performs relatively well in terms of educational attainment overall compared with the EU-15.

In the region, industrial restructuring led to the end of the vocational training structure of the communist era. Under socialism, many Central and Eastern European socialist countries operated an extensive dual apprenticeship system, with alternating school- and firm-based training. With the transition to the market economy, however, dual system training came under pressure and employer-provided training places plummeted (Ost 2000). Moreover, the governments were unable or unwilling to create sufficient financial incentives for training provision. In some countries, such as Hungary, the growth of school-based training places more than compensated for the decline in employer-provided training. However, the lack of on-the-job training or coordination of employers and training providers led to an increase in skill obsolescence and mismatch, as school-based training was frequently decoupled from current labor demand (Noelke and Horn 2011). Another adverse consequence was that it became more difficult for young vocational school graduates to enter the labor market. As a consequence, there was an increase in the relative demand of general secondary education granting access to tertiary education, which led to creaming the most socially advantaged students towards the academic track, exacerbating social inequalities (Bukodi and Róbert forthcoming).

The evidence on how well workers with vocational training perform in the labor market in the post-socialist transition countries is mixed. Right after the transition, the concern was that vocational skills were too occupation-specific preventing workers from easily moving from one occupation to another. As most of them had received training within firms, their human capital was extremely firm-specific. As a consequence, workers with vocational training in Eastern European countries during the mid-1990s experienced more employment difficulties than workers with general secondary education, as reflected by $10 \%$ higher odds of job loss and $15 \%$ lower odds of job finding (Boeri 2000). Barlett (2007) also finds that vocational training did not provide workers from the Western Balkans the flexibility the industrial restructuring required as they were over-represented among the unemployed. In contrast, qualitative evidence from the Ukraine, Georgia and Armenia during the mid-1990s suggests that vocational training gave workers a comparative advantaged in the transition to the market economy (Roberts et al. 2000). In a recent quantitative study, Audas et al. (2005) find that young people with vocational training in Hungary are less likely to be unemployed and more likely to transition from school to work than those who obtained an upper secondary degree and did not access tertiary education.

Nowadays, the new system of vocational training is still far from desirable. Several studies have identified the following inadequacies that could be improved (Bejaković 2004; World Bank 2005; Bartlett 2009): (1) subject-specific specialization takes place too early; (2) curriculum is too narrowly focused on subject specific skills and competencies; (3) the provision of vocational 
training is excessively decentralized across different Ministries leading to the multiplicity of structures; (4) the training systems are inflexible and unable to adapt to the new labor market needs; (5) institutional links between schools, employers, and social agents are lacking.

In the early1990s many Eastern European countries adopted passive labor market programs, including unemployment benefits. However, they soon realized the importance of offering ALMPs to those workers seeking jobs, and these programs were implemented beginning midto late-1990s. Recently several studies have evaluated how well training programs, job search assistance and related employment services, or self-employment assistance programs work in transition economies. They find that participating in one of these three ALMPs improves the employment prospects of their participants. In contrast, the effectiveness of public employment is still under debate (Rodríguez-Planas and Benus 2009). Rodríguez-Planas (2010) finds evidence that public employment services in Romania are effective for workers with little access to informal job-search channels-such as young workers and those living in rural areasand that small business assistance programs work best for workers with less access to the primary segment of the labor market (that is, less access to high-productivity wage and salary jobs).

\section{Russia}

At the start of the transition in the late 1980s, Russia had an established system of vocational education and training which was shaped to serve the demands of the planned economy. After the compulsory eight years of study in school (incomplete secondary education), students had several options for further studies: completing secondary education in a general school, entering specialized vocational training school, which were divided into a lower level school (socalled "PTUs" providing vocational elementary education) and higher level school (technicums providing vocational/professional secondary education). The latter option, as a rule, gave an opportunity to pursue higher education at institutes and universities.

The planning mechanism ensured that enterprises (nearly all of which were state-owned at the time) were connected with local general and vocational schools, as well as institutes and universities that provided pre-service and in-service training for the workers (Oleynikova 2009). In fact, it was mandatory for state enterprises to cooperate with and support schools at all levels of the education system. As mentioned by Bartlett (2009), "the Soviet education system had emphasized vocational education and a close functional fit between education and subsequent employment". However, all possible career routes, including no additional study after the compulsory eight-year school, guaranteed stable employment for new entrants in the labor market. The excess demand for labor, one of the key features of the planned economy, coupled with "job rights" incorporated in the socialist law was an important source of the economic security enjoyed by workers.

This fairly favorable situation started to change with the introduction of market forces in the economy. The demand for labor collapsed during the transition-related recession, which resulted in the loss of more than $40 \%$ of GDP over just a couple of years. The hunger for labor was 
replaced with downsizing and enterprise closures, resulting in the emergence of open unemployment. This change particularly hit the youth. At the peak of the recession in 1998, youth unemployment stood at $27.1 \%$, more than double the overall unemployment rate in the economy.

The system of vocational education started to quickly erode in the 1990s, most notably in the segment of lower vocational education. While most state enterprises got privatized, the education system largely remained state-owned, especially in the segment of vocational education. The curricula offered by vocational training became obsolete as few of them moved to offer courses suitable to the growing service sector. Since the 1990s, there was a growing mismatch between the demanded skills and those provided by the educational establishments. Lack of the current demand and substantial uncertainty as to which skills will be demanded in the future has induced a shift to tertiary education.

Overall, during the course of transition the vocational training system in Russia shrunk and became rather loosely connected to enterprises. As noted by Bartlett (2009): "In response to poor quality employment prospects in the factories, young people graduating from the VET sector pursue long periods of combined work and part-time study in an attempt to improve their prospects in the labor market. The transition to work has become individualized, as the formal apprenticeship system has declined. However, this process has not resulted in improved social mobility." 


\subsection{Africa and the Middle East}

\subsubsection{The Middle East and North Africa}

Key issues:

1. The demographic "youth bulge" creates significant challenges for labor markets in the Middle East and North Africa (MENA) region that are often unable to provide sufficient labor demand in the formal private sector. Spells of unemployment and informal work significantly shape the transition patterns of young labor market entrants.

2. Mismatch in labor supply and demand is aggravated by a general and vocational secondary and the tertiary education system failing to provide labor market relevant skills and competencies - thereby leaving increasing numbers of high-skilled youths unable to access formal jobs outside the public sector. Educational policies now focus on improving the quality of education by the reduction of central planning, involvement of employers and social partners and installment of performance-based funding mechanisms.

3. Vocational education and training do not play a significant role due to a missing link with the labor market and the traditional perception that they are inferior to participation in tertiary education. Formalized dual vocational training does not exist on a significant scale. Small scale projects are installed with the support of international partners; large scale enrollments risk being hampered by an absence of institutionalized involvement with employers.

\section{General facts}

While the potentially explosive power of the social, political and economic exclusion of youths of in the Arab world was anticipated by the expert literature (Chabaan 2009), the forceful dynamics witnessed during the "Arab Spring" were largely unexpected. It is understood that the structural lack of employment perspectives as way to achieve economic participation and prosperity constituted a particularly important factor leading to the recent uprising of youths. As inefficiently regulated labor markets and restricted labor demand are unable to absorb the massive supply of labor of the so-called "youth bulge" (Assad and Roudi-Fahimi 2007), an inherent mismatch between the skills required in the local economies and the skills provided by the education system impedes the active participation of youths in the labor market, thereby aggravating the situation.

The overall employment situation across Middle Eastern North African (MENA) states is significantly shaped by the expansive demographic development, which leads to a fierce competition for available jobs. The substantial decrease in child mortality and the slow decline in the female fertility rates during the past 50 years have led to a quadrupling in the population size. The strongest population growth occurred after the 1970s leading to the youth bulge pressing into 
today's labor markets. As neither the private nor the (oversized) public sector are currently able to absorb the large number of individuals in the labor market each year, many workers resort to employment in the informal sector accounting for $35 \%$ to $50 \%$ of employment in the region (Bardak, Huitfeldt and Wahba 2006), choose to emigrate, or, finally resort to unemployment awaiting a job offer from the public sector. More recently, structural changes caused by the following have created pressure towards a reform of current labor market structures and the education system (World Bank, 2008):

1. The attempts of governments to downsize the public sector (see Huitfeldt and Kabbani(2008) for Syria; Binzel (2011) for Egypt).

2. The effort of the regional labor importing countries (predominantly the Gulf-states) towards hiring more national workers.

3. The gradual opening of economies to international trade.

4. The increased developmental cooperation between the southern Mediterranean countries and the Europe Union.

\section{The education system in the MENA countries}

A recent assessment of the general education system in the MENA countries in the context of the UNESCO "Education for all" (EFA) initiative shows remarkable signs of positive development, but also points to substantial needs for further improvement (UNESCO 2011). In particular, the majority of the MENA states have experienced a substantial increase in the enrollment rates at all stages of the education system, indicating that the general education system managed to deal with the large cohort sizes quantity-wise. The enrollment rates in primary education almost achieved $90 \%$ in 2008 , with a simultaneous decrease in the drop-out rates, thereby reducing the overall illiteracy rates in the population. Enrollment rates in secondary education have also increased, but remain low compared to developed economies at a regional average of $68 \%$ in 2008. Low secondary enrollment also reflects regional and socio-economic differences inaccess to education, making entry difficult for youths coming from poor and/or rural backgrounds. Finally, post-secondary and tertiary education participation has also increased substantially to an average of $21 \%$ in 2008 (compared to $26 \%$ in the rest of the world). Besides tertiary education, the vocational education and training options (VET) provided in the MENA states are somewhat limited in scope and largely restricted to school-based vocational training. Conditional on an assessment of skills during secondary schooling, pupils can participate in the respective tracks of post-secondary education. Lacking the technical equipment and/or the financial means to afford additional tutoring, youth from a poor or rural background tend to concentrate in terminal technical secondary schools, or less selective higher education faculties (Heynemann 1997). For school dropouts some MENA countries offer so-called "secondchance"-programs installed to provide specific occupational skills for the labor market.

Conceptionalized in the 1960s, the vocational secondary or technical post-secondary programs, which provided technical and vocational education and training (TVET), are seen as part of the 
formal school structure and are organized by government agencies. Unable to meet the current demands of the labor market, and due to the general perception of VET as an inferior option vis-à-vis the tertiary education (Bardak 2006), it tends to be marginalized as a low-status track for poor academic achievers (Vlaardingerbroek and El-Masri 2008; Oketch 2007). Early figures on the return to vocational education show that they are associated with a lower return than secondary education (Heynemann 1997). The quantitative role of the TVET is therefore rather limited, too - in the majority of MENA countries, general, non-technical secondary education is the standard education, whereas fewer than $10 \%$ of secondary students are involved in TVET. Syria, Lebanon, Bahrain, Libya and Egypt are the exceptions with more than $10 \%$ or more of secondary school students taking part in vocational training (World Bank 2002).

The problems regarding the quality of the VET and TVET system are manifold and largely rooted in the centralized management by the government without the involvement of social partners and insufficient funding not based on performance. Increasing the linkage between skills provided and demanded by the private sector is considered a significant problem. The majority of countries have started a reform process along the lines of several defined areas of improvement (Bardak 2006):

1) Upgrading the performance, relevance of quality of education;

2) Development of employment-driven education and training strategies;

3) Involvement of stakeholders and social dialogue;

4) Enhancement of governance;

5) Institutional capacity building for definition of policies and decision making;

6) Increase and diversification of sources of funding.

The reform process is continuously supported by several international organizations such as the World Bank and the European Training Foundation (ETF) and cooperation agencies, and includes the financial investment into VET centers and a greater emphasis on output- and workbased training structures (Masson, Baati and Seyfriend 2010).

\section{Upgrading the performance and relevance of quality of education}

Besides the continual efforts to improve the relevance and efficiency of the vocational training system, education reforms in MENA states target the improvement of the quality of the secondary schooling system by reducing dropout rates and conveying skills and competencies required in increasingly knowledge-based economies. In particular, it was noted that despite the increase in overall education levels over time and a positive individual return to education in terms of wages, many MENA states did not experience significant growth in the per capita output or real wages during this time (Kabbani and Kothari 2005). A potential solutions to this "macroeconomic puzzle" is the important role of the public sector (Pritchett 1999), which provides high wages to graduates without asking for higher productivity in return, or the inflexible structures of the private sector, rewarding predominantly routine skills, but not the skills relat- 
ed to entrepreneurial efforts (Murphy and Salehi-Isfahani 2006). A further explanation is given by the low quality of the general secondary, vocational and higher tertiary schooling and training system.

In particular, when standardized performance tests were used to assess the quality of secondary education across the regions, they give a rather gloomy picture on the ability of the educational institutions in MENA to provide basic skills and knowledge. The TIMSS (Trends in Mathematics and Science Study) conducted in 16 MENA countries, showed that between $25 \%$ and $74 \%$ of pupils did not reach the lowest benchmark points, indicating a below-average ability of solving problems (Bouhlila 2011). The two most important reasons for this failure are seen in language problems caused by a diverse number of Arabic dialects spoken in families and in a curriculum that over-emphasizes the performance of routine tasks and the understanding of simple information (Valverde 2005). With the majority of youths in the region still having obtained at most a secondary schooling degree, the skills provided in general secondary schooling may be decisive in determining the ability to integrate into the labor market and/or start and maintain a prosperous business in the private sector.

\section{Development of employment-driven education and training strategies}

Based on the so-called 'Mubarak Kohl Initiative' started in 1991, Germany has assisted Egypt in setting up technical and vocational training structures modeled along the lines of the German 'dual model' with its emphasis on dual training and societal consensus. It aimed at improving relations between actors such as ministries, vocational schools, training centers and firm-level training as well as at setting standards for occupational qualification in Egypt. The German Society of International Cooperation (GIZ, Gesellschaft für Internationale Zusammenarbeit) supported the program until 2008 and assisted in the development of training curricula and trained instructors. The provision of apprenticeships was coordinated by the newly created National Center for Human Resource Development related to private employers in Egypt as well as by the Ministry-related Directorate for Vocational Education and Training. The program started to offer secondary school graduates in Egypt the possibility of entering into three-year courses of dual vocational training in 28 occupations involving around 1,600 firms providing training and 44 vocational schools. Available qualitative evidence gained from interviews with participants and follow-up tracing points at a smoother transition of program participations from school to work and better earnings after completing dual vocational training. Employers continue to support the program as they see a major benefit in a better trained workforce (Adams 2010). The pilot is now established as a regular part of the Egyptian training system run by the Egypt Ministry of Education and the industrial partners and put on stable legal basis. As of 2009, 32 occupational profiles were trained in 76 technical schools involving about 1,900 companies, mostly in the formal and industrial sector. Until 2009, 24,000 young people graduated, and 13,000 were in training. Compared to the overall challenge in Egypt, which needs to integrate about 1 million young people per year into the labor market, this is largely insufficient. Observers also question the sustainability of the program without external support. Other experts conclude when asked to evaluate the program that apprenticeship graduates of the Kohl-Mubarak- 
Initiative mostly move on to pursue tertiary education so that an actual skill upgrade within the vocational employment sector is impaired.

\section{Involvement of stakeholders and social dialogue}

With the public sector traditionally absorbing up to $50 \%$ of the highly educated workforce, it generates strong financial and social incentives for youths to orient their education efforts towards work choosing tertiary education to maximize employment probability in the public sector. A recent study on Syria investigated the job search focus of youths and found that across all education levels a substantial share of youths exclusively aims at working in the public sector. In this context, the Syrian project "Business SHABAB" aims to provide youths with information regarding alternative employment possibilities, e.g., in self-employment or the private sector. An evaluation of the impact of additional information provided indicates that job search efforts of youths are broadened by raising awareness (Kabbani and Al-Habash 2008).

\section{Institutional capacity building for definition of policies and decision making}

Between 2007 and 2008, the ETF conducted a project in the Southern European countries as part of the European Neighborhood Policy (ENP) initiative, aiming to exchange information and experiences, regarding quality assurance systems in the local VET systems. An analysis of the dialogue between decision makers and experts on both sides shed some light on the value of the European experience in implementing school-based VET systems for the Arab countries. Crucial points impeding the fruitful establishment of a VET system were weaknesses in monitoring and evaluation that focused predominantly on input indicators (teachers, facilities, curricula) rather than the success of the VET in achieving training objectives. Furthermore, when performance-based indicators were used, they did not seem to be adequately applied to re-assess and improve the current system. This emphasizes that the high degree of centralization and the lack of a systematic and continuous involvement of employer organizations requires a sophisticated system of monitoring, evaluation and control that is difficult to manage and maintain (Masson, Baati and Seyfriend 2010).

\section{Increase and diversification of sources of funding}

Among the initiatives aiming to improve the school-to-work transition of youths in MENA states, there are also several non-publicly financed ALMPs. The World Bank provides a recent assessment of the programs in place. For 2010, several programs could be identified across most of the MENA region. Most of them were found in Egypt (17), Morocco (14), the West Bank and Gaza (13) and Lebanon (10). Amongst the largest programs were "The Advancing Learning and Employability for a Better Future (ALEF)" in Morocco with about 270,000 participants per 
year and the INJAZ program in Jordan (but operating in some 12 MENA countries) with approximately 110,000 participants per year. The program encompasses the mentorship of business leaders who are brought into public school classrooms one hour per week to provide students with basic business skills. The "Info Youth Centre IT Training Program" in Tunisia reaches roughly 50,000 and the "Vocational Training Promotion Program" in Algeria 30,000 participants per year. All programs are restricted to larger firms, small and medium-sized enterprises are not involved. Most programs are funded by international donors such as, for example, the United States Agency for International Development (USAID) and the GIZ. About half of the GIZ programs were financially supported by local governments or ministries. But still, fewer than $5 \%$ of all training providers were coordinated by central institutions (such as Public Employment Offices or Ministries of Labor) indicating that the vast majority of programs does not operate with any closer connection to public stakeholders. The reasons for this are twofold: first, there are no common platforms for interaction, and second, training providers fear bureaucratic red tape since they face tremendous impediments in terms of coordinating training programs (AngelUrdinola, Semlari and Brodmann2010). 


\subsubsection{Sub-Saharan Africa and South Africa}

Key issues:

1. Sub-Saharan labor markets are characterized by high informality and traditional apprenticeships in crafts sectors. Both factors hamper high productivity and innovation in the economy which would also trigger more demand for skilled labor.

2. Vocational education at the secondary school level has a marginal position in most countries as there is a general lack of support and acceptance for vocational education both by employers and young people and their families.

3. Some attempts have been made to modernize vocational training and to establish dual vocational training systems, but they are still too small, often operate only as pilot projects, and they are mostly tied to traditional crafts.

\section{General facts}

Sub-Saharan African countries show high shares of informal employment reaching up to $95 \%$ interacting with weak economic development. In additional, youths find difficulties entering into (formal) employment. Yet, unemployment rates and youth unemployment are only one indicator of the vulnerable position of young people in these labor markets which is aggravated by a lack of education and training (Rioust de Largentaye 2009; Garcia and Fares 2008a, 2008c).

In many Sub-Saharan countries school attendance is less than complete, and child labor is still an issue. Despite some progress, only about $60 \%$ of all young people have completed primary education (Garcia and Fares 2008a). After leaving school, most young people face longer transition periods to their first job lasting between 1 (Cote d'Ivoire) and 6.7 years (Mozambique) (Garcia and Fares 2008b). In most Sub-Saharan African countries, technical and vocational education and training play only a marginal role (DFID 2007; Oketch 2007) despite the fact that strengthening vocational(ized) education has been a recurrent (but also controversial) policy measure to combat youth unemployment and promote economic innovation and productivity. Efforts to strengthen general education clearly dominate and tend to crowd out efforts at a more vocational educational approach. However, there is some role for public vocational education and training systems, not least initiated by international assistance agencies since the 1960s and 1970s.

In Sub-Saharan countries there are two major streams of vocational education and training:

1. Most countries have formal, institutionalized technical and vocational training and education at lower and upper secondary or post-secondary level, taking place mostly in parallel to general education in integrated schools; in many cases the distinction and relative shares of general and vocational education at different levels of secondary edu- 
cation are not transparent; these programs do not relate with the dominant economic activities in the informal sector.

2. There are traditional apprenticeships in workshops owned by master craftsmen, mostly in traditional occupations such as carpenters, masons, tailors, dress makers etc. After apprenticeship young people often enter informal employment or self-employment. Given the cost of school attendance and weak family background in some countries, enrollment in secondary education is far from complete so that some young people enter the (informal) labor market after primary education without any further formalized general or vocational training at the secondary level. They rather take up an apprenticeship in a small business or in formalized village polytechnics.

\section{Formal vocational education}

There are differences by region and country, however. Available data, although somewhat incomplete and dated, show that enrollment in vocational education as share of all enrolled in secondary education was below $10 \%$ in the early 2000 s in most countries except very few such as Liberia, Mali (with both reaching more than 30\%) as well as Angola, Rwanda and Sierra Leone with more than 10\% (DFID 2007; Atchoarena and Delluc 2001). The differences in the level of vocational training enrollment can, to some part, be explained by long-standing differences between French-speaking and English-speaking countries with French-speaking countries putting more emphasis on general content, but achieving higher enrollment rates than Englishspeaking countries - but in this context more artisan skills are largely neglected so that the needs of a mostly informal labor market are not met as examples from Cote d'Ivoire, Madagascar, Mali or Senegal show (Atchoarena and Delluc 2001; Oketch 2007). English-speaking countries, in general, have a more narrow vocational specialization and less academic content which limits further educational progression unless these systems are modernized and made more flexible (as was the case in Ghana, Botswana and South Africa to some extent). Furthermore, data show some decline in vocational education enrollment in many countries over time - and girls are hardly enrolled at all. In most countries provision of vocational education is a government responsibility via schools and training centers although private training providers have grown in importance.

Based on data from the UN, Oketch (2007) finds the provision of technical and vocational education and training to range between $2 \%$ and $5 \%$ of total secondary enrolment in countries such as Eritrea, Ethiopia, Malawi, Namibia, Niger and South Africa. In many of these countries vocational training courses tend to be more specific and therefore more exclusive regarding enrollment shares and mobility between different strands of education. In general, vocational education lacks government support in these countries. Expansion of basic general education has been a major policy priority of national governments and international donors in countries such as Kenya, Malawi, Lesotho, Chad or Senegal. Here young people tend to leave schools and enter the labor market directly or after a traditional apprenticeship. 
The vocational education enrollment share is above $5 \%$, but below $10 \%$ in countries such as Botswana, Cote d'Ivoire, Burkina Faso, Mozambique, Morocco, Togo, Tunesia and Uganda. These countries underwent some modernization of vocational training balancing general and specific education allowing for progression to higher education after graduation from vocational education. Finally, in Egypt, Cameroon, Congo, Gabon and Mali vocational training enrollment is above $10 \%$ of all secondary education enrolment.

A more in-depth analysis by Oketch (2007) shows that Botswana, for example, provides technical and vocational education at upper or post-secondary level, with courses at junior level also involving major general content, yet it is not clear to what extent vocational education is distinct from general. A similar situation is found in Senegal where technical and vocational education starts at the senior secondary level. Some courses prepare directly for labor market participation, e.g. as a mechanic. Zimbabwe has proper technical and vocational education and training at post-secondary level after general education at lower levels for those not qualifying for higher education. Observers estimate that about $12 \%$ of education at the junior and senior secondary level is vocational. Ghana provides technical and vocational education from lower secondary level onwards with some options to progress to higher education. Yet, after more preparatory courses at lower secondary level, pupils who opt for vocational education participate in three year courses at senior secondary level leading to a certificate examination. After graduation they can move to higher education. But still, vocational training has little prestige.

Besides government agencies running technical and vocational training institutions private providers - some registered, some informal - have grown in importance. In Mali, which reports one of the highest vocational training shares, government support for this type of education as a means to promote industrial modernization was crucial. It is also the country where private provision of training is most prominent, most notably also in technical occupations.

All in all, formal vocational education and training have a difficult standing in Sub-Saharan African countries, despite the fact that there is some evidence that vocational training leads to better integration into wage employment as a study on Ethiopia shows (Garcia and Fares 2008c; Guarcello, Lyon and Rosati 2008). This becomes manifest in the low enrollment rates and the stagnating and sometimes declining share of vocational training enrollment in those countries where this used to be more than marginal. The difficulties with the promotion of technical and vocational education and training can be attributed to a number of issues (Oketch 2007; Atchoarena and Delluc 2001):

1. In many Sub-Saharan countries vocational training meets only limited acceptance by young people and their families as benefits to be expected from vocational training in terms of access to jobs, better pay or job promotion are far from obvious in the African context so that participation in general education is preferred; existing vocational training programs are often perceived as an unattractive option leading to dead-end jobs. It is therefore only seen as an inferior alternative to general secondary schooling, which provides significant returns (Garcia and Fares 2008c) and progression to higher education which could in part lead to better jobs, also in white collar occupations, even if this involves major additional financial effort. 
2. The high shares of informality in economic activities and employment lower the potential for productivity increases, technological innovation and formal job creation. Stronger employer demand for better skilled workers in more productive activities would generate stronger incentives for participation in formal vocational training; but given existing firms and jobs, traditional apprenticeships after primary education seem sufficient to get access to employment.

3. In general, there is only limited institutional support on behalf of policy makers, governments and ministerial agencies, which would have to invest more into vocational training at schools (and in cooperation with business). Expanding general education (which has its merits) tends to crowd out vocational education.

These factors regarding families and young people, employers and governments tend to create an equilibrium which is unfavorable to the establishment of vocational training although technical and vocational education and training could in principle me a major trigger of economic progress in the African context.

In order for the public and even parents to not consider the vocational education track as dead end option, chances to proceed to higher education should be promoted. An interesting alternative to the 'classical' implementation of a dual vocational training system which faces severe reputation deficits could be fostering the establishment of 'German type' vocational academies. Students in these institutions acquire academic skills which are applicable in the work place. In order to enroll in such a vocational academy, students have to look for a company that is willing to employ them and partner with the academy. In the German context, many academies maintain agreements with various companies so that it is relatively easy for future students to find an employer. The subsequent training has a period of three years and is similar to the structure of the TVET system (such as alternating phases of school-based and on-the-job training) but its graduates hold a bachelor degree upon completion. It is thus likely that vocational academies awarding academic degrees would have a higher reputation and may not be seen as dead-end option while providing the students with valuable practical knowledge. By partnering with companies, one would also avoid educating students without really tackling the needs of companies and avoid having an overeducated but unemployed young workforce.

\section{Informal vocational education}

With formal vocational training programs unable to provide relevant labor market training, major parts of vocational training for informal activities are also provided by non-government providers such as NGOs, churches, for profit agencies and, most importantly, informal entrepreneurs. In particular, traditional and informal apprenticeships have taken an important role of preparing young people for activities in the often sizeable informal sector (Rioust de Largentaye 2009). Informal apprenticeships reach approximately $50 \%$ to $90 \%$ of young people in countries like Gambia, Ghana, Senegal, Madagascar, Zambia, Tanzania, Mali or Malawi; however, concrete figures are unavailable. The traditional of informal apprenticeship is particularly widespread in West African countries, with several common structural features emerging across the 
respective countries (Ahadzie, 2009). In particular it can be found that training is generally purely practically oriented, with apprentices learning from observing the craftsmen at work in their trades and skills as, e.g., tailors, mechanics, painters, bakers, carpenters, joiners, welders and hair dressers. The learning process might thereby be restricted to the production of only specific type of output, leaving apprentices with only partial knowledge of their respective trade after finishing the apprenticeship. It is found that the duration of the apprenticeship varies by type of trade and also the ability of the apprentice. Whereas the cost of the apprenticeship seems to be borne by the apprentice with the payment of fees or in kind payments, it can also be found that apprentices receive shelter and food during training, the value of which might exceed the total fees paid. The predominant source of apprentice recruitment is the familial and social network, so that the training might be seen as part of a social reciprocity system. Whereas the general schooling levels of youths do traditionally not matter for the selection of apprentices, it is found that craftsmen seem to value a completed lower general education. Written contracts for the apprenticeship are not very usual and do generally not contain specifics of the content and duration of training. However, it is particularly early school leavers who enter traditional and informal apprenticeship training. In terms of labor market outcomes, there is evidence from studies on Malawi and Tanzania that most graduates from informal apprenticeships were employed with the same business that had provided training or with some other employer, after some years there is also a considerable share of self-employed (Aggarwal, Hofmann and Phiri 2010; Nübler, Hofmann and Greiner 2009). An evaluation study of the informal apprenticeship system in Ghana (Monk, Sandefur and Teal, 2008) shows that there is an important negative selection of youth into informal apprenticeships, with youth with no low levels of general schooling entering this type of training. However, when controlling for this negative selection it is found that individuals with low levels of formal schooling benefit substantially from the informal training, with earning increases of $50 \%$.

In contrast to formal vocational education, informal apprenticeships bear the advantage that they are closer to the current needs of employers in the (informal) labor market. However, this type of training has its limits with regards to more modern, complex and technology-oriented occupations - which in turn also implies the need to have employers and labor demand in these fields. Informal apprenticeships face major barriers regarding technological advancement while informal employers, of course, are restricted in their access to credit which would be required for investment and firm growth. Last, but not least, there is some enterprise-based on-the-job training in larger, formal enterprises in the more productive sectors.

There are some more recent examples of modernized apprenticeship systems. Benin, for example, recently modernized its vocational training system in order to better meet urban economic demands. Since 2006 a dual apprenticeship system with alternating phases of theoretical and practical training has been in place, mostly devoted to traditional crafts, however, e.g. masonry, electrical trades and plumbing. While one day is spent at school, five days are devoted to learning on-the-job. After 600 hours in a training center participants can obtain a certificate of qualification (certificat de qualification professionelle). It is expected to have about 3,000 graduates per year, which indicates the small scale of the system. The new system should also be able to certify qualification from work experience. In Mali, where the vocational training share is far above the African average, a dual training model was introduced in 1997 combining about 
$80 \%$ time spent on work supervised by a trained artisan and $20 \%$ formal courses in training centers. There is some evidence that this reform has led to better skill formation and inclusion into the labor market, in particular due to the systematic involvement of the private sector (Rioust de Largentaye 2009). Still, these models are relatively small and tied to traditional crafts. In Ethiopia the education system was reformed around 2000 to strengthen primary education for all young people, which now lasts for 8 years, and to complement this with vocational courses in technical subjects lasting for one or two years. There is some preliminary evidence of improved labor market performance of recent training graduates (Denu, Tekeste and van der Deijl 2005). As the Gambian example of the National Youth Service Scheme established in the mid1990s shows, young people turn mostly to self-employment or work unrelated to the occupations learned (Lahire, Johanson and Wilkox 2011).

If addressed properly, apprenticeships and company-level training could be developed further by establishing better links between the (often informal) apprenticeship system and formal vocational education and by moving the apprenticeship model from traditional crafts to more productive and innovative sectors. Examples can be found in Benin, Togo, Senegal or Mali. Regarding formal, school-based technical and vocational training and education, reforms should lead to higher specificity - closer to current labor market needs, also in the informal part of the economy - without neglecting general skills and options for further higher education and continuous training. Morocco and South Africa have moved in that direction. Furthermore, improving general primary education and literacy are as important and promising as attempts at easing formalization of businesses. Last, but not least, any development of training systems requires the contribution of the social partners, employers and trade unions (Rioust de Largentaye 2009). A case in point is a recent attempt at dual vocational training in the Cameroon crafts sector supported by the national Chamber of Commerce and German development aid. Still, a major challenge is to move beyond pilot projects and to establish vocational training at a sufficient scale given the size of cohorts entering the labor market every year.

Attempts are made on a continuous basis to upgrade the informal training system by formalization. This is however a difficult task as the flexible, unbureaucratic forces of the traditional apprenticeship might easily be distorted and lead to "another supply-driven, dependency-induced training program" (World Bank 2004).

Palmer (2009) discusses several attempts of the Ghanaian government to formalize informal apprenticeships and points to potential unintended ramifications of the interference in Ghana and other African countries. In particular he cautions against the global or partial take-over of training costs, as proposed by experts in the National Apprenticeship Program (NAP) in Ghana 2008, as this falls short of the complex system of pecuniary and non-pecuniary payments made between apprentices, their families and the craftsmen during the training period. Based on past experiences, partial payments could be particular distorting as this might lead poor apprentices to leave the apprenticeship prematurely. As the training plan is not structured, it is furthermore not guaranteed that youths are able to acquire sufficient skills during this period. He further notes that the substitution of the practical work-based training for a more general school-based schooling is likely to disregard the abilities of youths and skill demands of the local economy. As potentially promising measures he highlights the introduction of practical short-term training courses lead by public or private to complement the work-based training as done in the Voca- 
tional Skills and Informal Sector Support Project in Ghana, as well as the targeted training of craftsmen to ensure a minimal level of training quality. With respect to the latter, projects conducted in Ghana, Tanzania or Kenya seemed to work similarly well, significantly improving both, the training content and the quality of the output produced (ILO 2012).

A further hurdle to formalization and standardization are the missing or only weak involvement of informal business associations. Although they factually exist in many countries, they are often not very strong representatives of their members due to a high degree of heterogeneity limited funding or lack of structure. An ILO initiative in Niger therefore targeted the restructuring of the National Crafts Association and an increase in their visibility in local communities. This led to a significant extension of their sectoral coverage and thus a higher representativeness in political consultations regarding the formalization of traditional apprenticeships. Besides a larger involvement in the political reform process, the business associations might are also found to benefit the training quality by increased monitoring, the definition of skill standards, or the joint acquisition of expensive tools (ILO 2012).

\section{ALMPs in the Sub-Saharan context}

Regarding ALMPs, they are of minor relevance in the Sub-Saharan context. Kenya is an interesting case for policy innovation. The Jua Kali voucher program, started in 1997 as a pilot, provides mostly young unemployed with training vouchers, which allow them to select a training provider. Participants pay $10 \%$ of the training cost. It can be shown that in the first four years of the program about 38,000 vouchers were issued and that $90 \%$ of the vouchers were cashed in with master craftsmen, showing the importance of these occupations in the Kenyan economy. There is some evidence of positive effects of the pilot program in terms of employment. Yet, the program was quite costly and difficult to administer by the government bureaucracy. Clearer targeting and better administration as well as reducing subsidization are most important lessons (Puerto 2007c). Positive effects from upskilling on taking up work or self- employment were also reported from an ICT, entrepreneurship and general life skills training program - the Youth Empowerment Program - started in 2007; a similar program was implemented in Senegal (International Youth Foundation 2011a, 2011b). Furthermore, research from Nigeria shows the potential of entrepreneurship in leaving unemployment (Awogbenle and Iwuamadi 2010; Cling et al. 2007).

In many respects, South Africa is a special case in the African context. South Africa has a different level of economic development and a much lower informal employment share (Oketch 2007). But in South Africa, a country with a large share of young people in the labor force, both the overall unemployment rate and youth unemployment are very high, the latter reaching more than 40\% (National Treasury 2011; Lam, Leibbrandt and Mlatsheni 2008). Only about one in eight young people has a proper job, and the employment of young people has declined by about $20 \%$ since 2008 . The difficult situation of youth unemployment can be explained by the large share of low-skilled and unexperienced young South Africans, with almost 60 percent not completing secondary education. Two thirds of the young have never worked, mirroring long 
phases of non-employment, and others leave school prematurely to enter directly into jobs. However, they face major barriers to entering the labor market above a casual and low-pay level, which is also most vulnerable to economic fluctuations. Existing schooling does not provide young people with the skills required by employers (National Treasury 2011). Furthermore, the South African schooling system still reproduces inequality between different social and ethnic groups. As comparative data shows, vocational training only plays a marginal role in the South African context and does not meet the requirements of the economy in particular as existing industrial training institutions and company-based training centers have declined in the 1990s and not been replaced by an up-to-date system (Lam, Ardington and Leibbrandt 2007).

In the late 1990s South Africa created a nation-wide regulatory framework for the labor market and skill development (Skills Development Act), which established a skill training levy on employers' payrolls. $80 \%$ of the revenue is used to fund training in firms and additional programs administered by Sectoral Education and Training Authorities (SETAs) while $20 \%$ is spent on the National Skills Fund supporting unemployed and informal workers. During recent years, however, to combat youth unemployment, the South African government, similar to other governments in the region, has also put major emphasis on expanding public works programs with labor-intensive modes of production. However, these programs are also expected to provide some training on-the-job (Didibhuku Thwala 2011). Labor market integration and training is to be promoted by the Accelerated Shared Growth Initiative for South Africa (AsgiSA) and the Joint Initiative on Priority Skills Acquisition (JIPSA). Both initiatives aim at a better and more expedient placement of unemployed graduates. 


\subsection{Latin America}

Key issues:

1. Young people in Latin America face particular difficulties in entering the formal labor market, more than facing challenges in the transition from school to work.

2. Vocational training has traditionally been part of the education system in Latin America, but the original system has been unable to adapt to the changing structure of the economy, producing a cohort of unemployed youth or informally employed youth in the 1970s-80s.

3. Training systems are no longer part of the long-term development strategy, but training programs and interventions have been on average effective in improving outcomes of the targeted population.

\section{General facts}

Generally speaking, the first vocational training programs (along the lines of the German model) were introduced in the1940s and 1950s. They did not survive the changing structure of the economy in the 1980s and 1990s. Currently, vocational training is provided as a labor market intervention for disadvantaged youths, but often close to high school completion or with high school degrees. These programs were successful in increasing labor market outcomes of the targeted populations. Between 1998 and 2008 youth unemployment rates significantly declined (-5.9\%) and stabilized around 14.3\% in 2008 (ILO 2010b). A second positive indicator for the situation of youth in Latin America is the decrease in the NEET rate from $21.1 \%$ in 2005 to $19.8 \%$ in 2008 (ILO 2010a).

The recent crisis has interrupted these trends with an increase of the unemployment rate from the 2008 level of $14.3 \%$ to a $16.1 \%$ level in 2009 (ILO 2010b). As a secondary effect, the crisis has pushed more youth of $15-19$ year olds into the informal sector, with $82.4 \%$ of teenagers engaged in informal employment in 2009 (versus 80.8\% level of 2007). As a comparison, only $50.2 \%$ of adults aged 30 to 64 works in the informal economy (ILO 2010b). For 2011 a small reduction in the unemployment rates $(-0.9 \%)$ compared to the 2008 levels is expected (ILO 2010b).

Vocational training started in Latin America with the economic expansion that followed World War II, when the demand of the manufacturing sector exceeded its ability to provide on-the-job training. The peculiarity of this region is the evolution of such programs over time. Three different phases can be recognized (Betcherman et al. 2007; Puerto 2007a).

This first phase of the development of vocational training can be dated to the founding of the National Service for Industrial Training in Brazil (SENAI) in 1942 and the following national vocational training institutions (VTIs) which emerged in the whole region on the same grounds. Orig- 
inally the SENAI was strongly influenced by the German model as each occupation was broken down into its constituent tasks, which were added into the training curriculum and applied in practice projects. The dual system, on the other hand, could not be recreated due to the lack of master craftsmen (Cinterfor 2008). The VTIs were primarily supply-driven, state managed, financed through payroll taxes, independent from academic schools and from the Ministry of Education and usually quite close to the needs of the industry (de Moura Castro and Verdisco1998). Throughout the region the VTIs had a tripartite structure with representatives of employers, workers and the government and the curricula were determined centrally.

The VTIs, however, did not adapt to the changing economic structure after the 1970s and to the economic challenges posed by the oil crisis and the subsequent economic downturns. At this point the demand for skilled and semi-skilled labor from the manufacturing sector started to decline. Graduates from these programs were now unable to find employment, informal labor markets became more common and budgets were dramatically cut for all these institutions. Such reduction in the emphasis on these programs was also a consequence of the preference for programs driven by market principles (de Moura Castro and Verdisco1998) and the dramatic changes in the demand for labor.

During this time, a second phase opened for vocational training programs in Latin America, targeted to other segments of the population (particularly disadvantaged youth). In the early 1990s, the Jóvenes Programs were created and remain today important training programs in the region. Such interventions are based on a demand-driven model targeted at disadvantaged youth. The first program was created in Chile and subsequently replicated in Argentina, Uruguay, Paraguay, Peru, Colombia, Dominican Republic and Venezuela. These programs targeted at youths from low-income families, poorly educated and unemployed or underemployed. They were provided with practical experience to help their entry into the formal labor market. Unlike the VTIs, the Jóvenes programs were not run by the government, but they were regulated by it: training was offered through a bidding system where private and public firms could participate; the training was therefore demand driven, in the sense that the government did not set the contents of the curriculum. Similarly to German vocational training, a classroom-training phase was followed by an internship (Ibarran and Rosas Shady 2009).

According to Weller (2009) the main changes and differences compared to the original VTIs are:

1. A greater diversity diversification of training providers, with stronger reliance on private institutions. In the public realm, delivery and regulation were institutionally separated and programs were decentralized which implied greater participation by local entities (provinces and municipalities).

2. More articulate interest in the certification of skills facilitated by a larger variety of training offered and the recognition of informal learning.

3. Attempts at making training more demand-oriented through greater involvement of private enterprise and trade unions which helped identify unmet needs.

4. More diverse target groups as, on the one hand, there was a move from one-time training to continuous training for personnel of strategic importance for the firm's competitiveness; on the other hand, training programs to encourage the reintegration 
of the unemployed and special schemes for groups with particular employability problems (youth and women with low education levels) or those working in lowproductivity, low-income activities (specific occupations, own-account workers, microentrepreneurs) were designed.

5. New instruments for the public funding of training, in particular tax incentives.

These new programs seemed to have guaranteed increased employability of the participants and higher earnings upon graduation (Betcherman et al. 2007). For example:

1. Argentina, ProjectoJoven (Aedo and Nunes 2001): the non-experimental analysis based on propensity score matching shows a $10 \%$ increase in the employment probability of adult women (not of men) and a $10 \%$ increase in monthly wages for young males and adult females.

2. Colombia, Jóvenesen Accion (Attanasio, Kugler and Meghir2007): the experimental analysis shows an increase a substantial increase (18\%-35\%) in earnings and a $5 \%$ increase in employment opportunities for both men and women, with larger results for women.

3. Dominican Republic, Joventud y Employ (Card et al. 2010): the experimental design finds no effect on employment probabilities, however finds a (marginally significant) $10 \%$ increase in wages.

4. Chile, Chile Joven (Aedo and Pizarro 2006): the non-experimental analysis based on propensity score matching shows a $21 \%$ increase in the employment probability of young women and a $26 \%$ increase in monthly wages, with best results for the young.

5. Peru, ProJoven (Díaz and Jaramillo 2006): the experimental analysis shows a $6 \%$ increase in employment probabilities and an $18 \%$ increase in hourly wages.

Overall, the Jóvenes model has been successful in improving job placement and earnings of disadvantaged youth, and in particular of disadvantaged females. This model is less close to the German vocational system than the VTIs of the previous phase, yet has been found to be successful. The original Jóvenes programs, however, have now become particularly expensive for some countries (Betcherman et al. 2007) due to the long duration of the program which reaches eight years on average. This has led to the development of new training programs and the start of the third phase of vocational training development in Latin America.

While the Jóvenes programs have represented a comprehensive intervention to improve youth employability and human capital for disadvantaged segments of the population, the third model introduced in the early 2000s aims to improve the employability of the youth aged 16 to 29 by providing skilled information and communication technology workers for today's information based economy (Betcherman et al. 2007). The prototypical program is Entra 21, an initiative developed in 2002 by the International Youth Foundation, co-financed by the International Monetary Fund, the Inter-American Development Bank and private corporations. These programs have started in Argentina, Belize, Bolivia, Brazil, Chile, Colombia, Dominican Republic, Ecuador, El Salvador, Guatemala, Honduras, Mexico, Nicaragua, Panama, Paraguay, Peru, Uruguay, and Venezuela. 
The key elements of Entra 21 are lectures and internships, continuous tutoring, financial scheme to increase participation in the program, an average length of 2 years and the targeting of high school graduates that are unemployed or underemployed (Betcherman et al. 2007). While no impact evaluation is available up to date, Betcherman et al. reports that "... studies in El Salvador, Dominican Republic, Peru, Panama, Colombia, Paraguay, Bolivia, and Brazil have shown positive "gross" impact on employability of participants. Estimated job placement rates have ranged from 68 per cent in Peru to 41 per cent in Paraguay, with high satisfaction levels of employers and beneficiaries. Placement rates have been lower for women, especially in Panama, where 34 per cent of female participants got a job, compared to 64 per cent of male participants. On the other hand, in Sao Paulo, Brazil, both genders obtained the same placement rate. Regarding earnings effects, evaluations found that average monthly wages were at least as high as the minimum wage in Peru, Bolivia, Dominican Republic, Panama, Paraguay and Brazil. Most youth attained a job in the formal sector with at least one or more benefits, such as paid vacations, one month bonus and health insurance."

\section{Challenges of the VET system}

Weller (2009) argues that current training programs have a number of deficiencies. In Latin American countries training systems are not conceived as part of a long-term development strategy focused on continuous improvements in systemic competitiveness. If they were, they would serve a key function in raising labor productivity. The coverage of training systems is generally limited, both in terms of training for first-time jobseekers and in terms of ongoing training or retraining for economically active individuals. In several countries, training expenditure has declined or program coverage has decreased, reflecting management difficulties and problems in matching supply and demand. One reason for this may be that, while the importance of demand-driven training is recognized, it is not always easy to determine future demand and to adjust training curricula accordingly. There is seldom any capacity for prospective analysis in this respect. Furthermore, available evaluation studies of the impact of training on labor-market integration reveal mixed results. At the same time, many firms face problems in finding suitable personnel, particularly more skilled individuals, while some are simultaneously underemployed in terms of their education and skills. This exerts downward pressure on the labor supply. Finally, the use made of incentives is often unequal, as they tend to be used more by large firms than by small ones, and their benefits go to higher-ranking or administrative personnel rather than to production workers.

Furthermore, conditional cash transfer programs are most notable in the Latin American countries. They were designed to encourage school attendance of children from poor families by providing parents with cash support only if they send their children to school (e.g. Bolsa Familia in Brazil or Oportunidades in Mexico). Many studies have shown that these programs can effective help raise educational attainment while successful entry into work has yet to be shown (OECD and ILO 2011). 


\section{ALMPs in Latin America}

Training provision seems to be the primary active labor market policy in Latin America. Weller (2009) gives an overview of ALMPs in those countries. Job creation programs for temporary work have hardly been used in the region except recently in the form of first job programs, where these programs help to overcome the structural barriers facing young labor market entrants. Employment services have been the second focus of labor policies in Latin American and Caribbean countries. Support for the self-employed and micro enterprises has been provided through training and financing programs, i.e., measures that facilitate and reduce the cost of registering micro-enterprises and formalize them.

\subsection{South and East Asia}

\subsubsection{India}

Key issues:

1. Young people face a particularly difficult situation in India. However, there has been a notable expansion of education with a strong trend towards academic studies.

2. Vocational training is of limited importance and mostly restricted to informal and traditional crafts training.

3. Formal vocational training in training institutes plays only a marginal role and does not reap significant benefits for young people as it does not meet the demands of the advance sectors.

4. Traditional apprenticeships in the informal sector cannot provide the skills for more productive economic activities.

The position of youth in the labor market in India is summarized in Table 2. According to available data, salaried employment accounts for only ten to $15 \%$ of the labor force in India, where informal work and self-employment dominate the labor market. The youth are more likely than adults to be casual worker, while the opposite holds for salaried employment and selfemployment. The lower self-employment rate is probably related to a lack of experience and finance to start an own business. Casual work is the least secure and lowest-paying type of work in the Indian labor market. These workers receive daily payment and have no written contract or social security benefits. Furthermore, the unemployment rate is two to three times higher among the youth compared to the entire adult population. There was a strong rise in unemployment between 2004/05 and 2009/10, particularly among the youth, increasing from 6.8 to $10.3 \%$. 
Table 2: Per 1,000 distribution of the labor force

\begin{tabular}{lcccc}
\hline & \multicolumn{2}{c}{ Youth (age 15-24) } & \multicolumn{2}{c}{ All (age 15+) } \\
& $2004-05$ & $2009-10$ & $2004-05$ & $2009-10$ \\
Self-employed & 483 & 407 & 557 & 496 \\
Salaried employee & 101 & 146 & 114 & 161 \\
Casual worker & 336 & 328 & 295 & 294 \\
Unemployed & 68 & 103 & 28 & 35 \\
\hline
\end{tabular}

Source: NSS Employment and Unemployment Survey 2004-05 and Government of India (2011). Statistics are based on current weekly status.

In the same period, however, the share of youth attending education increased substantially as well from 26 to almost $40 \%$. Based on the usual principal activity status, the NEET rate was stable at around 24 percent. This latter group consists almost entirely of girls and young women attending domestic duties. In general, the labor force participation rate of women in India is very low, especially in urban areas where it has been stable around 20\% since 1983 (Klasen and Pieters 2011). The key to a reduction of the NEET rates therefore lies in increasing education and participation rates of women at given education levels.

The returns to education and training in India are high and growing, especially for the tertiary level, indicating that education and skills are important determinants of labor market outcomes. Most children in India receive primary education, but transition into secondary schooling is a bottleneck in the educational system. In 2004-05 about half of the youth population had completed primary school or less (a quarter was illiterate). Some $10 \%$ completed higher secondary schooling and almost $5 \%$ graduate level education.

According to the World Bank (2007), relative supply and relative wages of workers with technical or vocational skills have declined since the early 1990s, which may be due to skill mismatching and a preference of students for entering higher education rather than the labor market. Hence, the quality of education and the match between training and industry requirements need to be improved, although the improvement of general education should be prioritized.

Data from the 2004-05 Employment and Unemployment Survey show that $12 \%$ of youth aged 15 to 29 received formal or informal vocational training. The large majority of this was 'hereditary' or family based (i.e. traditional apprenticeships) or informal training provided by employers outside of family networks (informal apprenticeships), and only 3.5\% of youth received formal vocational training (Table 3). Formal vocational training in India is publicly financed for the largest part, with a very limited role for the private sector in financing and design of training and apprenticeship programs. 
Table 3: Participation in vocational training in India

\begin{tabular}{lll}
\hline & Freq. & Percent \\
\hline receiving formal vocational training & $3,605,486$ & 1.18 \\
received formal vocational training & $6,908,749$ & 2.25 \\
received hereditary vocational training & $13,378,897$ & 4.36 \\
receive other informal vocational training & $12,292,979$ & 4.01 \\
did not receive any vocational training & $267,831,445$ & 87.36 \\
missing & $2,550,955$ & 0.83 \\
Total & $306,568,511$ & 100 \\
\hline
\end{tabular}

Source: NSS Employment and Unemployment Survey 2004-05.

Formal vocational training is dominated by the public Industrial Training Institutes (ITIS) and the private Industrial Training Centers (ITCS). Vocational training and apprenticeship training schemes prepare mainly for employment in the formal sector. The labor market outcomes for graduates of these training schemes are rather poor, which is largely due to skills mismatches, with over 60 percent remaining unemployed three years after graduation (World Bank 2007). There have been some projects to implement a dual model of vocational training within the National Skill Development Initiative. The National Skill Development Corporation was set up as a public-private partnership to improve the skills of the growing Indian workforce. It aims at skill training for the private and the unorganized sector covering a wide range of economic activities and providing both co-funding, training standards, quality assurance and support services. Private sector and industry involvement is seen as crucial.

In line with this, as shown in Table 4, the large majority of job seekers registered at the employment exchanges are younger than 30 year old. The National Employment Service Exchange is run by the Directorate General of Employment and Training at the Ministry of Labor. Employment exchanges in various states provide assistance to educated youth to register for future job vacancies on the basis of qualification and experience. Employers can request these exchanges to provide a list of job seekers to choose from the registered candidates as per their requirements. According to the Employment Exchanges (Compulsory Notification of Vacancies) Act, 1959, employers in every establishment in the public sector are required to notify vacancies to employment exchanges. 
Table 4: Number of Job-seekers on the live register of employment exchanges in the country classified by age-group 2004-2008 (in thousands)

\begin{tabular}{|c|c|c|c|c|c|c|c|}
\hline \multirow[b]{2}{*}{ Year } & \multicolumn{6}{|c|}{ Age Groups } & \multirow[b]{2}{*}{ Total } \\
\hline & $15-19$ & $20-29$ & $30-39$ & $40-49$ & $50-59$ & $60+$ & \\
\hline & 8814.2 & 19948.4 & 9443.9 & 1954.3 & 264.6 & 32.3 & 40457.6 \\
\hline 2004 & 21.8 & 49.3 & 23.3 & 4.8 & 0.7 & 0.1 & 100 \\
\hline & 8959.7 & 18867.9 & 9326.3 & 1961.1 & 217 & 15.8 & \\
\hline 2005 & 22.8 & 48 & 23.7 & 5 & $0.6-$ & & 100 \\
\hline & 9204.3 & 19876 & 10099.3 & 1995.5 & 271.1 & 20.4 & \\
\hline 2006 & 22.2 & 47.9 & 24.4 & 4.8 & $0.7-$ & & 100 \\
\hline & 8688.7 & 19221.5 & 9727.5 & 2043.5 & 242.9 & 49.9 & \\
\hline 2007 & 21.7 & 48.1 & 24.3 & 5.1 & 0.6 & 0.1 & 100 \\
\hline & 8317 & 18646 & 9572.7 & 2245 & 264.3 & 67 & \\
\hline 2008 & 21.3 & 47.7 & 24.5 & 5.7 & 0.7 & 0.2 & 100 \\
\hline
\end{tabular}

Source: Employment Exchange Statistics 2010, Directorate General of Employment and Training, Ministry of Labour and Employment, India (http://dget.nic.in/publications/welcome.html).

Training for the informal sector takes place mainly in the form of traditional and informal apprenticeships in a 'hereditary' way where older generations pass their skills on to younger generations either within or outside family ties. This is unlikely to develop the necessary skills for starting up a small business and increase productivity, but rather focuses on the simplest skills, which could explain the large share of youth in casual work rather than self-employment and the poor quality of goods produced in the informal sector (World Bank 2007).

In conclusion, the main problems for the labor market prospects of the Indian youth are:

1. Low levels of general education.

2. Inadequate quality of general education to develop academic skills required by employers.

3. Low enrolment in vocational training and poor match with demands in industrial sector.

4. Low quality of informal vocational training and apprenticeships. 


\subsubsection{China and East Asia}

Key issues:

1. In East Asia youth unemployment is around $10 \%$ but despite the relatively "low" numbers there is a question of in-work poverty.

2. In particular in China the labor market context is characterized by four major interconnected causes: (i) the one child policy, (ii) rural to urban migration, (iii) rise of educational enrollment and (iv) downsizing of state owned enterprises. These factors have created an oversupply of low-skilled workers which have turned to the informal sector. One challenge of training programs is to reach individuals who transit from school to the labor market as well as individuals who work in the informal sector. The Labor Preparation Program is an example of a systematic training program that has tried to do so. While enrollment rates in the program are high there is so far no systematic evaluation about its effectiveness and efficiency.

3. Similarly, in the rest of the region, there is no considerable evidence of vocational training systems and programs. It is difficult to make a judgment of what works and what the challenges are in the area.

4. The training programs that are in act were instituted in the last decade, present indicative evidence of effectiveness but are very limited in their coverage of the youth population.

In the past 20 years, youth unemployment in East Asia constantly exhibit levels that are rather low compared to other regions. Despite youth being hit more by the crisis more the adult population, the labor market has reacted quicker than in other parts of the world. Youth unemployment rate in the region was at about $8.6 \%$ in 2010. The unemployment in the South-East Asia sub-region is even lower, at levels of around $5 \%$ and similarly in the South Asia sub-region economic growth has taken off starting from 2010. The challenges in these regions seem more related to gender inequality and securing productive and decent jobs for the youth (ILO 2011a).

Looking at vocational training in the region, national vocational systems have been present in Asia since the 1960s. However, their extensiveness has been partly developed as a response to the 1998 crises (Betcherman and Islam 2001) with the objective to re-train the unemployed more than to provide the young with a smooth transition from school to work. Figure 11 shows the evolution of vocational training incidence since 1998 (expressed as percentage of enrollment in International Standard Classification of Education -ISCED- level 2 and 3). As it can be seen, the size of vocational training has been steadily around 10\% (simple average of the countries) which correspond to half of the incidence in Germany. However, there seems to be a slight increase in enrollment in recent years. 
Figure 11: Technical/Vocational enrolment in ISCED 2 and 3 as \% of total enrolment in ISCED 2 and 3

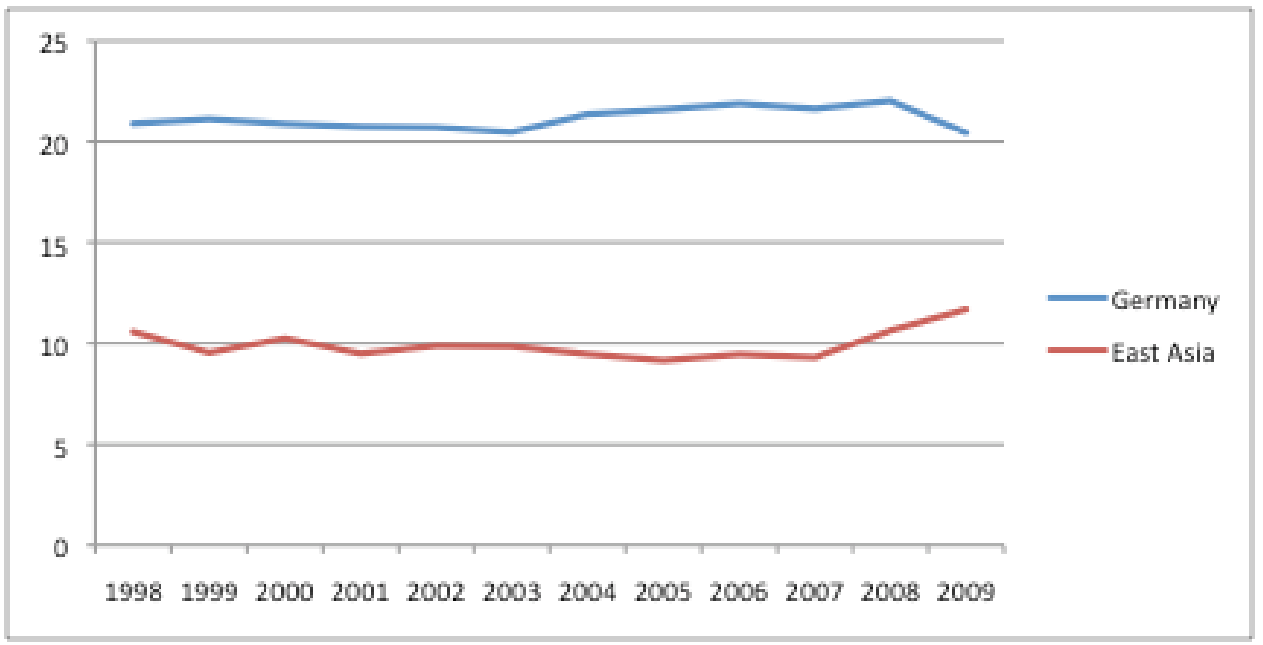

Source: Unesco Institute for Statistics.

These trends and numbers, however, are also far from homogeneous within the region. Figure 12 reports the percentage of technical and vocational enrollment in ISCED 2 and 3 as a percentage of total enrollments at the same levels for a few countries. Within East Asia, there is wide heterogeneity in the importance of vocational training. Enrollment varies from a low level in Vietnam (slightly above 6\% in 2008) to the higher levels of China, Korea and Thailand (about $15 \%$ in 2008). It is apparent then that trends are equally heterogeneous and mostly driven by middle-income countries, while in developed countries such as South Korea we observe a decline in vocational training enrollment. Hence it is difficult to find a clear association between development and vocational training patterns. 
Figure 12: Technical/Vocational enrolment in ISCED 2 and 3 as \% of total enrolment in ISCED 2 and 3 for representative countries, over time

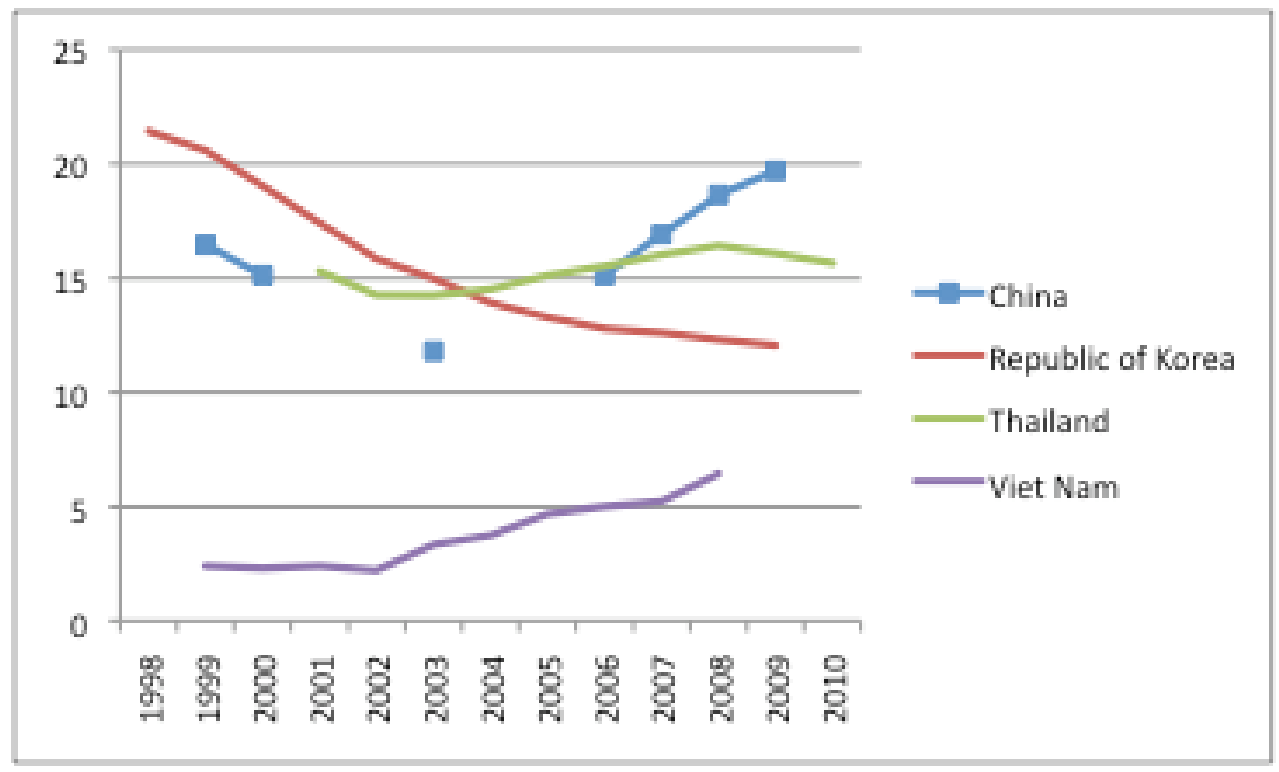

Source: Unesco Institute for Statistics.

It would be interesting to understand whether the existence of national vocational training systems or training programs have contributed to keeping youth unemployment at low levels. Unfortunately, evidence on the effectiveness of these systems is lacking. Stavreska (2006) reports that out of 21 labor market programs targeted to youth, 9 were vocational training programs. Financing primarily comes from the government and other sources, such as international institutions (UNIDO, UNDP, JFPR, Asian Development Bank, Swiss agency for developing cooperation), or self-generated funds. However, there are two main shortcomings of these interventions. First, overall these programs seem to have small coverage and have had an impact on average on only a few thousand individuals in each country. Second, sound impact evaluations are missing (Stavreska 2006) and the effectiveness and quality of the interventions are primarily evaluated with case studied or surveys conducted on voluntary basis. Therefore it is difficult to draw conclusions on what works in this area and on whether vocational training would be effective in improving the youth conditions. Below, however, are reported examples of programs instituted in a few countries.

1. China: Labor Preparation Program. This program consists of a minimum of one to a maximum of three years of vocational education and training with the aim of improving employability and of young individuals who want to start non-agricultural jobs. After 1998, when the program was piloted in only a few Chinese provinces, it has been extended to the whole China, and covers individual with completed primary or secondary education, in both rural and urban areas (MOLSS 2003). The duration of the program typically depends on the education degree of the participants, as well as on the level of training sought (basic, intermediate or high). As of 2000, the program involved more than 
1.3million participants. To the best of our knowledge, the program has not been evaluated to date.

2. Maldives: Employment skills project. Provides employment-oriented skills, aiming to train about 6000 youth, half of which female.

3. Nepal: Franchising SKILL, Training for employment project. Delivers training for disadvantaged youth. Started in 2003 , it has provided training to over 20,000 youth. The program website reports that $84 \%$ of the participants are now employed in various sectors. The program provides training based on manuals and curriculum guidelines developed in collaboration with the National Skills Testing Board. These training materials are franchised to entrepreneurs throughout the country. The franchisee conducts training and employs the graduate either directly or finds employment in the country or overseas.

4. Philippines: Working for Youth. The Dual Training System is adopted in accredited vocational and technical schools in the country (UN 2000). The Technical Education Skills Development Authority (TESDA) is the agency responsible for offering courses in 15 regional training centers. The agency also promotes the dual training system and the apprenticeship program and leadership program. In 1997, for example, a total of 23,278 individuals were registered as apprentices (UN 2000). It should be noted that this agency is considered by the Constitution as managing the non-formal education in the country, therefore vocational training has a marginal position in the educational system. Further, no data are available on the success of people undertaking vocational training and vocational training is mostly present in occupations that are traditionally male oriented (UN 2000).

5. Samoa: Opportunity for Vulnerable Poor Youth. This program supports informal and vocational training activities for unemployed youth to improve their earning opportunities and self-identity.

6. Vietnam: Training for Disadvantaged Youth (КОTO). KOTO is a non-profit restaurant and vocational training program. Every six months around 25 people between 16 and 22 are provided training in the hospitability industry. The program lasts 24 months and the training takes place partly in two non-profit restaurants party in training centers (Youth Employment Inventory). No impact evaluations are available for this program. 


\section{Conclusion and Policy Recommendations}

\subsection{Major lessons from the comparison}

Several factors influence the labor market situation of youth in a country: On the one hand, the interplay between demographic developments, economic growth and labor market regulations regarding wages and employment protection determines the aggregate demand and supply for young workers; and on the other hand, the education and training system influence the speed and quality of the matching that takes place between youth and employers. Accompanying policies such as active labor market polices and career guidance services are important elements for yielding a more smooth linkage between school and training at a first step and training and work at the second step, and avoiding long spells of unemployment.

In this paper our focus lies on the education system as necessary precondition for the employability and productivity of young people.Education clearly matters. General education and vocational education and training are crucial in making young people employable at a higher level of productivity. Education and training are core drivers for economic progress. There is strong evidence that more and better general education raises the chances of finding good jobs and stable employment and reduces the risk of unemployment.

When distinguishing between general education as a foundation and vocational education and training as an additional component, empirical facts show that vocational skills bring additional benefits to young people as their employability is improved - assuming that vocational education is providing relevant skills matching employer demands. Acquiring occupation-specific skills and firm-related work experience helps establish closer links with the labor market and facilitate the transition into employment. Furthermore, one can make the case for dual apprenticeships as a particularly effective mode of vocational training compared to school-based vocational education on the one hand and more or less unstructured learning on-the-job. Comparative and national evidence suggests that vocational training can bring additional benefits substantially different, but also complementary to general education.

In this paper, we have seen that vocational systems ought to combine national education frameworks and quality standards with expertise of the private sector and local stakeholders to adapt the training system to changing needs. There are at least three "general principles" that successful training policies would need to follow. First, a clear understanding of what the market and government failures and skills gaps are; second, making sure providers (public or private) have the incentives to respond to market demands and ensure quality (which often has to do with contracting and payment systems and not simply "involving employers" or "creating partnerships; third, ALMP schemes targeting the unemployed as well as early interventions for the youth at risk can be complementary actions to training systems in place for the workers. Vocational education and training exhibits highly diverse features in different world regions. Taking a comparative perspective, there is some robust evidence that combining work experience with training on the job and general occupational skills (certificates) helps bring down unemployment of young people and helps create stable employment prospects, resulting in more 
time spent in employment after leaving school and in higher rates of successful transition. In particular the 'German model' of dual vocational training seems to be an operative model of training that raises not only employability of individuals but also productivity, seems conducive to stable employment and to firms' competitiveness. Yet, most other countries also have some forms of vocational training, often involving mainly schools-based vocational education and more traditional forms of apprenticeships and learning on the job.

Experiences with the introduction of more 'modern' and formalized models of vocational training in particular in developing countries, but also elsewhere show that establishing such systems is contingent upon a set of specific institutional and socio-economic conditions, in particular support by core actors such as governments, firms and employer associations as well as trade unions, young people and their families. An ideal-type of a dual vocational training model along the lines of the German arrangement relies on a number of demanding preconditions:

1. support from employers (and their associations) regarding their willingness to provide training in a systematic fashion and certify it, seeing training as investment in favor of competitiveness, productivity, and to open up sustainable employment prospects,

2. support from young people, trade unions (and parents), accepting apprenticeship as a phase of lower earnings in exchange for skill acquisition so that it is not seen as inferior to academic training,

3. Provision of vocational schooling, including funding, a regulatory framework (by government and/or employers) and monitoring to ensure timely adaptation and labor market relevance of training curricula.

Formalized dual apprenticeship systems seem particularly effective in preparing young people for employment, but such complex vocational training systems are not easily implemented and transferred. Obviously, governance and involvement of core actors play a crucial role, in particular government at different levels, employers' associations and unions, in the design and implementation of vocational training. Organizational capacities of governments and social partners are crucial. A critical mass of supply and demand cannot be created artificially and needs time to develop.

This explains why a highly complex system such as the German model of dual vocational training has hardly been transplanted at a significant scale outside continental Europe. Yet, better vocational training can play a crucial role in economic and social development if models are developed that work in a given context. As most countries have some forms of vocational training - formal or informal, school-based, firm-based or mixed - they are well advised to start with those elements and reform their systems to bring vocational education and training closer to labor market needs.

Feasible vocational training needs to be adapted to local economic conditions and labor market institutions to make the most out of it. This requires an assessment of existing preconditions and experiences so that better vocational training can be built upon existing framework conditions. In particular, some experiences with pilot projects, regional or sectoral clusters of employers or traditional apprenticeships can be instructive. The main challenge is to make on-the- 
job learning more systematic and to bring school-based vocational training or general education closer to labor market needs. To achieve this, employer participation and some more systematic vocational training are crucial.

\subsection{Some general needs for action}

Challenges, but also capacities to act vary across countries and world region, depending on economic, institutional and societal context. Yet, there are some general points to be made which are relevant for most of the countries.

\section{Promoting general education}

In many low- and medium income countries, policies to ensure primary and secondary school attendance, avoid early school drop-outs and leaving school at low levels of qualification are needed. Policy makers should aim at providing basic skills to every young person by compulsory participation in support classes and intensified personal support. This implies stronger emphasis on individualized, tailored support to young people at risk, educational guidance, job search assistance (also considering incentives to parents such as conditional cash transfers). In some countries this could also mean longer statutory schooling to achieve upper secondary educational level, in particular by involving girls.

\section{Stimulate the creation of formal and sustainable jobs}

In countries where high shares of informal employment form a major barrier to upward mobility and economic progress policies should be designed to create more enterprises in the formal sector which offer formal jobs. This can be addressed by economic policy reforms such as the abolition of bureaucratic business registration procedures, tax reforms, stimulating investment in the private sector and creation of formal companies start-up support. In countries with a large segment of fixed-term contracts with limited access to training and promotion to more stable jobs, overcoming the regulatory divide between permanent and temporary jobs is the major priority. This can best be achieved by creating a flexible system of employment protection easing the barriers between fixed-term and permanent jobs.

\section{Modernize vocational schooling}

Many countries should strengthen the vocational part of their educational or schooling system and bring existing vocational education and training systems closer to the current needs of the 
labor market so that young people can experience a smoother transition to jobs. In particular, vocational education provided in the framework of secondary schooling (vocational schools or vocational tracks) should be modernized and complemented with phases of practical work experience, e.g. via internships or passing the final year with an employer. Employers should also be consulted regarding the design of vocational schooling curricula. This requires a systematic coordination with networks or associations of employers. Furthermore, in order to avoid a negative perception of vocational education as a dead-end option, transition to further education, including tertiary education, should be facilitated. Finally, in some countries reducing vocational education fees can help raise enrollment.

\section{Bring academic education closer to the private sector}

In countries with high shares of university graduates with major difficulties in finding adequate jobs a major option is to make academic training more labor market-oriented, incorporating internships with employers into academic curricula so that some experience with current work practices in the private sector can be acquired. Governments responsible for funding academic education can require public universities to modify academic curricula accordingly.

\section{Starting from regional or sectoral clusters}

As can be seen from many examples in the developing world even under adverse conditions, some elements of (dual) vocational training can be implemented - and with sufficient support and interest from governments and employers regional or sectoral training clusters can be established. Most countries could therefore implement feasible or 'lighter' forms of dual vocational training with limited institutional requirements. Starting points could be existing sectoral or regional clusters of firms with a shared interest in a specifically skilled labor force in particularly relevant occupations, larger (also foreign-owned) firms in modern sectors or sectoral training schemes run by employer associations. Where there is a basic agreement on training curricula and training provision this can lead to mutually recognized certificates; public support would be helpful such as support for schooling phases and some non-bureaucratic regulation of training elements and standards so that acquired skills can be recognized.

\section{Upgrading vocational training in the informal sector}

Providing better training for the informal sector is a core issue for many developing countries (ILO 2012). In countries where traditional or informal apprenticeships are dominant, but mainly confined to traditional crafts, these apprenticeships should be articulated better with the schooling system and the formal sector. They should also be opened up to new technologies 
and occupational change. This, of course, requires some recognition of informal employment as part of the economic and social reality in many countries.

A first option is to bring societal initiatives aimed at better training closer to the informal sector, family business and local networks. A concrete step could be to encourage informal workers and employers to participate in training activities, e.g. by providing informal apprentices with some vocational schooling focusing on more general skills and theoretical aspects. Participation in vocational courses for young people working in the informal sector could be increased by setting some incentives to participants and employers, in particular compensating for hours not worked because of training courses. To avoid deterrence, these courses should not be delivered by governments directly but rather by NGOs, churches or non-profit associations with sufficient acceptance and in-depth knowledge of the economic situation in local communities. Involving larger employers or (formal) training centers is another option. Funding may come from governments and international donors. NGOs, churches or other non-profit associations can also facilitate the creation of (informal) associations or networks of informal employers.

Given the fact that traditional or informal apprenticeships tend to be restricted to a number of traditional craft, raising productivity and potentials for innovation is crucial. Experiences from the African continent show that master craftsmen benefit from skill upgrading courses so that they can better develop their businesses and become more innovative and productive. They also benefit from better access to technical equipment and capital, which should be made more easily accessible to informal firms.

Furthermore, some experiences from Sub-Saharan Africa show that ensuring skill recognition outside the local community by some sort of official skill testing open to informal apprenticeship graduates raises the attractiveness of these training courses and enhances mobility on the job market.

\section{Extend career and educational guidance services for youth}

The successful implementation of vocational training risks to be stifled by the low level of acceptance among the population that perceives vocational training as inferior type of professional education. While part of these prejudices may be related to the low level of development of vocational training structures, they are also often rooted in traditional and out-dated perceptions on the returns to public sector employment and/or certain types of higher tertiary education. Targeted initiatives that inform youth and their parents about current and expected labor market opportunities and the benefits of vocational schooling may therefore be crucial supporting initiatives to the extension of vocational training. In the design of these measures, the cultural background should be taken into account. In particular, the ability of independent decision making of youth is often limited in community oriented societies. Besides a strong involvement of the local community, it should be considered to train the decision-making abilities of school-leavers by integrating broader career and educational guidance services in regular school curricula in the medium to long run. 


\section{Data and evaluation}

Finally, research into the effects of vocational training and related ALMPs would benefit enormously from the availability of better data and a suitable program design allowing for the proper evaluation of policy initiatives. Regarding data, the generation of representative survey data, in particular longitudinal data with a full set of individual characteristics, is essential. Training and ALMP programs should be accompanied by a systematic collection of evaluation data.

\subsection{Policy recommendations for different types of countries}

Regarding the further development of vocational education and training policy action should take into account the main challenges in particular country clusters in order to be successful.

\section{Germany and its neighbor countries}

Regarding Germany and its neighbor countries where dual vocational training systems exist and continue to be the most important pathway from school to work the main policy priority is to ensure continued support from employers by adapting the system in time to changing economic conditions and requirements. Of course, the German type of dual vocational training is facing the challenge of timely adaptation and updating of training curricula to newly emerging technologies and occupations. In a labor market characterized by accelerating change, emphasizing general skills and adopting a more modular approach to initial and continuous training is required in order to avoid an early and narrow specialization which hampers job and occupational mobility later in life. Furthermore, reinforcing general education to make all young people able to participate in the labor market and to pass the first hurdle at entering vocational training is essential. Preparatory systems within the realm of ALMPs must be made most effective in bringing young people closer to employment or training. Misallocation of resources and youths in artificial types of jobs and training should be avoided.

\section{Mediterranean countries}

In the Mediterranean countries, in particular Spain, barriers between different types of employment contracts, which lead to a deep segmentation of the labor market, need to be eased, e.g. by establishing a more universal, but flexible type of contract. In those countries it is also very important to reduce the large share of early school leavers. Given the mismatch between formal education and actual labor market needs it is essential to bring university graduates closer to private employers, in particular via regular internships and other forms of work experience. Attempts at establishing (dual) vocational training will required the involvement of employers. Here, large firms and existing regional networks can be activated. Existing vocation training schemes at the secondary and the tertiary level can also be strengthened. In principle it 
seems possible to mobilize some social partner support and to set some incentives by the government to provide training in a systematic fashion. This strategy is probably more effective than expanding subsidized temporary contracts or apprenticeships.

\section{Anglo-Saxon countries}

Anglo-Saxon countries with a clear distinction between general education (and vocational schooling) and learning on-the-job need to improve general education and school completion rates. Furthermore, it should be possible to bring in a more systematic character into learning on-the-job. Existing sectoral models of vocational training can in principle be extended to areas outside manufacturing and crafts.

\section{Transition countries}

Transition economies can build upon existing elements of vocational training that continue to exist in some countries. At the same time, a better articulation between universities, vocational schools and employers seems feasible given that such an infrastructure is in principle available. Provide better general and additional vocational schooling to non-academics would help ease bottlenecks and skills shortages in these labor markets.

\section{Middle East and North Africa}

In the MENA region, stimulating private sector activities and enterprise creation is essential to promote job creation in the formal private sector. This requires de-bureaucratization of business regulations, start-up support and changes in the taxation system as well as labor law. Furthermore, general upper secondary and tertiary education should be redesigned to facilitate careers in the private sector rather than prepare for public employment. This would mean to establish links between employers and school-based vocational education, which is under current modernization in some countries, and to bring employers and university graduates together, e.g. via regular internships. Existing models of dual vocational training, often developed with foreign support, show some potential, but remain limited to narrow regions and sectors. They could in principle be transferred to other regions and sectors if employers support this.

\section{Sub-Saharan and South Africa}

In Sub-Saharan and South Africa, apart from stimulating enterprise and job creation in the formal private sector, a prior policy objective still is to expand general education and ensure participation and attendance there as schooling provides basic skills which are required to further educational progress. In some countries, projects to establish formal dual vocational training have already been started in the past and could be extended to other regions or sectors, based on employers' interest and support. Most importantly, informal or traditional apprenticeships still play a dominant role in bringing young people into jobs as vocational schooling lacks acceptance. These informal apprenticeships could be upgraded in order to mobilize their devel- 
opmental potential as recent experiences show. First, informal apprentices could benefit from participation in some courses. Second, master craftsmen would benefit from further education to make them familiar with new technologies and from granting them easier access to credit and modern equipment. Third, NGOs and local networks could support the creation of associations of informal employers which would help disseminate knowledge, promote innovations and lead to some agreement regarding the structure of informal apprenticeships as well as the recognition of skills acquired through informal apprenticeships. Skills testing of informal apprentices by formal business associations or government bodies would enhance mobility to the formal sector.

\section{Latin America}

In Latin American countries a main policy priority is to modernize existing, but dated vocational training schemes so that they can be major contributor to economic growth and societal development. Adapting these systems to the current needs of employers in a major issue as vocational training in many Latin American countries are still tailored to the economic structures of the past. Modernization can continue to build upon those models that are run by employers and employer associations but requires an expansion to new and dynamically growing sectors. As with other regions, bringing some simplified forms of vocational education to the informal sector is important in Latin America as well.

\section{South and East Asia}

Fostering vocational training in South and East Asia could be seen as an important channel for improving working conditions of young individuals who have a job and to further boost the employability of those more vulnerable (such as low skilled). A major objective is to expand the vocational education especially in those countries where its incidence is rather low (e.g., India and Vietnam). In countries where vocational education is marginally present, it should be proactively promoted to further boost participation of young individuals. Training programs should have ample geographic coverage, especially in countries where the rural-urban divide is still substantial. Piloting of a "dual system"" is also desirable - at least in countries where prerequisites exist. This should be initiated by implementing a systematic approach to bring the education system near to the private sector. In general, also based on lack of current evidence, the expansion of training and vocational education should be accompanied by a systematic evaluation of programs and initiatives in order to understand what works. 


\section{References}

Abowd, John M.; Kramarz, Francis; Lemieux, Thomas; Margolis, David N. (2000): Minimum Wages and Youth Employment in France and the United States, NBER Chapters, in: Youth Employment and Joblessness in Advanced Countries, 427-472 NBER.

Adams, Avril V. (2010): The Mubarak Kohl Initiative - Dual System in Egypt. An assessment of its impact on the school to work transition.

Adda, Jerome; Dustmann, Christian; Meghir, Costas; Robin, Jean-Marc (2011): Career Progression and Formal versus On-the-Job Training, Mimeo.

Aedo, Cristian; Pizarro, Marcelo (2004): Rentabilidad económica del programa de capacitación laboral de jóvenes Chile Joven, Mimeo.

Aedo, Cristian; Nunes, Sergio (2001): The impact of training policies in Latin America and the Caribbean: the Case of Programa Joven, ILADES and Georgetown University, May 2001.

Aggarwal, Ashwani; Hofmann, Christine; Phiri, Alexander (2010): A study on informal apprenticeship in Malawi, Employment Sector Employment Report 9/2010.

Ahadzie, William (2009): The Traditional Informal Apprenticeship System of West Africa as Preparation for Work, in: Maclean, Rupert; Wilson, David N. (eds.): International Handbook of Education for the Changing World of Work, Springer.

Alet, Elodie; Bonnal, Liliane (2011): Vocational schooling and educational success: comparing apprenticeship to full-time vocational high school, Mimeo.

Angel-Urdinola, Diego F.; Semlali, Amina; Brodmann, Stefanie (2010): Non-Public Provision of Active Labor Market Programs in Arab-Mediterranean Countries: An Inventory of Youth Programs, World Bank.

Assaad, Ragui; Roudi-Fahimi, Frazaneh (2007): Youth in the Middle East and North Africa: Demographic opportunity or challenge?, Reference Bureau MENA Policy Brief, April.

Atchoarena, David; Delluc, André M. (2001): Revisiting Technical and Vocational Education and Training in Sub-Saharan Africa, IIEP Paris.

Attanasio, Orazio; Kugler, Adriana; Meghir, Costas (2011): Subsidizing Vocational Training for Disadvantaged Youth in Colombia: Evidence from a Randomized Trial, American Economic Journal 3 (3), 188-220.

Audas, Rick;Berde, Éva; Dolton, Peter (2005): Youth unemployment and labour market transitions in Hungary, Education Economics13: 1-25.

Awogbenle, A. Cyril; Iwuamadi, K. Chijioke (2010): Youth unemployment: Entrepreneurship development programme as an intervention mechanism, African Journal of Business Management 4 (6), 831-835.

Bardak, Ummuhan (2006): An overview of educational systems and labour markets in the Mediterranean region, Mediterranean Journal of Educational Studies, Vol. 11, 1, pp. 103-125.

Bardak, Ummuhan; Huitfeldt, Henrik; Wahba, Jackline (2006): Employment policy reforms in the Middle East and North Africa: Selected Issues on the Functioning of the Labour Market, Turin: European Training Foundation. 
Bartlett, Will (2007): Economic restructuring, job creation and the changing demand for skills in the Western Balkans, in: Fetsi, Anastasia (ed.): Labour Markets in the Western Balkans: Challenges for the Future, Turin: European Training Foundation, pp. 19-50.

Bartlett, Will (2009): The effectiveness of vocational education in promoting equity and occupational mobility amongst young people, Economic Annals, LIV(180): 7-39.

Bassanini, Andrea; Duval, Romain (2006): Employment Patterns in OECD Countries: Reassessing the Role of Policies and Institutions, OECD Social, Employment and Migration Working Paper 35.

Bejaković, Predrag (2004): How prepared is Croatia for a knowledge-based society? In:Ott, Katarina (ed.),Croatian Accession to the European Union: Facing the challenges of negotiations, Vol. 3, Zagreb: Institute of Public Finance, pp. 109-128.

Bell, David N.F.; Blanchflower, David G. (2011b): Young People and the Great Recession, IZA Discussion Paper 5674.

Bentolila, Samuel; Cahuc, Pierre; Dolado, Juan José ; Le Barbanchon, Thomas (2010): Two-Tier Labor Markets in the Great Recession: France vs. Spain, IZA Discussion Paper 5340.

Bernabè, Sabine (2002): A Profile of Informal Employment: The Case of Georgia, ILOEmployment Sector working paper no. 2002/9, ILO, Geneva.

Bertschy, Kathrin; Cattaneo, M. Alejandra; Wolter, Stefan C. (2009): PISA and the Transition into the Labour Market, Labour Vol. 23 (Special Issue) pp. 111-137.

Betcherman, Gordon; Islam, Rizwanul(2001): East Asian Labor Markets and the Economic Crisis. Impacts Responses and Lessons, World Bank and ILO.

Betcherman, Gordon; Godfrey, Martin; Puerto, Susana; Rother, Friederike; Stavreska, Antoneta (2007): A review of interventions to support young workers: Findings of the youth employment inventory, World Bank Social Protection Discussion Paper 0715.

Binzel, Christine (2011): Decline in Social Mobility: Unfulfilled Aspirations among Egypt's Educated Youth, IZA Discussion Paper 6139.

Blanchflower, David G.; Freeman, Richard B. (2000): The Declining Economic Status of Young Workers in OECD Countries, in: Blanchflower, David G.; Freeman, Richard B. (eds.): Youth employment and joblessness in advanced countries, Chicago, 19-55.

BMBF (Bundesministerium für Bildung und Forschung)(2009) (ed.)Datenreport zum Berufsbildungsbericht 2009 - Informationen und Analysen zur Entwicklung der beruflichen Bildung,Bonn. Berlin, 2009.

BMBF (Bundesministerium für Bildung und Forschung)(2011) (ed.)Datenreport zum Berufsbildungsbericht 2009 - Informationen und Analysen zur Entwicklung der beruflichen Bildung,Bonn. Berlin, 2011.

Boeri, Tito (2000):Structural Change, Welfare Systems, and Labour Reallocation: lessons from the transition of formerly planned economies, Oxford: Oxford University Press.

Boeri, Tito; Terrell, Katherine (2002): Institutional Determinants of Labor Reallocation in Transition, Journal of Economic Perspectives, 16(1): 51-76.

Bonnal, Liliane; Mendes, Sylvie; Sofer, Catherine (2002): School-to-work transition: apprenticeship versus vocational school in France, International Journal of Manpower, Vol. 23 Nr. 5, pp. 426-442. 
Bouhlila, Donia Smaali (2011): The quality of secondary education in the Middle East and North Africa: what can we learn from TIMSS' results?, Journal of Comparative and International Education, 41, 3, pp. $327-352$.

Bover, Olympia; Gómez, Ramón (2004): Another Look at Unemployment Duration: Exit to a Permanent Job vs. a Temporary Job, Investigaciones Economicas, 28(2): 285-314.

Bukodi, Erzsébet; Róbert, Péter (forthcoming):Education and labor market entry in transition: the case of Hungary. In: Kogan, Irena et al. Making the Transition. Education and labor market entry in Central and Eastern Europe. Stanford: Stanford University Press: forthcoming.

Bundesministerium für Arbeit und Soziales (Ed.) (2010): Vorstudie zur Evaluation von Fördermaßnahmen für Jugendliche im SGB II und SGB III.

Caliendo, Marco; Künn, Steffen; Schmidl, Ricarda (2011): Fighting Youth Unemployment: The Effects of Active Labor Market Policies, IZA Discussion Paper 6222.

Card, David; Kluve, Jochen; Weber, Andrea (2010): Active Labor Market Policy Evaluations: A MetaAnalysis, The Economic Journal 2010, 120, F452-F477.

Card, David et al. (2011): The Labor Market Impacts of Youth Training in the Dominican Republic, Journal of Labor Economics, 29 (2), 267-300.

CEDEFOP (2010): Employer-provided vocational training in Europe.

CEDEFOP (2011a): España, Una Mirada a la Formación Professional.

CEDEFOP (2011b): VET in Europe - Country Report France.

CEDEFOP (2011c): VET in Europe - Country Report Italy.

Chabaan, Jad (2009): Youth development in the Arab countries: The need for a different approach, Middle Eastern Studies, 45, 1, pp. 33-55.

Cho, Yoonyoung; Newhouse, David; Margolis, David; Robalino, David (forthcoming): Labor Markets in Middle and Low Income Countries Trends and Implications for Social Protection and Labor Policies, World Bank Social Protection Discussion Paper.

CINTERFOR, Centro Interamericanopara el Desarollo del Conocimiento en la Formacion Professional (2008): Recent evolution and future prospects for technical cooperation in vocational training in Latin America and the Caribbean, Discussion Paper prepared for the Technical Meeting Technical Cooperation in the Development of Vocational Training in Latin America and the Caribbean, Buenos Aires.

Cling, Jean-Pierre; Gubert, Flore; Nordman, Christophe J.; Robillard, Anne-Sophie (2007): Youth and Labour Markets in Africa - A critical review of literature, Agence Francaise de Développement, Paris.

Commander, Simon; Kollo, Janos (2004): The Changing Demand for Skills: Evidence from the Transition, IZA Discusission Paper 1073.

Coupé, Tom; Vakhitova, Hanna (2011): Recent Dynamics of Returns to Education in Transition Countries, Kyiv School of Economics Discussion Paper No. 39.

Crissey, Sarah R. (2009): Educational attainment in the United States: 2007, U.S. Census Bureau.

Cuddy, Natalia; Leney, Tom (2005): Berufsbildung im Vereinigten Königreich,Kurzbeschreibung, Cedefop Panorama Series 112, Luxembourg. 
Danish Ministry of Education (2008): The Danish Vocational Training and Education System, $2^{\text {nd }}$ edition, Copenhagen.

De Giorgi, Giacomo (2005): Long-term Effects of a Mandatory Multistage Program: The New Deal for Young People in the UK, Institute for Fiscal Studies Working Paper 0508.

De Moura Castro, Claudio; Verdisco, Aimee (1998): Training Unemployed Youth in Latin America: Same Old Sad Story?, Inter-American Development Bank, Washington D.C.

Denu, Berhanu; Tekeste, Abraham; van der Deijl, Hannah (2005): Characteristics and determinants of youth unemployment, underemployment and inadequate employment in Ethiopia, ILO Employment Policies Unit, Employment Strategy Paper 2005/07.

Department for International Development (DFID) (2007): Technical and vocational skills development, Briefing.

Díaz, Juan José; Jaramillo, Miguel (2006): Evaluation of the Peruvian "Youth Labor Training Program ProJoven", Working Paper, October, Grupo de Analisis para el Desarrollo, GRADE, Lima.

Didibhuku Thwala, Wellington (2011): Public works programmes as a tool to address unemployment and skills shortages among the youth in South Africa, African Journal of Business Management 5 (15), 6011-6020.

Dionisos, Regina; Muehlemann, Samuel; Pfeiffer, Harald; Walden, Günter; Wenzelmann, Felix; Wolter, Stefan C. (2009): Costs and benefits of apprenticeship training - A comparison of Germany and Switzerland, Applied Economics Quarterly 55(1), pp. 5-38.

Dolado, Juan J.; Felgueroso, Florentino; Jimeno, Juan F. (2000): Youth labour markets in Spain: Education, training, and crowding-out, European Economic Review 44 (4-6), 943-956.

Eamets, Raul; Masso, Jaan (2005): The Paradox of the Baltic States: Labour Market Flexibility but Protected Workers? European Journal of Industrial Relations, 11(1):71-90.

Ebner, Christian (2009): Neue Wege für die duale Berufsausbildung - Ein Blick auf Österreich, die Schweiz und Dänemark,WZB Brief Arbeit, Nr. 4.

ETF (forthcoming): Transition from education to work in EU Neighbouring Countries, ETF, Turin.

European Commission (2006): European Employment Observatory, Review: Spring 2005,DirectorateGeneral for Employment, Social Affairs and Equal Opportunities, Brussels.

Felgueroso, Florentino (2010): Reforma Laboral y Empleo Juvenil, El Comercio.es 25 June.

Fedorets, Alexandra; Spitz-Oener, Alexandra (2011): Flexibility and adaptability of the employees with a dual vocational training degree, Journal for Labour Market Research 44 (1-2), 127-134

García, Juan Ramón (2011): Youth unemployment in Spain: causes and solution, BBVA Research Working Paper 11/31.

Garcia, Marito; Fares, Jean (2008a): Why is it important for Africa to invest in its youth?, in: Garcia, Marito; Fares, Jean (eds.): Youth in Africa's Labor Market, World Bank, 3-14.

Garcia, Marito; Fares, Jean (2008b): Transition to Working Life for Africa's Youth, in: Garcia, Marito; Fares, Jean (eds.): Youth in Africa's Labor Market, World Bank, 15-25.

Garcia, Marito; Fares, Jean (2008c): The Effect of Education on Income and Employment, in: Garcia, Marito; Fares, Jean (eds.): Youth in Africa's Labor Market, World Bank, 39-47. 
Gomez-Salvador, Ramon; Leiner-Killinger, Nadine (2008): An analysis of youth unemployment in the euro area, ECB Occasional Paper 89.

Government of India (2011): Key Indicators of Employment and Unemployment in India, 2009-2010, National Statistical Organization, June.

Guarcello, Lorenzo et al. (2008): School-to-Work Transitions: Regional Overview, in: Garcia, Marito; Fares, Jean (eds.): Youth in Africa's Labor Market, World Bank, 109- 146.

Guarcello, Lorenzo; Lyon, Scott; Rosati, Furio (2008): Child Labor and Youth Employment in Ethiopia, in: Garcia, Marito; Fares, Jean (eds.): Youth in Africa's Labor Market, World Bank, 181-223.

Güell, Maia; Petrongolo, Barbara (2007): How Binding are Legal Limits? Transitions from Temporary to Permanent Work in Spain, Labour Economics 14, 153-183.

Hanushek, Eric A.; Woessmann, Ludger; Zhang, Lei (2011): General Education, Vocational Education and Labor Market Outcomes over the Life-Cycle, IZA Discussion Paper 6083.

Heckman, James J. (2000): Policies to foster human capital, Research in Economics 54 (1), 3-56.

Heynemann, Stephen P. (1997): The quality of education in the Middle East and North Africa (MENA), International Journal of Educational Development, Vol. 17, 4, pp. 449-466.

Hippach-Schneider, Ute; Krause, Martina; Woll, Christian (2007): Vocational Education and Training in Germany - Short Description, Cedefop Panorama Series 138, Office for Official Publications of the European Communities

Hoeckel, Kathrin (2008): Costs and Benefits in Vocational Education and Training, OECD Education.

Hoeckel, Kathrin; Schwartz, Robert (2010): Learning for Jobs - OECD Reviews of Vocational Education and Training - Germany, OECD

Huitfeldt, Henrik; Kabbani, Nader (2006): Returns to Education and the transition from school to work in Syria, Mimeo, paper presented at the $12^{\text {th }}$ annual conference of the Economic Research Forum in Cairo.

Ibarrarán, Pablo; Rosas Shady, David (2009): Evaluating the Impact of Job Training Programs in Latin America: Evidence from IDB funded operations, Journal of Development Effectiveness, 1 (2), 195216.

ILO (2006): Career Guidance: An International Resource Handbook. Geneva: ILO.

ILO (2010a): Trabajo Decente y Juventud en América Latina, Avance, February.

ILO (2010b): Global Employment Trends for Youth, Special issue on the impact of the global economic crisis on youth, August.

ILO (2011a): Global Employment Trends for Youth: 2011 update.

ILO (2011b): Upgrading Informal Apprenticeship Systems, ILO Policy Brief.

ILO (2012): Upgrading informal apprenticeship, A resource guide for Africa, ILO.

International Youth Foundation (2011a): Youth Empowerment Program Evaluation Report: Kenya - Informal Sector Business Institute.

International Youth Foundation (2011b): Youth Empowerment Program Evaluation Report: Senegal Synapse Center. 
Jütting, Johannes P.; de Laiglesia, Juan R. (2009) (eds.): Is informal normal?Towards more and better jobs in developing countries, OECD Development Centre.

Kabbani, Nader; Kothari, Ekta (2005): Youth Employment in the MENA Region: A Situational Assessment, World Bank, Social Protection Discussion Paper No. 0534.

Kabbani, Nader; Al-Habash, Leen (2008): Raising awareness of alternatives to public sector employment among Syrian youth, Economic Research Forum, Working Paper No. 387.

Klasen, Stephan; Pieters, Janneke (2011): Drivers of female labor force participation in urban India during India's Economic Boom, Proceedings of the German Development Economics Conference, Berlin.

KMK - Sekretariat der ständigen Konferenz der Kultusminister der Länder der Bundesrepublik Deutschland (2011): Synoptische Darstellung der in den Ländern bestehenden Möglichkeiten des Hochschulzugangs für beruflich qualifizierte Bewerber ohne schulische Hochschulzugangsberechtigung auf der Grundlage hochschulrechtlicher Regelungen

Koettl, Johannes; Oral, Isil; Santos, Indhira (2011): Employment Recovery in Europe and Central Asia, Knowledge Brief, special issue No. 1,World Bank, Washington.

Kolev, Alexandre; Saget, Catherine (2005): Towards a Better Understanding of the Nature, Causes and Consequences of Youth Labor Market Disadvantage: Evidence for South-East Europe, Social Protection Discussion Paper no. 0502, World Bank, Washington D.C.

Kolos, T.;Tóth, I.;Vukovich, G. (1999):Social Report 1998(TÁRKI).

Korenman, Sanders; Neumark, David (2000): Cohort crowding and youth labor markets: a cross-national analysis, in: Blanchflower, David G.; Freeman, Richard B. (eds.): Youth employment and joblessness in advanced countries, Chicago, 57-105.

Kotzeva, Mariana; Pauna, Bianka (2006): Labour Market Dynamics and Characteristics in Bulgaria and Romania - Challenges for a Successful Integration in the European Union, Global Development Network.

Krueger, Dirk; Kumar, Krishna, B. (2004): Skill-specific rather than general education: A reason for USEurope Growth Differences?, Journal of Economic Growth, Vol. 9, pp. 167-207

La Cava, Gloria; Lytle, Paula; Kolev, Alexandre (2006): Young People in South Eastern Europe: From Risk to Empowerment, World Bank, Washington D.C.

Lacuesta, Aitor; Izquierdo, Mario (2006): Wage Inequality in Spain: Recent Developments, Working Paper no 615, Banco de España.

Lahire, Nathalie; Johanson, Richard; Wilcox, Ryoko Tomita (2011): Youth Employment and Skills Development in the The Gambia, World Bank.

Lam, David; Leibbrandt, Murray; Mlatsheni, Cecil (2008): Education and Youth Unemployment in South Africa, SALDRU Working Paper 22.

Lam, David; Ardington, Cally; Leibbrandt, Murray (2007): Schooling as a lottery: Racial differences in school advancement in urban South Africa,SALDRU Working Paper 18.

Lamb, Stephen (2011): Pathways to School Completion: An international comparison. In S. Lamb et al. (Eds.), School Dropout and Completion: International Comparative Studies in Theory and Policy, Springer 2011 
Lehmann, Hartmut; Muravyev, Alexander (2012): How Important Are Labor Market Institutions for Labor Market Performance in Transition Countries?, Economics of Transition, forthcoming.

Lerman, Robert I.; Rauner, Felix (2012): Apprenticeships in the United States, in: Barabasch, Antje; Rauner, Felix (eds.): Work and Education in America, 175-193.

Malamoud, Ofer; Pop-Eleches, Christian (2010): General Education versus vocational training: Evidence from an economy in transition, The review of economics and statistics 92 (1), 43-60.

Martin, John P.; Grubb, David (2001): What Works Among Active Labour Market Policies: Evidence from OECD Countries' Experiences, OECD Labour Market and Social Policy Occasional Paper 35.

Masson, Jean-Raymond; Baati, Mounir; Seyfried, Erwin (2010): Quality and Quality Assurance in Vocational Education and Training in the Mediterranean Countries: lessons from the European approach, European Journal of Education, Vol. 45, 3, pp. 514-525.

Matkovic, Teo (2008): Recent developments in the education system and school-to-work transitions in Croatia, Working Paper, Mannheimer Zentrum für Europäische Sozialforschung.

Micklewright, John (1999): Education, inequality and transition, Economics of Transition, 7(2): 343-376.

Ministry of Labour and Social Security, Department of Training and Employment, People's Republic of China (MOLSS) (2003): Skills training in the informal sector in China, http://ilomirror.library.cornell.edu/public/english/employment/infeco/download/china.pdf.

Monk, Courtney; Sandefur, Justin; Teal, Francis Teal (2008): Does Doing an Apprenticeship Pay Off? Evidence from Ghana, CSAE Working Paper Series 2008-08, Centre for the Study of African Economies, University of Oxford.

Murphy, Russell D.; Salehi-Isfahani, Djavad (2006): Labor market flexibility and investment in human capital. Working Papers e06-5, Virginia Polytechnic Institute and State University, Department of Economics.

National Treasury (2011): Confronting youth unemployment: policy options for South Africa, National Treasury Discussion Paper.

Neumark, David; Wascher, William L. (2007): Minimum wages and employment, IZA Discussion Paper 2570.

Newell, Andrew; Reilly, Barry (1999): Rates of return to educational qualifications in the transitional economies, Education Economics, 7, pp. 67-84.

Noelke, Clemens; Horn, Daniel (2011): Social Transformation and the Transition from Vocational Education to Work, Budapest Working Papers on the Labour Market, 2011/5.

Nübler, Irmgard; Hofmann, Christine; Greiner, Clemens (2009): Understanding informal apprenticeship: Findings from empirical research in Tanzania, Employment Sector Employment Working Paper 32/2009, ILO.

O’Higgins, Niall (2010): Youth Labor Markets in Europe and Central Asia, IZA Discussion Paper 5094.

OECD (2004): Career Guidance: a Handbook for Policy Makers. Paris: OECD

OECD (2008): Jobs for Youth, United Kingdom, Paris.

OECD (2009): Learning for Jobs, OECD Review of Vocational Education and Training, England and Wales, OECD Publishing, Paris. 
OECD (2010a): Off to a Good Start?, Jobs for Youth: United States, OECD Publishing, Paris.

OECD (2010b): Off to a Good Start?, Jobs for Youth: United Kingdom, OECD Publishing, Paris.

OECD (2011a): Perspectives on Global Development 2012: Social Cohesion in a Shifting World.

OECD (2011b): Education at a Glance.

OECD; ILO (2011): Giving youth a better start, A policy note for the G20 Meeting of Labour and Employment Ministers, Paris, 26-27 September.

Oketch, Moses O. (2007): To vocationalise or not to vocationalise?, Perspectives on current trends and issues in technical and vocational education and training (TVET) in Africa, International Journal of Educational Development 27, 220-234.

Oleynikova, Olga (2009): Involvement of Labour-Market Partners in TVET in the Russian Federation, in: Maclean, Rupert; Wilson, David N. (eds.): International Handbook of Education for the Changing World of Work, Part III, Section 4, 689-702.

Ost, David (2000): Illusory Corporatism in Eastern Europe: Neoliberal Tripartism and Postcommunist Class Identities, Politics \& Society,28:503-530.

Palmer, Robert (2009): Formalizing the informal: Ghana's National Apprenticeship Programme. Journal of Vocational Education and Training, 61 (1), 67-83.

Parey, Matthias (2009): Vocational Schooling versus Apprenticeship Training - Evidence from Vacancy Data, Mimeo.

Peltzer, Roger (2011): Competitive African Cotton Initiative Background Paper(COMPACl), DEG: http://www.gtz.de/de/dokumente/giz-2011-de-competetive-african-cotton-initiative.pdf

Petrolongo, Barbara; van Reenen, John (2011): Youth Unemployment, CentrePiece Magazine Article No. CEPCP338.

Pijoan-Mas, Josep; Sanchez-Marcos, Virginia (2010): Spain is Different: Falling Trends of Inequality, Review of Economic Dynamics 13(1), 154-178.

Planas, Jordi (2005): Vocational training in Spain: Changes in the model of skill production and in management modalities.

Plug, Erik; Groot, Wim (1998): Apprenticeship versus vocational education: Exemplified by the Dutch situation, October, unpublished manuscript.

Pritchett, Lant (1999): “Has Education Had a Growth Payoff in the MENA Region?" World Bank, Middle East and North Africa Working Paper Series No. 18, December 1999.

Puerto, Olga Susana (2007a): Interventions to Support Young Workers in Latin America and the Caribbean, Regional Report for the Youth Employment Inventory, World Bank.

Puerto, Olga Susana (2007b): Labour Market Impact on Youth: a meta-analysis of the Youth Employment Inventory, World Bank.

Puerto, Olga Susana (2007c): International Experience on Youth Employment Interventions: The Youth Employment Inventory, World Bank.

Quintini, Glenda; Manfredi, Thomas (2009): Going Separate Ways? School-to-Work Transitions in the United States and Europe, OECD Social, Employment and Migration Working Paper 90. 
Quintini, Glenda; Martin, John P.; Martin, Sébastien (2007): The Changing Nature of the School-to-Work Transition Process in OECD Countries, IZA Discussion Paper 2582.

Rioust de Largentaye, Armand (2009): Vocational Training and the Informal Economy.

Roberts, Ken; Fagan, Colette; Tarkhnishvili, Levan; Ivaschenko; E. Abidekian, A. (2000): Employment and social mobility: evidence from Armenia, Georgia and Ukraine in the 1990s,European Journal of Education 35: 125-36.

Roberts, Peter; Saar, Ellu (2012): Learning and Working: The Impact of the 'Double Status Position' on the Labour Market Entry Process of Graduates in CEE Countries, European Sociological Review., Online pre-release January, 2012.

Rodríguez-Planas, Núria; Jacob, Benus (2009): Evaluating active labour market programs in Romania.

Rodríguez-Planas, Núria (2006): Does Inclusion Pay? Evaluating Impacts and Cost-Effectiveness of Active Social Policy and Active Labor Market Policy on Inclusion. Chapter on Spain. Ministry of Labor of Finland, November 2006.

Rodríguez-Planas, Núria (2010): Channels through which Public Employment Services and Small Business Assistance Programmes Work, Oxford Bulletin of Economics and Statistics 72 (4).

Rodríguez-Planas, Núria (2011): Mentoring, Educational Services, and Incentives to Learn: What Do We Know About Them?, Mimeo (see IZA Discussion Paper 5255, 2010).

Roger, Muriel; Zamora, Philipppe (2011): Hiring young, unskilled workers on subsidized open-ended contracts: a good integration programme?, CREST.

Rutkowski, Jan (2006): Labor Market Developments During Economic Transition, World Bank Policy Research Working Paper no. 3894, Washington D.C.

Rutkowski, Jan; Scarpetta, Stefano; Banerji, Arup; O’Keefe, Philip; Pierre, Gaelle; Vodopivec, Milan (2005): Enhancing Job Opportunities: Eastern Europe and the Former Soviet Union, World Bank, Washington D.C.

Ryan, Paul (2001): The School-to-Work Transition: A Cross-National Perspective, Journal of Economic Literature, Vol. 39, 1, pp. 34-92.

Saar, Ellu; Unt, Marge; Kogan, Irena (2008): Transition from Educational System to Labour Market in the European Union: A Comparison between New and Old Members, Working paper.

Scarpetta, Stefano; Sonnet, Anne; Manfredi, Thomas (2010): Rising youth unemployment during the crisis: How to prevent negative long-term consequences on a generation?, OECD Social, Employment and Migration Paper 106, Paris.

Shapiro, David (1999): School-to-work partnerships and employer participation: evidence on persistence and attrition from the National Employer Survey, National Center for Postcompulsory Improvement.

Sondergaard, Lars; Murthi, Mamta (2012): Skills, Not Just Diplomas: Managing Education for Results in Eastern Europe and Central Asia, World Bank, Washington D.C.

Stavreska, Antoneta (2006): Interventions to Support Young Workers in South, East Asia and the Pacific, Regional Report for the Youth Employment Inventory, World Bank.

Steedman, Hilary (2010): The State of the Apprenticeship in 2010, International Comparisons, Working Paper, Centre for Economic Performance, London. 
Stockmann, Reinhard; Menzel, Ulrich; Nuscheler, Franz (2010): Entwicklungspolitik - TheorienProbleme-Strategien, Oldenbourg Verlag München

Sultana, R.G. and Watts, A.G. (2004): Career Guidance Policies in 37 Countries: Contrasts and Common Themes. International Journal for Educational and Vocational Guidance , 2004, Vol. 4, 105-122.

Sultana, R.G and Watts, A.G. (2008): Career guidance in the Middle East and North Africa, International Journal for Educational and Vocational Guidance, Vol.8 (1), 19-3.

Sweet, R. (2007): Career Guidance in the Western Balkans Region. Turin: European Training Foundation.

Tattara, Giuseppe; Valentini, Marco (2009): Can employment subsidies and greater labour market flexibility increase job opportunities for youth? Revisiting the Italian On-the-job Training Programme, Business and Economics 42 (3), 197-212.

Thelen, Kathleen (2007): Contemporary Challenges to the German Vocational Training System, Journal of Regulation and Governance (1), 247-260

UGAPRIVI (2012): http://www.ugaprivi.org/index.php?option=com content\&task=view\&id=21\&/temid=47

UN ESCAP Economic and Social Commission for Asia and Pacific (2000): YOUTH IN THE PHILIPPINES: A Review of the Youth Situation and National Policies and Programmes, Economic and Social Commission for Asia and Pacific, United Nations.

UNESCO (2011): Education for All - Global Monitoring Report. The hidden crisis: Armed conflict and education.

Valverde, Gilbert (2005): Curriculum policy seen through high-stakes examination: Mathematics and Biology in a selection of school-leaving examinations from the Middle East and North Africa, Peabody Journal of Education, 80, 1, pp. $29-55$.

Verick, Sher (2010): Who is hit hardest during a Financial Crisis? The vulnerability of Young Men and Women to Unemployment in an Economic Downturn, in: Islam, Iyanatul; Verick, Sher (eds.): From the Great Recession to Labour Market Recovery: Issues, Evidence and Policy Options, Basingstoke, Hampshire, UK; ILO/Palgrave Macmillan.

Vlaardingerbroek, Barend; Hachem El-Masri, Yasmine (2008): Student transition to upper secondary vocational and technical education (VTE) in Lebanon: from stigma to success, Journal of Vocational Education \& Training, 60, 1.

Walther, Richard (2011): Building Skills in the Informal Sector. Background paper prepared for the Education for All Global Monitoring Report 2012, UNESCO.

Watts, A.G. and Fretwell, D. (2004): Public Policies for Career Development: Case Studies and Emerging Issues for Designing Career Information and Guidance Systems in Developing and Transition Economies. Washington, DC: World Bank.

Weller, Jürgen (2009): Regulation, worker protection and active labour-market policies in Latin America, United Nations, Economic Commission for Latin America and the Caribbean.

Wilkinson, David (2003): New Deal for Young People: Evaluation of Unemployment Flows, PSI Research Discussion Paper 15, London.

Winkelmann, Rainer (1996): Employment prospects and Skill Acquisition of Apprenticeship-Trained Workers in Germany, Industrial and Labour Relations Review 49 (4), 658-672. 
Wolf, Alison (2011): Review of Vocational Education - The Wolf Report, Department of Education, United Kingdom.

Wolter, Stefan; Ryan, Paul (2011): Apprenticeship, Handbook of Economics of Education, Volume 3, edited by Eric Hanushek, Stephen Machin and Ludger Woessmann, Elsevier..

World Bank (2002): Reducing Vulnerability and Increasing Opportunity, Social Protection in the Middle East and North Africa, Washington D.C.

World Bank (2004): MENA Development Report, Unlocking the Employment Potential in the Middle East and North Africa, Washington D.C.

World Bank (2005): Expanding Opportunities and Building Competencies for Young People: A New Agenda for Secondary Education, World Bank, Washington, D.C.

World Bank (2006) Serbia: Labor Market Assessment, World Bank, Washington, D.C.

World Bank (2007): Development and the Next Generation, World Development Report Washington D.C.

World Bank (2007): Skill development in India, the vocational education and training system, Human Development Unit, South Asia Region.

World Bank (2008): MENA Development Report, The road not traveled - Education reform in the Middle East and North Africa, Washington D.C. 